Rhode Island College

Digital Commons @ RIC

Master's Theses, Dissertations, Graduate

Master's Theses, Dissertations, Graduate Research and Major Papers Overview

Research and Major Papers

2014

\title{
Exploring a "Mor-In-Touch" Approach to Art Teaching
}

Micaela E. Morin

Rhode Island College

Follow this and additional works at: https://digitalcommons.ric.edu/etd

Part of the Art Education Commons

\section{Recommended Citation}

Morin, Micaela E., "Exploring a "Mor-In-Touch" Approach to Art Teaching" (2014). Master's Theses, Dissertations, Graduate Research and Major Papers Overview. 96.

https://digitalcommons.ric.edu/etd/96

This Thesis is brought to you for free and open access by the Master's Theses, Dissertations, Graduate Research and Major Papers at Digital Commons @ RIC. It has been accepted for inclusion in Master's Theses, Dissertations, Graduate Research and Major Papers Overview by an authorized administrator of Digital Commons @ RIC. For more information, please contact digitalcommons@ric.edu. 
EXPLORING A "MOR-IN-TOUCH" APPROACH TO ART TEACHING: PROMOTING PERSONAL CONNECTIONS THROUGH A HIGH SCHOOL COLLABORATIVE

MOSAIC RELIEF INSTALLATION

\author{
A Thesis Presented \\ by \\ Micaela E. Morin
}

Approved:

Dr. Virginia K. Freyermuth, Committee Chair

Date

Dr. Cheryl L. Williams, Committee Member

Date

Dianne M. Reilly, Committee Member

Date

William Martin, Chair- Department of Art

Date

Dr. Earl L. Simson, Dean- Faculty of Arts and Sciences

Date

Dr. Leslie Schuster, Dean- Graduate Studies

Date 
EXPLORING A “MOR-IN-TOUCH" APPROACH TO ART TEACHING: PROMOTING PERSONAL CONNECTIONS THROUGH A HIGH SCHOOL COLLABORATIVE MOSAIC RELIEF INSTALLATION

\author{
by
}

Micaela E. Morin

\author{
A Thesis Submitted in Partial Fulfillment \\ of the Requirements for the Master of Arts \\ in the Department of Art Education \\ The School of Arts and Sciences \\ Rhode Island College \\ 2014
}




\begin{abstract}
Problem: How can students be more in touch ("Mor-in-Touch") with their artistic process through materials, decisions, social interactions, and environment when creating a work of art about identity for a collaborative mosaic relief installation?
\end{abstract}

Study Description: This thesis explored an opportunity for my students to work together to create a collaborative art installation in our high school. This was important to do because the school had just been recently renovated and the new environment felt devoid of any art or personality that once reflected its former students. The important factors behind the installation design were to bring the visual dialogue of community into the new space and provide an opportunity for the current students to reflect their personal identities. The term "Mor-in-Touch," which I developed in my research phase, can be described as an art-teaching philosophy. It is my belief that being or becoming more in touch or "Mor-in-Touch" will bring deeper meaning and personal connection to the artistic process. It supports my own art-making, how I want to teach, and what I want my students to learn.

Summary of Findings: While this thesis project was a huge success in connecting with my students' and their processes, the final stretch resulted in an unexpected learning outcome that proved far more powerful than I anticipated. While I initially proposed and planned this approved project in detail, I only later found out that there were safety regulations unique to the area intended for the art installation. Unfortunately by this time, the art installation had already been completed by the students. Finding ways to 
turn this devastating negative into a positive was the new challenge. In the end, the "Mor-in-Touch" art installation taught my students about personal commitment and the collaborative power that can result when individuals work together. Even though the installation was short-lived, the experience fostered a small group of inspired artists to believe that art can bring people together in the hope of transforming spaces. The overall thesis project taught me more about my process as an artist and how I can use my experiences to enhance the learning and teaching in my classroom. 
I dedicate this thesis to my greatest teachers and parents, Robert and Louise Morin.

You always believed in me and supported my passion for art. Without your unwavering guidance and patience, along with the endless hours of childcare for my daughter Matejah, I wouldn't have made it this far in my educational journey. So thank you for all you have done. I am honored to walk the stage (for the first time and three degrees later) with you cheering me on; I know I have made you proud.

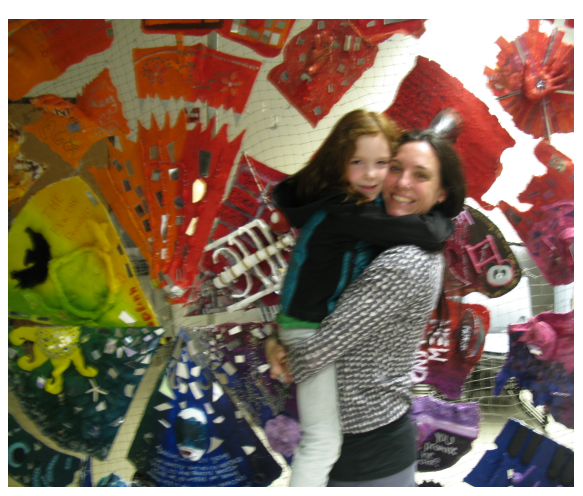

Sweet Matejah- After 6 years at this, we finally made it. Now, we can get a dog or two! 


\section{ACKNOWLEDGEMENTS}

I would like to recognize and thank the people who influenced my life path: Gale Goodwin-Gomez, who introduced me to the beauty of indigenous cultures and their artmaking along with the awesomeness of the rain forest; Scott Nicol, who taught me about ecological art, which guided my art-making to form a close relationship with nature; Linsey Wallace- my safari partner, Mokanna Weir- my spiritual mentor, and Darcie Lee Hanawaymy forgiving saint, whom are all truly inspiring, beautiful, artist friends that continue to help me grow more authentically; my dear sister, Danielle, who reminds me that I am always capable of great things when I work hard; and Geoffrey Champagne- my companion for the rest of life's chapters. I would also like to thank my professors and committee members at Rhode Island College: Dr. Virginia K. Freyermuth, who was the most instrumental in the success of this thesis. Through her extensive knowledge, positive feedback, and compassionate care as my thesis advisor, I gained tremendous growth as a reflective artistteacher in the art education field. Dr. Cheryl L. Williams' effort and dedication to develop a strong art education program made me confidant I was entering the teaching career for the right reasons. Her professional and personal support the entire way through both my undergraduate and master's art education programs is memorable. Dianne M. Reilly, metalsmithing professor, opened up my world to see new ways of connecting my interest in the human form with my artwork through jewelry design. I appreciate the level of expertise you all bring to the art field. Thank you again for your time, effort, guidance, and feedback to make my thesis successful. 


\section{TABLE OF CONTENTS}

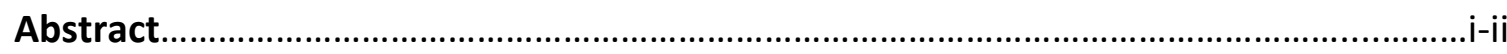

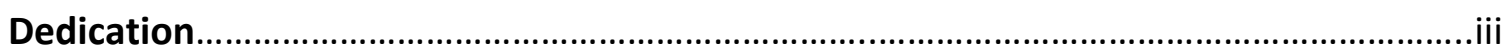

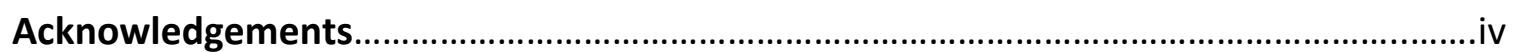

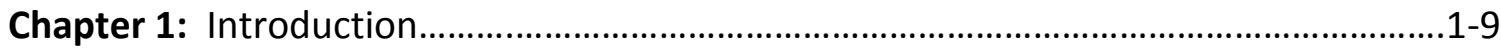

Chapter 2: Literature Review

Exemplar Artists Who Model Self-Exploration........................................10-15

Self-Reflection as Artist and Educator: How they Unite............................16-21

Holistic/Student-Centered Art Education..............................................22-28

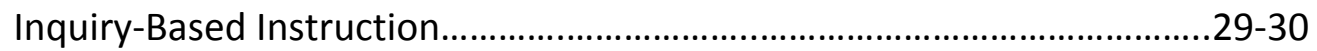

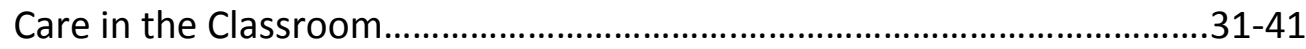

Chapter 3: Research Methodologies........................................................................42-49

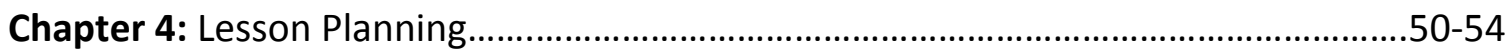

Chapter 5: Implementation: Becoming 'Mor-in-Touch' Installation..............................55-88

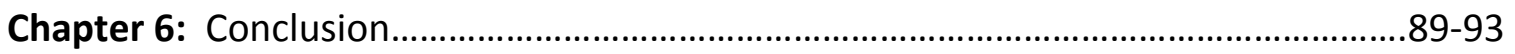

\section{References}

\section{Appendices:}

Appendix A- Unit Handout

Appendix B- Identity Brainstorm Sheet

Appendix C- Homework Sketch Handouts

Appendix D- Self-Reflection Handout

Appendix E- Examples of Completed "Mor-in-Touch" Artist Self-Reflections

Appendix F- More Noteworthy “Mor-in-Touch" Self-Reflections

Appendix G- Rubric Handouts

Appendix H-PowerPoint Slides

Appendix I- Ceremonial Picture Honoring the Installation Artists 


\section{Chapter 1: Introduction}

I am an artist who can become inspired at any moment of the day--especially when

driving. When creating art, I spend hours without a sense of time or commitment. I find myself asking these questions: "What is it that motivates me so much, to do what I love, which is to make art? Why is art so important to me? Why do I devote my educational and graduate studies and professional life to the teaching of art? Why do I love what I do?" In my lifetime journey, where art visualizes my personal experiences, motivations, and processes, I have committed myself to conduct a guided self-inquiry into this journey, presently, and retrospectively, in order to realize my abilities, passions, and drive. "Mor-in-Touch" initially became a term I coined to describe a discovery of my own identity, language and values through art - with the underlying intention to use my role as an artist-teacher as an opportunity to engage my art students to discover who they genuinely are.

The term "Mor-in-Touch" is, thus, a short phrase that I have created to describe the process of becoming more in tune with myself. This is a new word that I came up with during my thesis research, which grew out of some quiet reflection time. It is also an extension from my last name. The phrase is meant to encapsulate the relationship of my beliefs, inspirations, and surroundings; essentially, this process encompasses everything that I as a person can connect with on a deeper level emotionally and spiritually. While my intention to be a positive mentor and teacher are affirming, I want 
to clarify that "Mor-in-Touch" is not art therapy; rather, I envision it to be a meaningful form of art education. This mantra-like term is a way for me to bring meaning and value to my life as a teacher and as an artist.

My specific focus for this thesis was to develop an opportunity for my students to work together to create a collaborative art installation in our school. I felt that this was important to do because the school had just been recently renovated and it felt devoid of any art or personality. The school's vibe had drastically changed from what it once was. Up until the new addition and building renovations started taking place last year, the school was filled with art. The painted ceiling tiles and mural-covered walls were a true expression of the students who went to school at Norton High School; actually, it was a rite of passage for seniors, who were art students, to leave their mark before graduating. This legacy got taken away from seniors once plans for an addition and renovation passed within the town, mainly because administration wanted to keep it 'new looking.' In September 2013, when school was back in session, everyone was impressed with the advanced updates and finishes, but the energy, color, and artistic expressions of the school's former students were all covered as if they never existed. Not a single work of art remained.

I couldn't help but notice that this empty feeling permeated not only myself, but the students and staff. I had a strong urge to impart change in the environment and provide an opportunity for my art students to see themselves reflected in the new space. After 
some preparation, my mission became clear; I wanted to propose a collaborative art piece that united all of my current art students together through an installation. This project would transform and highlight the architectural features of the school, bring color to the blank walls, and send the message of each student's individuality, all while establishing a community vibe. Using my "Mor-in-Touch" perspective, my goal was to provide a valuable experience for the students to capitalize on their changed school by taking ownership for, connecting with, and changing their new learning environment. Ultimately, through this thesis I wanted to learn how my "Mor-in-Touch" process could inform my students to connect with their art on a more meaningful level.

To begin, this paper describes how my research was conducted and what methods proved most helpful in this process. By laying down the groundwork for my readers, I am able to unfold my experiences and thoughts that have made this process insightful. The following topics that contributed to my experience are titled 'Exemplar Artists that Model Self-Exploration,' 'Self-Reflection as Artist and Educator,' 'Holistic LearnerCentered Art Education,' 'Inquiry-Based Learning,' and 'Care in the Classroom.'

Research for this thesis really began with my own personal inquiry towards artists whom I have connected with along the way. I explored how the artwork of a few selected artists resonated with my art-making process through subject matter, concepts, and choice of materials. Further, I expanded on what it meant for me to share strong connections and ideas with other like-minded artists. Knowing there is a 
common link with other creative exemplar artists, I felt that my artwork becomes a part of some larger recognizable community that, speaks a similar language. My intrigue lays in the drive and connection that exists between humans and their art-work, their relationship with nature, and their spiritual processes that connect them to their work. Even though a large component of my initial research was nature based, I ended up leaning towards a collaborative installation for the thesis art project. The timing of this decision came after much of my research was already done. Furthermore, this exploration of exemplars helped to inform my own driving force as an artist and as a practicing teacher in regards to forming ideas within the classroom to build stronger connections with my students.

Another area of study for this research that drove me can be seen through my passion for the self-reflective process, which I experience as an artist and educator. Throughout the years, I have found the process of journaling and recording my experiences very valuable. Looking back through my journals, I have seen myself grow as a person out of these experiences and have gained a greater understanding about my creative outlet and ideas as an artist. Being present in the moment and reflecting/recording what is going on, both visually and verbally, are vitally important to me as an artist. This creative spirit lies at the heart of my soul and encompasses the sensitive and emotional artist that I am. In retrospect, I also visually and verbally documented my experience of this entire art installation with my students through the lens of a teacher. I had never documented a lesson I taught so closely before. The steps 
my students and I took together from the very beginning until the end are tremendously valuable and insightful. This charged feeling I have from this thesis project justifies the reason I chose to be a teacher. Looking back at both my personal and artistic experiences that I've had along the way, teaching was a natural choice for me. My hope is that through this critical study of my "Mor-in-Touch" process, habits, and questions, that I will be better equipped to guide my students into their own interior inquiries.

This research of my own process and beliefs also examined the power of holistic and student-centered art education. I firmly believe that a student's life is central to their artistic expression. Period. I strive to have my students connect to the assignment given to them when it allows. I want the end product to be for them and for them tomake important connections to their lives and interests. I don't want them to make art for me, but for themselves. Since sculpture is my passion and is such a visceral and hands-on process, my intention was to teach this art form to connect to my students' reality in a tangible and emotional way.

Further, I have strong connections to the process stage of art making. What I mean by that is I use my body's form as a way to self-reflect with myself, like a mirror, in a specific moment and time. "Through the body come powerful ideas, feelings, and moods seeking wordless forms of expression" (Campbell \& Simmons III, 2012, p. 5). I physically manipulate, mold, and contour materials against the surface of my body's 
skin. This process physically and emotionally connects me with the medium by infusing energy into my artwork and materials. I believe that I have a healthy relationship with my art. My process is very central to me and as an artist-teacher; I seek ways for my students' art making process to also resonate and connect deeply with them.

Furthermore, as I consider art making as a vehicle for learning and selfunderstanding, the idea of inquiry-based art education is central to this concept. When teachers offer a thought-provoking guiding question, students are able to seek out a meaningful answer. When a person devotes himself or herself to an internal investigation, truth and clarity about the individual emerge, and this is a powerful learning tool.

My teaching and my research seeks to take the whole child into account. This is relevant for my paper because if I am looking deep within myself for inspiration as a practicing artist, then it is only natural for me to want my students to experience the same deep source of inspiration for themselves. I believe this forges strong connections with students and gives them the opportunity to express who they are. To me, art that comes from the heart is important to a person's growth as an individual. It helps to process and communicate life in all of its ups and downs. This is important to me in my teaching because it is my fire; it is what gives life to everything around me. I believe that I am an inspiring, positive, energetic, and hard-working teacher and that these values relate to my practice as an extension for my love of life and growth. "There's a 
joy in knowing my spirit soars when I'm able to empower and teach the people around me" (May 11, 2010, personal journal entry). Attempting to nurture the inner life of a person is a healthy way to approach those I teach and care about and want to see grow into strong individuals. I ask: How can I, as an art teacher, draw out personally significant ideas and concerns of my students and guide them into certain processes and materials toward outcomes that can help them better connect to who they are and who they might yet become? During the initial stages for my research project, I spoke to the students about self-identity and gave the students time to brainstorm words and symbols that defined them. I helped to guide each student from their initial ideas and sketches towards a variety of available material that they could use to express their concepts. Even further, I opened up my art storage closet to them! This opportunity to explore other materials was done to provide further inspiration for the students' projects. Several students actually brought in personal materials of their own or went out to purchase what they needed. When someone receives an opportunity to express their idea for a specific topic and a variety of material choices are available, then students are allowed more possibilities, which result in unique outcomes not expected or predicted. In my opinion, teachers should be open and embrace the many ways in which an idea may turn out; students should be allowed to show their individuality.

This leads to the last area of my research that describes how the classroom can honor and nurture the inner spirit or life of a person. This would be an important contribution to the art field because it seems to me that too often the whole student is 
not taken into account. I believe that every student has an inner artist, and helping that artist reveal their self takes patience, trust, and care. This can be manifested in many ways from the physical classroom setup, visual and musical inspirations, encouragement of open-ended exploration, hard-work, and reciprocal respecting and caring relationships - to name a few. I know that when I am in a comfortable environment, I feel safe to express who I am. I don't think that I would like to show my true colors in a place that didn't feel welcoming and friendly. A comfortable environment makes delving deep into one's self a safer place to unfold. All members of the classroom community must feel comfortable being together in the same space. This area of research is meant to give teachers more to think about when creating their community space; what vibe are you giving off? Furthermore, I believe that teaching can be at its best when the learner can safely and comfortably focus on learning. A student is less likely to share that which is personal if the space and all who are in it do not honor each individual.

From what I value as important to learn, teach, bring light to, stand strong for, and spend time on, it is my hope that these inquiries will constantly push and challenge me to grow. Philosophically, growing is a strong and repeating force in my artwork. "Morin-Touch" is a natural process, infused with metaphorical language, of my soul's light making its way from the inside out. It's a gratifying release and makes me feel good. When inspiration hits, ideas brew unconsciously in my mind which flash and leak into my consciousness and together create images I can see; soul shine. These ideas are 
layers of me coming together, peeling to look back towards the past, reflecting on the here and now, and growing forward to the inspiring newness of life and experience. While this personal journey of "Mor-in-Touch" continues to unfold and grow every day, my overall hope is that this paper will inform and solidify my artistic process of creating, my teaching of art, and also hopefully inspire other artists and educators. 


\section{Chapter 2: Literature Review}

\section{Exemplar Artists Who Model Self-Exploration.}

There have been numerous artists who have inspired my artistic path in life. Many of the more prominent ones are documented in my journals and sketchbooks, which I recently re-examined. The reason I have chosen each artist below is either based on the similarity of our art product/use of materials, and/or our art-making beliefs, and methodologies. The artists I chose are all sculptors, who work with natural materials and spiritual subject matter ideas, and their artwork informed and inspired me to explore my own processes more deeply. The selected exemplary artists that have influenced my own work are: Andy Goldsworthy, Adrian Arleo, Rona Pondick, and Janine Antoni. I will explain how their work is of significance, how it specifically informed mine as an artist, and how their work could potentially inform my students.

It is important for me to note that my thesis research started off as nature based, but as the process evolved and my ideas were refined, I became interested in designing a collaborative installation. I can't tell you exactly why I didn't combine these two ideas, except for the fact that I was off and running in a new direction. Much of my initial research was already done at this point, but the following artists most certainly helped to inform my direction with this thesis project. The last artist I decided to add was installation artist, Sandy Skoglund.

Andy Goldsworthy was one of the first sculptors I learned about who works in a completely natural way. Goldsworthy works directly outdoors with nature using the 
materials available there to create works of art; this is called biosculpture. His artwork is ephemeral. Ephemeral is a term used to describe the brief time that a work lasts after an artist has finished creating it. His artwork breakdowns by either decomposing, melting, and/or falling apart in the very environment where the materials were gathered and assembled. Because of this, Goldsworthy captures his work through photographs to share with others. This artist inspired my own work by the way he directly interacts with the materials around his environment and in his belief that he 'sees art as a growth within himself' (Source unknown from a classroom poster). My sculptures incorporate organic substances such as moss, vines, and metal, which breakdown at different rates due to their structural integrity. His work was able to inform my role as a teacher in a way that I can bring his idea about materials and ephemeral qualities to my students. My hope was that the students will be able to appreciate the relationship with their direct environment in a more acute way, especially in this trying time of human destruction and environmental issues.

Adrian Arleo fascinated me because she lives out in the woods in Montana, where her studio is submerged within nature. She is inspired by the close encounters with the animals that inhabit the environment around her. Her artwork shows this strong connection by pairing the human form, particularly her own, with the natural world that connects, grows, and morphs from it. The relationship and dialogue that she creates inspire me. They are powerful, rich, original, and beautiful. I am also closely connected with the natural world in a way that makes it an extension of myself. My 
figurative sculptures are a reflection of myself and my relationship with my natural surroundings. Currently, my figures naturally morph and grow the way nature has roots and energy pathways. Arleo's work was able to inform the work I do with my students by demonstrating the close connections we share with the world around us in ways that are meaningful. The dialogue the students can assess within themselves in relation to their place in the environment is a powerful way for them to connect; this is especially true with the growing number of students who feel disconnected nowadays according to Louv's book titled Last Child in the Woods (2008).

Rona Pondick's work attracted me in her ideas about artistic connections and in her engagement with the figure. She said, “I'm very interested in my artistic roots... I was trying to understand my likes and dislikes and building my ancestral tree" (Unknown book source, p. 164). Pondick's interest in her aesthetic roots and connections to certain cultures are an interesting thing to think about. She said, "I have always looked back. Art is my history and it feeds me" (Worcester Art Museum, p. 2). Why and how do these ideas manifest themselves in a person and how can this idea be brought into the classroom? Are we all born with these ideas or are they formed in the life we experience?

My other interest in Pondick was in her process with the figure. She creates life casts using her body and morphs or "fuses human and animal or human and flora forms" (Worcester Art Museum, p. 2). "I'm interested in how the body fragment 
engages the viewer differently from the whole" (Unknown book source, p. 164). I can relate to her connection to the natural world and to the process of working directly with her body to create a representation of it. What I founnd curious and fascinating was how her work was displayed in a 2009 show at the Worcester Art Museum. There she referenced her artistic connections through ancient sculptures and paired her sculpture right with the others! She said, "When these different historical sculptures and mine are installed next to one another, there is a visual communication spoken in 'body language' that needs little explanation" (Worcester Art Museum, p. 2). As a teacher, I think that it is important to realize intent and motivation and gain perspective to where they fit in with art history.

Janine Antoni first caught my attention at the 2012 NAEA conference in New York City. She held a massive lecture that was more interactive than anything I had seen before. She was a performer, dancer and sculptor during this time. Her artwork was an extension of her body interacting with it. On March 18, 1999, Antoni said, "All of my work deals with... objects that mediate our intimate interaction with our bodies... I've noticed a reoccurring desire in my work to get outside of myself in order to see myself... Are you more yourself when you're alone with yourself?" (Unknown book source, p.227). I believe that making three-dimensional figurative work marks an existence in a physical way beyond ourselves. Antoni brings up a good point about tapping into working in solitude. Does she mean physical solitude or quiet space like meditation? As an artist and a teacher, I believe that getting quiet is crucial to listening to yourself and 
what you're feeling at the moment. She also said, "I realized that I have to be physically exhausted to be happy. I also identified the labor as kind of meditative" (Unknown book source, p.228). I completely agree. As a sculptor, there is a certain sort of energy that is needed to produce this tangible reality we create. When I get into my work, it is allencompassing and I lose myself in the moment...minutes...hours. I like that we both share in the idea of using our bodies to physically define space on a spiritual and interactive level. Antoni's work has informed the work I do with my students to show that artists can use the creative force as a meditative process to explore meaning in their lives. Her work also informed the importance of the interactive process between the artist and their work.

Sandy Skoglund is an interesting artist who is able to transform an environmental space with her artwork. She works both indoors and outdoors and uses a variety of materials including food like popcorn, cheese curls, and bacon! Her work was of importance because she used color, texture, and proportion to transform an ordinary space into something not so ordinary. She is a skilled sculptor and sometimes creates several forms for her installations. These forms are highly detailed and are achieved by closely looking at pictures pinned up in her studio from multiple angles and positions. I have seen this through pictures found in various Scholastic Art magazines. Sometimes it takes her years to sculpt all the necessary forms for one installation! While her work is much different than my own, I respect her ability to make a space feel different. Her work specifically informed my instruction for this installation because of 
her use of color and imagination for materials. My hope was to "wow" the students and to open up their minds to the possibilities that the project could have. 


\section{Self-Reflection as Artist and Educator: How they Unite.}

The process to self-reflect as an artist, an educator, and as an artist-educator has brought both struggle and clarity. I have had a natural tendency to associate certain thoughts and processes to each persona, but when I tried to combine my thoughts and processes into one role of artist-educator it seemed impossible and frustration set in. Throughout this initial portion of my research, I felt that each should be separated into different areas of self-reflective studies. This was probably because I felt the artist in me is an internal, sacred space where I spend a lot of time in my shell, like a hermit; while on the other hand, the teacher in me is an external environment, a performer in some way, who ventures out to make connections with those around me. One might ask, "How can it be so difficult to explain your multiple roles as a person?" But if you have never attempted to do it before, it was harder than you think. I believe that this was because the role of a visual artist is someone who is emotionally invested in exploring themselves in some sort of unspeakable language. When I tried to unite the inner ideas into an outer physical manifestation, through the lens of an instructor, it became a challenge for me inside my head and heart, which could not reason with the other. This opportunity to connect what I've researched about the topic with how I function as an artist and as a teacher has been clarifying. I have come to understand that one MUST complement and inform the other. Through the process of uniting both the artist and educator in me, I have come to learn that while each fulfill my life uniquely, the interconnection of them makes each stronger. 
"For human beings live from within outward" (Walters, 1997, p. 61). This quote resonated with the artist and teacher in me. The artist in me said, "Of course it does! You enjoy creating outward expressions of what you feel and experience." While the teacher in me asked, "How can the feelings that I carry about teaching become apparent in my classroom?" This thinking brought me to the conclusion that the artist goes within to create something physical, whereas, the teacher goes within to create experiences to share with others. Self-knowledge is really important; Rilke's (1934) advice to a young poet says, "Go into yourself. Search for the reason that bids you to write (or teach), find out whether it is spreading out its roots in the deepest places of your heart" (Ayers, 1993, p. 129). If your heart and soul are touched by students, then you allow yourself to open up and share your knowledge. I firmly believe that teaching should tug at your heartstrings because teachers should teach what they love, while honoring the opportunities to shape the impressionable minds before them. Being an introspective artist has made me very sensitive to my surroundings, which has made me "Mor-in-Touch" with the way I perceive situations and the people in it. Since a teaching career was a natural progression for these ideas to extend into, responding to the interrelated connection of artist-teacher fit well into the structure for this research. "It often happens that, when we communicate our feelings and ideas to others, our very effort to do so clarifies them for ourselves. A sincere attempt at communication brings into the open thoughts and impressions that, previously, were not yet completely clear in our own minds" (Walters, 1997, p. 27). Kessler's The Soul of Education helped to 
inform me about the "soul" of students within a school setting. She states that "soul" in her book refers to the "attention to the inner life; to the depth dimension of human experience; to students' longings for something more than the ordinary, material, and fragmented existence" (Kessler, 2000, p. x). It put a lot of my own practice into perspective and made me think of past scenarios that could have played out differently in my classroom. Kessler helped me to see her viewpoint on the "seven gateways to the soul," which made me reflect on each component andwhat I know, what I do, and what I hope to become.The time I spent going deeper into my own soul or inner spirit during this thesis project has been an authentic way to make sense of the artist-teacher I am now and strive to be in the future. As an artist, I look forward to and respect the inner quiet, reflective, and subconscious spirit that lies inside. More so, the process of coming to know this energy and how it is manifested resonate closely with me as an artist- the process of awareness. Greene says that teachers "are part of a process, part of an opening. They're not in a product-orientated profession. They are in a processorientated profession. They are helping people become different; they are helping people find their way. And in helping other people find their way, the teacher is in some way finding her way... I believe that we create our selves-our identities-by our projects" (Hatton, 2005, p. 64). In this light, the bridge between artist and teacher are so very clear for me. Research has said that to really hear and connect with the inner truth means taking time to reflect in a quiet space. More of that to come in the chapter, 'Care in the Classroom' under the sub-subsection 'Quiet Solitude'. 
To inspire my students is one of the main reasons I teach. Greene said that "For me there is nothing more fascinating, nothing more life-affirming, because teaching, again, is an open-ended kind of undertaking. You never really know if you are successful. You are working with human possibility" (Hatton, 2005, p. 64). I believe that human possibility means the unknown reactions to some given stimuli. When a teacher puts himself or herself out there, there is some inevitable risk that is taken. How might each student react and respond? If a teacher puts passion into their lessons, then they are sharing energy with their students. "Personal passion and professional passion cannot be separated. Each is ultimately interwoven to the support or detriment of the other. Excitement is contagious. Students are drawn into its wake despite themselves when the teacher brings in genuine curiosity and enthusiasm into the classroom" (Wink \& Wink, 2004, p. 169). Sharing your passion makes for inevitable pathways to connect with the passions of your students. When doors open, journeys can be shared with another person in meaningful ways. Graves says, "Immersion. Do it with your students. Invite them in to do something that you're already doing yourself" (Hatton, 2005, p. 45). When I see that my passion has inspired my students, they are affirming that my life has a sense of worth and purpose. Sharing my light has been one of my greatest joys and accomplishments. I love to make connections with my students, inspire them to grow their hearts and minds, and strive to create a community out of compassion. When I am capable of growing as a person, an artist, and a teacher, life is good. Parker Palmer's mentor Bob Lynn once said to him, "If you care about it that much, you need to write 
about it so you can share that caring with others" (Hatton, 2005, p. 77). This was how I truly felt about my thesis work! Self-awareness is important to the artist in me and my future in teaching; "We teach who we are" (Kessler, 2000, p. 163). Artist-teachers -- ask yourself what unique gifts are yours to share with your students?

Looking deep within myself to discover my artistic sensibilities has awakened a realization for my strong connection to my spiritual life and the natural world. My purpose for making art has always spoken about my inner relationship to the outer world. In looking back at my life and experiences, mainly through my sketchbooks of visual ideas and written thoughts marking moments in my life, I know that art has been a visual outlet for my existence. A proposal topic for my thesis research was not too difficult because I knew that self-inquiry has always fascinated me and I wanted to spend more time exploring myself more deeply. I wanted to be able to use my thesis project to share my ideas, talents, and caring personality to promote arts in a holistically powerful way.

More so, Hatton, the author of the book Teaching by Heart, supports the "importance of teachers reflecting on their work in order to take risks in their classrooms, improve their thinking and practice, and grow as educators" (p. 8). If we didn't take this time to look back and make sense of what has come into our lives and the decisions we have made, then we wouldn't have the opportunity to move forward with new insights and perspectives. Parker Palmer has also been a motivational voice in 
this self-reflective process for me. He "works to support teachers in their own personal growth towards self-realization, a process he says is necessary before someone can be a true teacher. He exhorts teachers to look within to find ways to teach that are personally meaningful to them" (Hatton, 2005, p. 123). My thesis research endeavor is exactly that, a learning and growing endeavor used to clarity the life I lead, the life I teach, and the art I make.

In conclusion, I feel support from others in my professional field that this investigation will only strengthen me. One example of this can be found in the NAEA article, 'A Self-Exploration of the Relationship Between Art Teaching and Artistic Practice' written by Christy Ortiz. She examined her behaviors as a teacher and artist and used the new arts-based research methodology concept called "A/r/tography," to examine her multiple roles; specifically, the ' $\mathrm{A} / \mathrm{r} / \mathrm{t}$ ' of $\mathrm{A} / \mathrm{r} /$ tography relates to the artist, researcher, and teacher (Buffington \& McKay, 2013, p.241). I feel a sense of excitement that there are other similar minded artist-teachers in my field doing this type of research. 


\section{Holistic/Student-Centered Art Education.}

Holistic/student-centered art education was a central idea for my focusing question: 'How can we as teachers, draw out the ideas/concepts of our students and translate them into certain processes/materials/outcomes that connect them to who they are?' Holistic/student-centered education is "an approach to educating the whole child, addressing and integrating the physical/sensory, emotional, intellectual, social and spiritual needs of the individual, while connecting the individual to peers, teachers, the community, the wider society, the world and the environment" (Campbell \& Simmons III, 2012, p. 310). After researching this topic more closely, I realized that this a very difficult challenge to immediately incorporate as part of a teacher's philosophy; it is best approached as an ongoing process that evolves as the teacher evolves in their development.

While I firmly believe that a student's life is central to their artistic expression, I find it difficult to believe that I can be a holistic teacher $100 \%$ of the time. I am required to teach my foundation classes so that the students gain experience and familiarity with basic concepts/skills taught, especially if they choose to advance to an upper level art class. This is considered a "non-holistic ...curriculum focused on a particular dimension", where certain art elements and principles along with certain materials and techniques are taught to the students (Campbell \& Simmons III, 2012, p. 310). While I understand the reason to limit the available range of media at a beginner's level, Walters writes that “art cannot be reduced ... to a formula ...of technique. No mediocre artist, imitating the 
methods of a great one, could thereby produce a great work of art" $(1997$, p. 78). I think that he is saying that artists need to be authentic to their individual self in terms of approach and technique; we shouldn't try to imitate the work of others and that we need to find our own way of doing things. For example, a teacher could introduce a particular medium through the technique of a particular artist and then the student wouldn't explore the medium in their own approach. I discussed my concerns with the other art teacher at my school and she said that the students need to know how to use and gain skill in a variety of materials in order to advance and find their own style. I agreed on that aspect, but wondered how the advantages of student-centered learning as opposed to skills-based learning would effect our art department. I really like Alfie Kohn's advice: "either you believe the course is fully formed and delivered to the students or, before the first day of class, you realize that there is nothing but a framework and hunches and first starts and the course remains to be created together" (Hatton, p. 101). I am interested to know if being open to the idea of giving students more choice, specifically in materials, that students would take more interest in the art department and enrollment would grow. A holistic/student-centered approach to education creates an exciting journey for both the students and teacher to embark on together, starting with the first unknown step.

Before I can take this first step, I must address that I am personally torn about teaching holistically at the foundational level. A part of me wants to say that it is important for students to understand certain concepts and hands-on skills before 
moving on to more advanced ideas. Walters makes a statement that I don't entirely agree with: "formal study can be ...an actual disadvantage. Solutions learned from others tempt one to accept a choice that is facile but not fully understood" (1997, p. 42). I believe that from this exposure to foundational skills, that holistic teaching can actually grow and flourish because certain main concepts and materials will already be established for more progressive, self-directed studies. Unfortunately, if a student decided not to continue taking art, beyond foundations, than they could possibly loose the opportunity to experience a more student-centered approach to learning. On the other hand, I want to believe Ayers who says that teachers "too often implement the initiatives of others; we pass on someone else's ideas of what is valuable to know or experience" (1993, p. 19). I believe that I need to question my practice and my curriculum in a more thoughtful way that benefits the student. I have a small fear of relinquishing total control in my classroom and going against what I have grown comfortable teaching; power is hard to relinquish suddenly. Ira Shor would say that being student-centered means sharing in this power (Hatton, p. 108). I know I should listen to my curious and adventurous spirit and venture forward and be open to what insights might come my way through this process.

So how would I go about making changes in my established routine to become more student-centered? Stacey McKenna says that to develop a more holistic approach she "altered old assignments with the intention of creating more relevant, engaging problems. ...regardless of whether they were in introductory or advanced classes. ...I 
still wanted them to learn fundamental art processes and techniques" (Campbell \& Simmons III, 2012, p. 307). So, there is hope that I don't have to dismiss everything and start anew. While I have already established lessons that I thought engaged my students, I will need to really reflect and revise my lessons in order to find better ways to connect with ALL of them. This is the driving force behind all of this research! To transform my teaching philosophy will be an ongoing process that is tweaked and evolved over the years. I essentially want my students to teach me something every day; I want to be able to experience new points of views, ideas, and stories that I hadn't thought of before. This awareness will keep things fresh and new. It's a process that I look forward to and recognize will be an important aspect to my life as an artist and as a teacher.

The author Ayers poses several questions for teachers to think about in a student-centered curriculum (1993, pp. 94-96):

1. Are there opportunities for discovery and surprise?

2. Are students actively engaged with primary sources and hand-on materials?

3. Is productive work going on?

4. Is the work linked to student questions or interests?

5. Are problems within the classroom, the school, and the larger community part of student consciousness?

6. Is work in my classroom pursued to its far limits? 
I believe that to find meaning in a student's life is like peeling away an onion's layers. The deeper you go- the more vulnerable they inside become, and the more likely that tears may be felt. As a teacher, how do I create opportunities for my students to open themselves up to find meaning in their life? The Transformative Teacher Project says that a teacher needs to make "ongoing inquiries as to the need and feelings of students. ...Choices are made available that promote experimentation. Permission is given to explore inquiries of personal significance" (Freyermuth \& London, 2011). I believe that this can be seen in the carefully sequenced lessons that evolve throughout a curriculum paired with the authentic unfolding of the student/teacher relationship. When a student feels recognized and is offered an opportunity to visually express who they are in a safe and caring classroom environment, than the peeling away of layers becomes possible. A teacher can only hope that the learning space becomes an area where the student is comfortable opening up as the days, weeks, and months go by; therefore, the possibility of purpose and meaning become deeper.

If a "person's art expresses who he is. ...Art, then ...should be a process at least of reaching out toward the achievement of clarity" (Walters, p. 65). I really believe that art is a therapeutic process, not only for myself as an artist, but in the classroom for my students. I visually value this process when I can actually observe them in the act of opening up, reflecting and growing; it makes me feel a sense of gratitude that I am able to facilitate opportunities like this. Lucy Andrus has coined the term "therapeutic approach" which means to "facilitate the process of self-discovery that occurs in the 
special relationship between the student, his or her mental images, and the use of media to express these ideas" (Campbell \& Simmons III, 2012, p. 301). Looking deep within myself has always been crucial for the artist and teacher in me; it is a place that provides inspiration and gives significance to my thoughts and life. "Allowing my creative spirit to shine- following my own path and having ownership for it. Art therapy is soothing and personal"; these were my words taken out of a personal journal entry from within the past several years. If looking deep is what it takes to find meaning, than it is only natural to want my students to experience the same positive outlet for themselves. Just to clarify, I am not an art therapist, but an art teacher and I do value the importance of art and its therapeutic properties to teach art. Art that comes from the within the interior is important to a person's growth and this is what captures the essence of a holistic/student-centered art education. If it is what I value as an artist, then I cannot deny it for others to share in and explore along with me. Kessler's book The Soul of Education was the first book that I read about holistic teaching. It was through her words that I found Kessler to be a mentor and believe that her "Seven Gateways to the Soul in Education" can help any teacher breakdown important components to draw out their students spirit in a holistic classroom (2000, p. 17). Specifically, the chapters on deep connection and meaning and purpose were most helpful. Kessler said that, "Although young people are filled with questions about themselves, much of modern life keeps them from the search to understand and care for themselves. Television, video games, and now the Internet are all pulling 
adolescents into almost addictive outer-directedness" (2000, p. 20). My hope is that through the process of art-making that students can find meaning in their lives and to give their souls and inner spirits an opportunity to express and share who they are with others. "I often wonder, if all children were given the gift of arts to fully explore their inner lives and develop their authentic voices, what would our communities be like and how would our culture change?" (Lantieri, 2001, p. 78).

Another important resource that values the importance of holistic education was the book called Teaching by Heart: The FoxFire Interviews; it is a compilation book where several well-known educators who believe in the FoxFire approach are interviewed. The author Hatton says that "the FoxFire approach ... creates classrooms" where "learning grows out of student interests ...meaningful in the lives of students ...and must meet high levels of academic expectations. ...At the very center of encouraging students to choose and make decisions is an understanding of the value of personal experience" (2005, pp. 2-3). When students value their lives and/or teachers place value on their experience, we honor life, their perspective and their voice in the story. If we give children the opportunity, then we are creating a world that I would describe as 'Mor-in-Touch'. 


\section{Inquiry-Based Instruction.}

A close extension to the idea of holistic/student-centered learning was inquirybased instruction. "Inquiry-based instruction is a student-centered and teacher-guided instructional approach that engages ...students in a way that connects with their interests within a broader thematic framework" (Inquiry Based Learning, 2012). When a teacher has the opportunity to offer a guiding question, students are able to seek out a meaningful answer. Furthermore, this can become part of a teacher's philosophy. Another part of this same website goes on to say that "Arts Integration Theory ...is about a methodology and a philosophical approach to education that creates a level of personal connection and added depth in the classroom through a creative inquiry-based process of teaching and learning" (Inquiry Based Learning, 2012). The idea that students can create personally meaningful connections in a way that shows their creativity is an important aspect for an art environment, which has invited the student at the center of learning. If a body of students share in the process of discovering an answer for themselves and take into account how others approach the question in a meaningful way, than deeper levels of understanding develop out of this. The benefits to this type of inquiry-based/ arts-integration instruction is that it can:

"assist students in understanding and applying skills to standardized exams. Focus and concentration can be developed through an appreciation and application of different learning styles, such as linguistic, visual or kinesthetic thinking. Through the connection of personal experience with the subject matter, and an emphasis on the 
process of discovery which allows for unexpected outcomes, teachers help students to develop more complex thinking skills." (Inquiry Based Learning, 2012).

In conclusion, when minds that inquire find an outlet for expression, then what is learned is central to the student and to the classroom. 


\section{Care in the Classroom.}

So how does a teacher begin to know his or her students and how does this relationship grow into a healthy reciprocal partnership of teaching and learning? Through my research, I focused on what values I believed were important and what others have written about to reflect and formulate an idea of what kind of learning environment that would inspire both an artist and a teacher to thrive. Since my thesis research was about the inquiry in regards to reaching the personally meaningful depths of my students, my concern for how to do this in a safe, non-threatening, and caring way are of upmost importance to me. My personal pedagogy has valuedthe varying interpersonal relationships in the classroom, mainly because the process of art-making is so therapeutic to my well-being. As a teacher, my hope was to produce a classroom in which the students could find meaning and develop connections to the process of artmaking at whatever level of introspection was comfortable for them. Caring is nourishment for the soul. By educating myself, I now have a better idea of how this can be achieved. I want my energies and efforts to be meaningful not only to myself, but to others. Positive intentions!

Being at my best and being conscious of the importance this carries in my classroom resonated with the reading article I did on the website Transformative Teacher Project (London \& Freyermuth, 2011). In an online article called 'Invitation' the characteristics that a teacher would encompass as a 'transformative teacher' would be a good listener, smart, encouraging, and available to their students. All of these traits would emerge 
from within the teacher's interior and is the link for a successful education with children. The act of "becoming," as explained in this article "shifts the usual self-conscious, hesitant entering behavior of most students to behaviors that can be legitimately described as artistic. That is, there is a greater flow and abundance of ideas, effort becomes focused, a greater interest and empathetic regard for all develops, there is a decided grace and ease of movement, joyfulness and spontaneity in both thinking and acting blossom, and forms of expression become richer and fuller" (London \& Freyermuth, 2011).

The "FoxFire Core Practices" taken from The FoxFire Interviews was also a very useful guide for a teacher to show care in the classroom. Specifically, the core practices state that the "role of the teacher is that of facilitator and collaborator,"... "there is an audience beyond the teacher for learner work"... "imagination and creativity are encouraged in the completion of learning activities" and "reflection is an essential activity that takes place at key points throughout the work" (Hatton, 2005, p. 140-41). Every day in my classroom, I strive to be a positive, enthusiastic, supportive, and a respectful mentor who places high value on the ideas of exploratory, creative fun along with serious, focused, and skilled art-making. To set these high expectations means that I have set the tone that I value quality art-making in my art room. By being invited to inspire and transform the lives of our students, teachers need to be more acutely aware of their ever-changing needs and embrace flexible intentions. 
The idea of care can be seen in many ways in the classroom. While this list is not exhaustive, the following are key components for cultivating -emotional safety and a nurturing physical environment.

- The Teacher: personal teaching philosophy, disposition and why one becomes a teacher. London \& Freyermuth (2011), Noddings (2005).

- Open Communication: an open door policy; acceptance of gay, lesbian, bisexual, transgender, queer and questioning (GLBTQQ) and dismissing negative language. London \& Freyermuth (2011), Ruiz (1997), Sultan (2013), Intrator (2002 \& 2003).

- Respect: listening skills and quality individual attention spent with students to guide their inquiries and provide motivation as needed. Hatton (2005), Ayers (1993), Kessler (2000), Sultan (2013).

- Acceptance: of all ideas even if they are different than one's own and having the students feel authentic and genuine in their artistic endeavors. Ayers (1993), Kessler (2000).

- Quiet Solitude: downtime for the mind to rest and reflect in order to realize one's deepest ideas and connections to their self. Walters (1997), London \& Freyermuth (2011), Kessler (2000), Lantieri (2001).

- Honoring Talents and Efforts: of all students and making this recognition visible. Walters (1997), Hatton (2005), Ayers (1993), Kessler (2000), Lantieri (2001).

- Creative Choice and Access to Materials. Hatton (2005), Ayers (1993), Kessler (2000), Lantieri (2001).

- Physical Classroom Arrangement: creates an organic flow of energies and having the students and teacher's interests reflected in the space creates visual dialogue and marked experiences. Ayers (1993), Coutts \& Jokela (2008).

- Physical Classroom Environment-Natural and Organic: incorporates the outside in and deviates from the man-made sterile feel that a four-walled room usually carries. Ayers (1993).

- Community: classroom space strives to welcome and accept every student, so that it is a place where everyone can be themselves. One cannot learn to explore their private inner landscape if their surroundings don't allow it. Walters (1997), Hatton (2005), Kessler (2000), Lantieri (2001), Intrator (2002 \& 2003). 


\section{The Teacher.}

To start at the beginning of what is meant to care in the classroom, one must look at the teacher or caretaker of impressionable students. A teacher takes into the classroom an idea of what a teacher is supposed to be, what they should do and how they should act. I came into the profession of teaching with a passion for art, a thirst for gaining more knowledge, and a desire to pass this knowledge along. After two bachelors' degrees, one in studio arts and one in teaching, along with a minor in Anthropology, I found myself saying, "I love to learn." "When we bring our passions into the classroom, our enthusiasm is infectious. Students intuit this" (Wink \& Wink, 2004, p. 175). This passion can be seen extending into my classroom through the interactions with my students. For example, I enjoy the process to learn about my students lives beyond the classroom (it's the anthropologist in me) and also into the inner workings of their creative mind, especially when they show me new ways of approaching a problem that I had never thought of before. I find it enjoyable when my students become my teacher. I show them that I'm a real person with feelings and that to open, share, and express who I am means that we can relate on a more meaningful level. When I am able to go beyond my teacher role and share my artistic processes to these young artists, I have joined the artist-teacher in me with them. "By inviting the stories of our lives to dance with the stories of our traditions we have to be prepared to be open and vulnerable" (Intrator, 2003, p. 64). To open myself up to my students, who come with varying levels 
of maturity and experiences, I expose myself to their questions and comments. We bond more closely because of this.

On a wall in my classroom, I have created a poster of Don Ruiz's "Four Agreements." It has been hanging there since I began teaching 6 years ago. Ruiz, a New Age writer, said that there are "Four Agreements" by which to live: "Be impeccable with your word, don't take anything personally, don't make assumptions, (and) always do your best." It was my initial hope and intention that these basic thoughts would help to keep my students and myself on a more positive path with life.

\section{Open Communication.}

To have an open forum for respectful communication was crucial for me to show care in the classroom. When everyone's voice can be honored and taken seriously, people can feel trust. It is true that "adolescents need opportunities for deep conversation. The developmental turbulence of adolescence requires it. To ignore this need squanders a growing mind's vitality and curiosity" (Intrator, 2003, p. 60). I believe when you honor the voice and people see it, time and time again, then it carries over into a part of the culture dynamic in the classroom. When open dialogue can exist amongst the class, then we are able to learn about everyone better. "They wanted to have heartfelt conversations in their classrooms and with their teachers. They believed that as maturing young people they needed space and time to discuss issues pertinent to their lives" (Intrator, 2003, p. 61). I have believed that an open forum and a sense of 
trust with your classmates and teacher, where questions can be asked and discussions can be had are supportive environments. Intrator interviewed and observed a high school teacher who said that "what is true and good is the ideal classroom (...) It is a place energized by conversation through both explicit statements and illustrative stories" (2003, p. 115). Once the students in a classroom start to feel comfortable with one another, then the classroom culture becomes more obvious to everyone in it. Bruce Feiler, says that through the ideas expressed about what is valued, there are "benefits of making a family (class) mission statement, which captures a family's (classes) core beliefs about what they are all about" (Sultan, 2013, April 14). Currently, I do not have a classroom mission statement, but I do believe that I would like to adopt one in the near future to create a more caring classroom.

\section{Respect.}

In addition to an open forum for communication, a student can see that you care when you take the time to get to know them and listen to what they have to say because "The teacher makes ongoing inquiries as to the need and feelings of students" (London \& Freyermuth, 2011). Throughout my research, I have read time and time again through multiple authors such as, Hatton, Ayers, Kessler, and Sultan, that listening is a crucial factor. Bruce Feiler's quote (as cited in Sultan, 2013, April 14) says that "it's vital to really hear the child's input and be able to incorporate those ideas, so the child is invested in its success." Students are complex individuals and to allow them the chance 
to open up and explore their interior can be beneficial when done responsibly and with care. The educator, Nel Noddings said that "the most fundamental thing to do is listen to your students. Listen to them and try to connect what you think they should learn with what they want to learn. And if you connect those two things, you're going to have a wonderful partnership with kids or students of any age" (Hatton, 2005, p.71). Sometimes students need to talk through their ideas with an adult in order to gain clarification on what's going on. Advice, given to me by my professor Dr. Virginia Freyermuth, was when I needed to help a student work through any difficult situation, then I was to answer the student's question with another question. The teacher should avoid giving the student the answer, but rather help them to answer the question themselves; by doing this, the student is mentored along the way to find their voice in the questions and answers. I have a magnet on my art room fridge that reads, 'sometimes questions are more important than the answers.' When helping students discover who they are, my hope was that there existed a motivation that happens to both parties in the process. What I mean by this is that from the student's excitement to explore their ideas further, the teacher will also benefit from their guidance of the student when they see the fruit of their efforts unfold, which result in discovering something new about the student. On the other hand, sometimes just to listen and guide a student has nothing to do with art-making, but with the person itself. Nel Noddings said, "I learned that people are very different and go through very different experiences, and teachers ought to be sensitive to these experiences" (Hatton, 2005, p. 
67). Each student has vulnerabilities and a teacher needs to be acutely aware of the fine line that exists between their world and ours. At times we just need to be strong for them. Louise Dery-Wells, a spiritual psychotherapist, wrote, "I have learned to hold hope for others if they cannot carry it for themselves" $(2005$, p. 18). In conclusion, "(a)s the whole is greater than the sum of its parts, the goal is to tap into the combined inner strength of each person to enhance each member and the group" (Wink \& Wink, 2004, p. 179).

\section{Acceptance.}

If a classroom was respectful to everyone's ideas that are different than one's own, much can be learned from other people. When ideas are valued by classmates and the teacher, there generally is a sense of genuine authenticity that goes along with it. I have found that this only happens when relationships already exist because there is a level of trust that is transferred. This feeling can feed one's artistic endeavors.

\section{Quiet Solitude.}

Through my research, many authors such as Kessler, Walters, and Lantieri place emphasis on the importance of quiet and calm. Kessler said that "longing for silence and solitude" exist within the classroom (2000, p.17). I agree that quiet is needed for the mind to rest and reflect in order to realize one's deepest ideas and connections to their self; personally, this means journaling to me. "Through journaling, students will be able to slow down their thought processes rather than share them with others. This 
opportunity to engage in self-conversation will turn them inward to register their perspectives" (Intrator, 2003, p. 117). Intrator goes on to say that inspiration won't come to you without invitation" $(1997$, p. 133). I believe that the artist has to be open to receive ideas and inspirations. Without this, the artist doesn't allow the possibility of authenticity and meaning to surface. John W. Gardner said, "We can keep ourselves so busy, fill our lives with so many diversions, stuff our heads with so much knowledge, involve ourselves with so many people and cover so much ground that we never have time to probe the fearful and wonderful world within" (Intrator, 2003, p. 70). He also says that Maxine Greene wants teachers to change the state of our world through opportunities that engage their minds into thinking more critically. The best time for creativity comes "during moments of reflective calm. Very rarely is the moment for artistic expression that of the actual experience which inspired it" (Walters, 1997, pp. 101-102). In conclusion, artists need quiet solitude to move toward the physical act of creation and to find meaning within themselves.

\section{Physical Classroom Arrangement.}

The physical classroom arrangement is a map created for energies of creative minds to flow in and out of accessible inspirations. The term Feng Shui can describe this. A classroom "space is a key element, dynamic and powerful, in creating relationships between people and place (...) how space is handled can make places seem safe or friendly, imposing or cozy, comfortable or claustrophobic" (Coutts \& Joklela, 
2008, p. 168). Environments have a huge effect on how someone feels when they enter a space; interior designers have a history of concerning themselves with arrangement and flow for their clients. I believe that if physical flow was blocked, the creative chi or life-force spirit also is. "The environment-- like the students --is a living thing" (Ayers, 1993, p. 64). This means that things need to move and bend with those in it. Having organization within this space would also be an important point to keep chaotic energies from interrupting flowing energies. Especially when inspiration strikes, it is helpful to know where all the tools and supplies are.

\section{Community.}

Community can be a beautiful thing when it's a supportive group of people who believe in some greater good for each other during a specified period of time:

“...genuine learning and effective teaching are more likely to occur when we belong to a community that cherishes nurturing, listening to, and caring for each other. The promise of community is a nurturing space where we can stretch our minds with fellow learners and do so in ways that reveal our true selves" (Intrator, 2003, p. 49). Without students in my classroom, it is hard to teach and without these students it is difficult to have a community of learners who can adapt, respect, learn, and grow. Intrator quotes the educator Parker Palmer:

"A learning space should not be filled with abstractions so bloated that no room remains for the small but soulful realities that grow in our students' lives. In this space there must be ample room for the little stories of individuals, stories of 
personal experience in which the student's inner teacher is at work. But when my little story, or yours, is our only point of reference, we easily become lost in narcissism. So the big stories of the discipline must also be told in the learning space (...) We must help students learn to listen to the big stories with the same respect we accord individuals when they tell us the tales of their lives" (2003, p. 62).

In conclusion, Nel Noddings (1992) says that “(p)reparing to care can feel like the most vulnerable step of the process... teachers do not have the safety of caring from a distance...caring is up close and personal, minute by minute, day by day. Placing caring at the core of each day challenges us to great courage and great love... It is often the most lasting legacy a teacher can share, and it is the greatest gift a student receives" (Wink \& Wink, 2004, p. 185). I want to be remembered for how I made my students feel. I want my students to return years later and share that how they felt in my classroom was a positive experience for them. "As Maxine Green famously urged upon us; make of your classroom the arena of your own becoming, and it will surely follow, that the children will do likewise, for only as you strive to become the person you desire to be, so will they" (in London \& Freyermuth, 2011). Be authentic and they will follow. When I am able to grow as a person, teacher, and artist, I know that I am in the right place and that I am "Mor-in-Touch." 


\section{Chapter 3: Research Methodologies}

When someone has a question, it is natural to develop curiosity and seek out answers. The journey to search and collect for information varies as much as the initial question. There are many different ways to conduct research that a researcher needs to understand what styles and methods best suit their quest in the question. My initial questions for this thesis research began within myself. As an artist, I work with my emotions to bring them into a visual form. I have always been very intuitive with my feelings and look within myself for answers. What I wanted to learn more through this research process were the deeper reasons connecting me to my dedication towards my education and professional careers of both art and art education. My first form of research began with a self-reflective process. Then, I started to look at Parker Palmer's methodologies, arts-based research, living theory action research, qualitative research, and feminist research. Once these particular methodologies that interested me were understood, I began to investigate ways in which I could implement these approaches into a unit to fit four different art class curriculums. After brainstorming and figuring out what concepts I still needed to teach my students, I decided to plan and implement a collaborative art installation that would utilize all of my art classes. The idea behind the art installation was to address a real life concern in the school, which was to transform a particular space into a colorful and positive environment that honored the students and their work. This would be done by connecting my "Mor-in-Touch" process with the students being more in touch with their school's space. 
To begin my research, I started reading about different research methods. From there, I was able to recognize ways that did and did not resonate with the way I wanted to go about this. I did not want to do quantitative research because I was not looking to gather numerical and statistical data, which feels cold and removed from such a personal process like art as I wanted to explore it. I also wasn't particularly interested in performing any case studies, which take one or more people and studies them based on some question. While interviewing seems to relate to the personal process better than a case study, I wasn't sure whom to question. It may have been interesting to interview an exemplar artist that I really connect with on an artist level, but what I wanted to get out of this research was a way to connect to my students from the angle of an artistteacher. Particularly, I was interested in how I could use my "Mor-in-Touch" process, which is a personal approach to my art-making and extend it into my life as a teacher. Interestingly, this thesis project actually turned into a case study because I was focused on doing this work in a particular location and situation. Rather, than study the students involved in the installation, I choose to study the "Mor-in-Touch" artistic process used by my students along with my own process as the designer and facilitator for these experiences. In addition, arts-based, action-based, and qualitative research also weaved together with the case study to form the foundation of this research. One of the most important aspects of my research came from reflecting on my ideas, processes, and values as an artist and as an educator, as well as the exemplar artists that have inspired my personal work and my work with my students. Taking the time to go back into my 
journals and reconnect with ideas that shaped who I am today, made me place value on the act of writing even more than I had before. The process of going back in time made me aware that my experiences as a younger artist and the life experiences I had along the way shaped the person I am today. Reading passages helped me to find artistic and spiritual influences that have come through my life. This process gave clarity and connectivity to both the artist and teacher in me. This revival emphasizes the fact that we should all follow our own path, take risks and share ourselves with others verbally and visually. Self-reflecting gives insight into the "expression of who we are and who we are becoming" (Lichtman, 2006, p. 206).

Parker Palmer was another important part of my research approach. Through many of his books and a website called the 'Center for Courage and Renewal', I was able to find a voice that resonated with my self-study as an artist-teacher. His website says that " $(w)$ hen you're committed to making the world a better place, it's vital to align your daily life and work with your core values" (http://www.couragerenewal.org/). A person's integrity paired with positivity makes Palmer's outlook holistic in its approach; to see the whole person and how each aspect of their life connects with others means that we can make a difference in the world. Through Palmer's words of wisdom and available retreats to embark on, an educator can reconnect and renew themselves to be "Mor-in-Touch" with themselves. 
Arts-based research uses art making as a form of investigation. Leavy (2009) says that this form of research delves "into the artistic process as a primary mode of inquiry, creating various forms of art as a way to collect data, conduct analysis, and/or represent social science research"

(http://isites.harvard.edu/icb/icb.do?keyword=qualitative\&pageid=icb.page340895). This type of specific research will work to better understand my students, but more specifically, my own artistic processes. McNiff (1998) says that arts-based research includes "the making of art by the researcher, as ways of understanding the significance of what we do within our practice" (p. 13). I believe that by understanding my artistic process better, which I analyzed in a self-study, that I wasable to inform my own teaching in the classroom better. Studio art is a visual language that manifests itself many times without words; arts-based research believes that there is significance in this form of "communication in order to express meanings that otherwise would be ineffable" (Barone \& Eisner, 2012, p. 1). This particular form of research was explored in depth through the documentation of the installation process and how each student was able to approach it in their own way.

Jack Whitehead's action research called "Living Theory Approach" informed me that “ $(p)$ ractitioners investigate their own practice, observe, describe and explain what they are doing ....and produce their own explanations for what they are doing and why they are doing it. ....monitor what they are learning, and how their learning influences their actions" (Whitehead \& McNiff, 2006, p. 13). This research approach means that I 
am able to take what influences extend into my classroom as a form of self-study to reflect and draw from. This "action-orientated research ...seeks to facilitate personal and societal change" (Neuman 2000, p. 83). I am a reflective practitioner because I am aware of how my actions inform my students, as well as, how my students inform my actions. "Living educational action researchers believe that their theories constantly need revisiting and reforming as the circumstances of their lives change, so their theories are always in a state of live modification" (Whitehead \& McNiff, 2006, p.30). Since the changes are a direct relationship between what is going on with my students and myself, I can improve my teaching practice and be better equipped to understand and act on outcomes based on my decisions. When I think of the word living, thoughts of change and growth come to mind. This concept has been a huge theme for me, especially because it permeates my artwork on mental, spiritual, physical, and visual levels. This particular research approach works very well with my intuitive personality because I welcomed the unexpected and embraced the ambiguous. It left wiggle room for just that - change and growth. I am highly driven by feeling and act instinctively; this helped me to adjust my teaching to meet the changing needs in the classroom. This research approach was best applied in the section titled 'Becoming Mor-in-Touch Installation,' that documents the project from conception to finished product. It is a journal that records my experiences of change and growth.

More so, my act of journaling can be described as a way to record qualitative research. I have observed my students for the past six weeks go through the process of 
creating an installation. Once I introduced the project to my classes, I began to take pictures of their engagement with the materials. Since this was a collaboration project, there was a lot of discussion and interaction amongst the students at first. As the project evolved, many students became more reclusive and thoughtful in coming up with their designs. Once ideas were established, the dynamics of the classroom shifted. Students were investigating a variety of new materials and approaches that were unique to their designs. In walking around the classroom, watching what was happening, and helping my students, I was able to use all of this information to gain immediate feedback for my teaching. Bogdan \& Biklen (1998) write that "qualitative research is frequently called naturalistic because the researcher frequents places where the events he or she is interested in naturally occur. And the data gathered by people engaging in natural behavior: talking, visiting, looking" (p. 3). I always want to know my students on a more meaningful level, so watching their behavior is an important way for me gain valuable feedback in creating the right atmosphere for learning. "If you want to understand the way people think about their world and how those definitions are formed you need to get close to them, to hear them talk and observe them in their dayto-day lives" (Bogdan \& Biklen, 1998, p. 32). Since observations are an ongoing part of my daily routine, this means that my relationship with the participants are intentional and personal; my hope is that this type of holistic and natural research will help to inform my teaching, so that I can better understand my students behavior in the art room environment, that we both have shaped (Lichtman, 2006, p. 11). 
In addition to observation, I am also very interested in the process that my students (and myself) take when creating art. I hold high expectations for all of my students and believe they have the capacity to work hard; this is because I know firsthand that with hard work comes success. "Qualitative strategies have suggested just how the expectations are translated into daily activities, procedures, and interactions" (Bogdan \& Biklen, 1998, p. 6). The power to see what is happening amongst certain people at a certain time is very informing with regards to the artistic process because it allows for an immediate dipstick or sense of understanding. Neuman (2000) says that the "incorporation of the researcher's personal feelings and experiences into the research process" is a feminist act (p. 83). In this particular project, my goal was really to get the students to be more in touch with themselves, their classmates, the materials, the space, the school, etc. So, yes, I was most definitely incorporating my personal feelings, suggestions, and experiences into the dialogue! Lichtman (2006) writes that feminist research "frequently includes the researcher as a person" (p. 78). This is true because the basis for the project stems from my "Mor-in-Touch" process.

In conclusion, there are many ways that a researcher can go about seeking answers to a topic. My investigation includes: self-reflective artist/arts-based, student/arts-based, living theory action-based, qualitative/observational/case study, and feminist research methods. I have to agree with Bogdan \& Biklen (1998) that a qualitative researcher is "not putting together a puzzle whose picture (they) already know" they "are constructing a picture that takes shape as you collect and examine the 
parts" (pp. 6-7). I didn't have any idea how this inquiry would unfold, but this study has brought meaning and a new perspective to my "Mor-in-touch" artistic processes in its manifestation though my students. 


\section{Chapter 4: Lesson Planning}

The curriculum design for this relief installation project began with the concept of identity. A handout was prepared for the students, which prompted them to think about who they were and how they identified with themselves. The students were asked to quietly reflect on their identity and then draw symbols/visual imagery along with words to best describe these personal connections. This time of quiet solitude was intended to give the students an opportunity to get "Mor-in-Touch" with their thoughts and ideas.

Next, the students were shown a PowerPoint piece that touched upon the main themes for the project. I showed exemplar works of art in this PowerPoint and prompted discussion throughout. The key questions asked were: 'what is an art installation?', 'what does collaboration look like?', and 'what is a mosaic?' The PowerPoint concluded with a slide that showed a basic sketch for the installation and the question, 'where is your real estate?' This prompted a discussion between the students and teacher to connect the ideas of installation, collaboration, and mosaic components together for the purpose of addressing the visibility of art in the school issue. The importance of bringing art back into the newly renovated school, which once was a vibrant, colorful, and creative learning environment, had been felt by everyone including, student, teachers, administration, parents, and friends. This project was designed with the intention to provide an opportunity for the students to get "Mor-inTouch" with their new school environment and classmates. 
The main design for the installation was drawn by me using theCAD software on a school computer. The design included enough spaces for all of the art students to participate and have ownership for their own space. Rather than knowing the intended layout and placement for each student and the design, the idea for the students to picki numbered real estate randomly was suggested by my fiancée. Each number corresponded to a specific location in the relief installation, which dictated color and size. In doing this, favorites for location, color, and size were eliminated; some students even swapped amongst each other if they agreed. Overall, each student was committed to and responsible for designing and creating a thoughtful work of art that would cumulate with their classmates into a collaborative art installation.

Then the students used paper to prepare the shape of their reliefs. They used another CAD drawing that measured out each real estate space to get a general size. From there, they were told to make neighborly connections with the shapes already established. In doing this, the parts of the relief create a mosaic, where each part fits nicely with its surrounding shapes like a puzzle. The netting which was used for holding the individual reliefs for the installation was laid down on the floor for the duration of the project. A key point here is to have the students physically go to their real estate location and make connections to the space and their surrounding real estate shapes on the spot. I found that when the students weren't part of the reality of their real estate, then their shapes didn't interact as well as they could have and had to revise their work. The dialogue of shapes grew after each class. What I mean is that each student left 
their paper shape identifying their name and color right there where it belonged on the floor. By doing this, there was a dialogue going on without having all the students there at the same time. You could visually see where people where placed and what shapes they took at the beginning of this collaboration.

*Handouts for the unit are located at the end of the paper in the 'appendices' section.

If you are interested in planning and installation with your students, please use the following master plan to help guide you.

First, you need to decide where you want the installation to go.

- Will it be an exterior or interior location?

Second, you will need to look at the space and size and start to brainstorm possible ideas to transform the space.

- What will work and transform the space? What does it need?

Third, once you have an idea then work out your design details with a sketch and/or small model.

- Start working with materials that would be appropriate for your age group, budget, students' health, curriculum, and proposed location.

- Decide which idea would be the best and prepare an example project. If you just gather potential materials to be used, then it might be hard to visualize the idea for others. (Note: that I did not have an example project prepared when I began planning this; I was undecided.) 
Fourth, type up a proposal and create your plan of action.

- This should include: your idea for the installation, a sketch of what it is intended to look like, dimensions, materials, construction, how its hung/removed, images of location, curriculum connections, learning objectives/standards, teacher guidance, funding, estimated length of project, additional help needed (custodians, woodshop teacher, other art teacher/staff members, etc.), ceremony, and assessment/rubric.

Fifth, once your proposal is written up then you prepare to meet with your administration for approval.

- Once approved, I highly recommend setting up a meeting with the local fire marshal to get the official acceptance. Small detail in the grand scheme of planning, but one of the biggest!

Sixth, decide if further sources of funding are needed and prepare documents. Seventh, prepare the details of how the art making for the installation will connect to the curriculum in your classes.

- Make yourself available as the project draws to a close if some students need more time to finish.

Seventh, create your plan to install the work of art.

- Who is going to help? Check to see if custodians are under height/weight restrictions in their contract.

- Will there be a plague to describe what the installation is about?

- Will there be an unveiling ceremony?

- Will you contact the local media/newspaper to promote the arts in your school? 


\section{Summary of Steps for Master Plan.}

1. Pick a location

2. Brainstorm ideas

3. Plan a sketch of your idea; gather pieces of materials to be used

4. Create a plan of action

5. Meet with administration and fire marshal for approval

6. \$ource of funding

7. Design lessons

8. Plan/Execute to install into space 


\section{Chapter 5: Implementation: Becoming 'Mor-in-Touch' Installation}

The following section documents the process of the 'Mor-in-Touch' installation from the proposal to the final outcome. Each daily log marks a moment of reflection for me. I was able to keep track of how the project unfolded and any issues, surprises, or connections that came to be. Italicized portions are additions and changes in retrospect that were added in only after the project ended. I found taking pictures enjoyable, but I wish that I had taken video segments of students processes and thoughts while working. It would have been beneficial for the students, staff, administration, family, and future teachers inspired by my project to have insight of how the installation manifested. When someone has passion in their professional field, it can be felt by others in many ways. When a passionate person provides an opportunity for people to work towards positive change, regardless of the results, the experience is inspiring and should be shared with others.

\section{Proposal.}

"MOR-IN-TOUCH"- is a term that I created during my research course for my thesis. The term can be described as one's self being more in touch with their process, materials, decisions, social interactions, environment, etc. when creating artwork. This particular process will encompass the foundation for an installation in the new entryway of the school where each of my art students will create a relationship between their art work and the other art students, alongside our new school space/environment. Artwork such as murals and painted ceiling tiles were visually seen all over our pre-renovated 
school, but only were intended for the seniors. This project is designed to include all of the students enrolled in my studio art classes because all students need to feel visible. Further, the installation project will seamlessly fit in with the established curriculum of the art classes and provide an opportunity for the NHS students to see themselves as part of the new space. This process-orientated project will focus on each student-artist to personalize, express, ad reflect themselves through visual symbols, images, and language. The "Mor-in-Touch" collaborative installation project has the hope of infusing the new school's main entrance space with a sense of a positive, inspiring, energizing and universal sense of community that reflects the students' unique identities.

Projected Sketch of Installation:

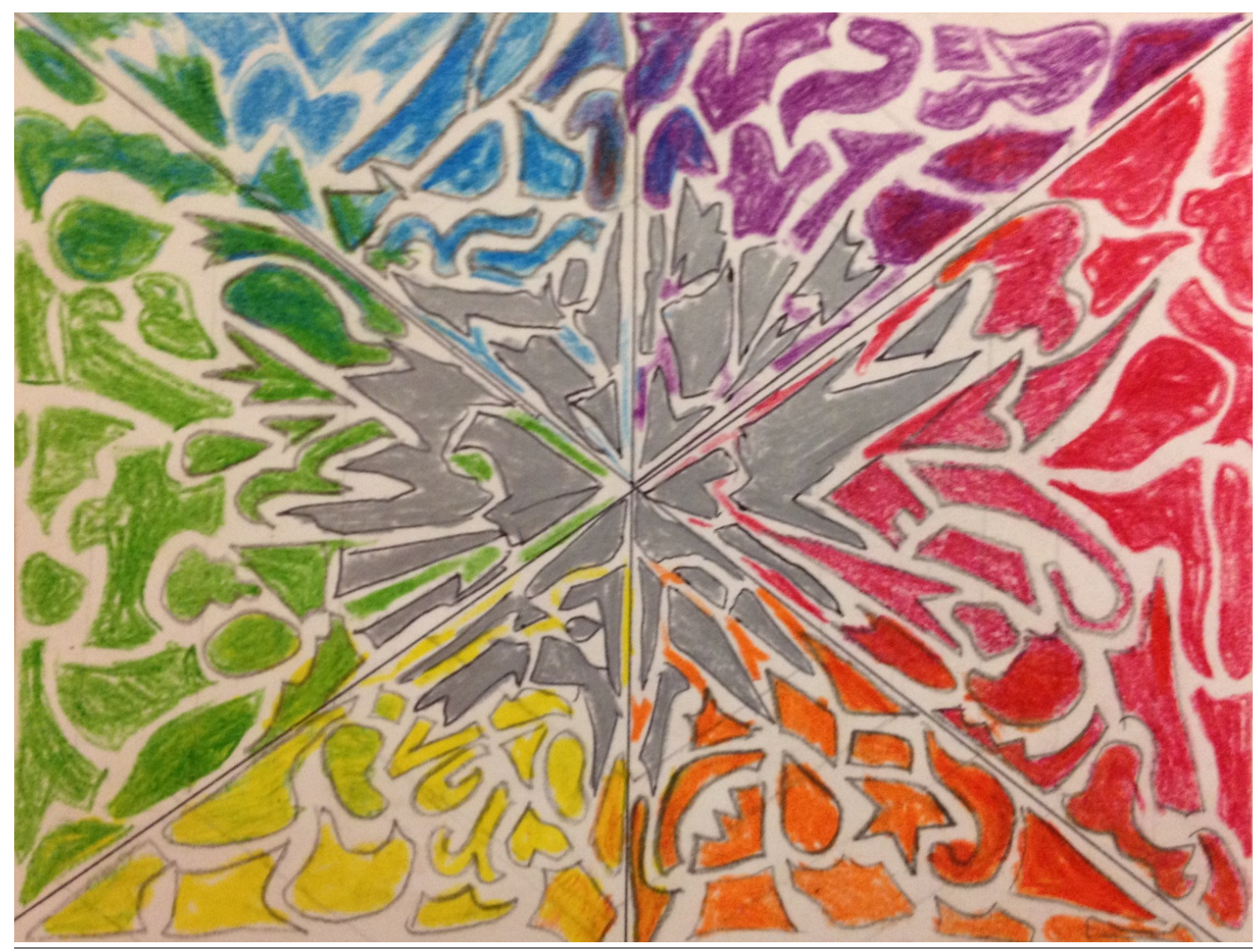


Overall Installation Dimension: About 10' height $\times 16^{\prime}$ width $\times 2^{\prime \prime}-12^{\prime \prime}$ depth (final depth size changed to $24^{\prime \prime}$ in only a few areas)

Art Materials:

- Clay (heavy weight and fragile/breakable; time consuming/firing/expensive material)

- Plaster strips (lightweight; time efficient; not as expensive/uses less material) hand/face casts used to make reliefs

(Not sure if administration knew there was cardboard under the plaster strips in the example I prepared for them; at the time, I am not sure if I thought it was an issue.)

- Plexiglas Mirror super glued into/onto the surfaces (pre cut into shapes: squares, rectangles, triangles, but can be customized with a jewelers saw and bench hook or drilled to hang)

- Acrylic Paint/Paint Markers/Gesso base for longevity/vividness

- Assorted Wires (aluminum is lightweight is more light reflective)

- Strings/Fabrics/Papers (kept to a bare minimum/fire code)

- Armature (nylon fishing net- keeps wall visible and less heavy feeling)

Construction/How the separate elements are attached:

Students will design and fabricate individual relief pieces that will come together as a mosaic with their classmates into one larger work of art to create the installation. Students will be aware of their neighbor's decisions- to create a unified art piece in the end. Individual reliefs will be fastened onto the sturdy nylon fishing net using wire. Secure and safe attachments will be stressed for safety of the space/students/staff/etc. 
How it's hung on the wall/Removal:

The nylon fishing net will provide an airy and open concept to the installation, as well as, provide a reliable supportive structure for the artwork to hang from. This will keep the newly construction walls free from holes, tape, glue, etc. The fishing net will use the existing metal hardware to attach to- specifically the upper and lower metal bars. Clear zip ties will attach the installation to these bars. Depending on finished product weight, a few additional screws may be used where there aren't any in the hardware. This will make it sturdy and when the art piece is ready to be removed, the zip ties can be cut off from the railing and if needed, the screws can be taken out, with no visible holes in the wall. The anticipated weight of the art piece could range anywhere from $25-40 \mathrm{lbs}$.

(The piece was a bit on the heavier side despite using lightweight materials. Custodians recommended using structural support for secure measures once they saw the installation in its final stage.)

Below: Installation Location- main entrance in the new addition; middle top panel
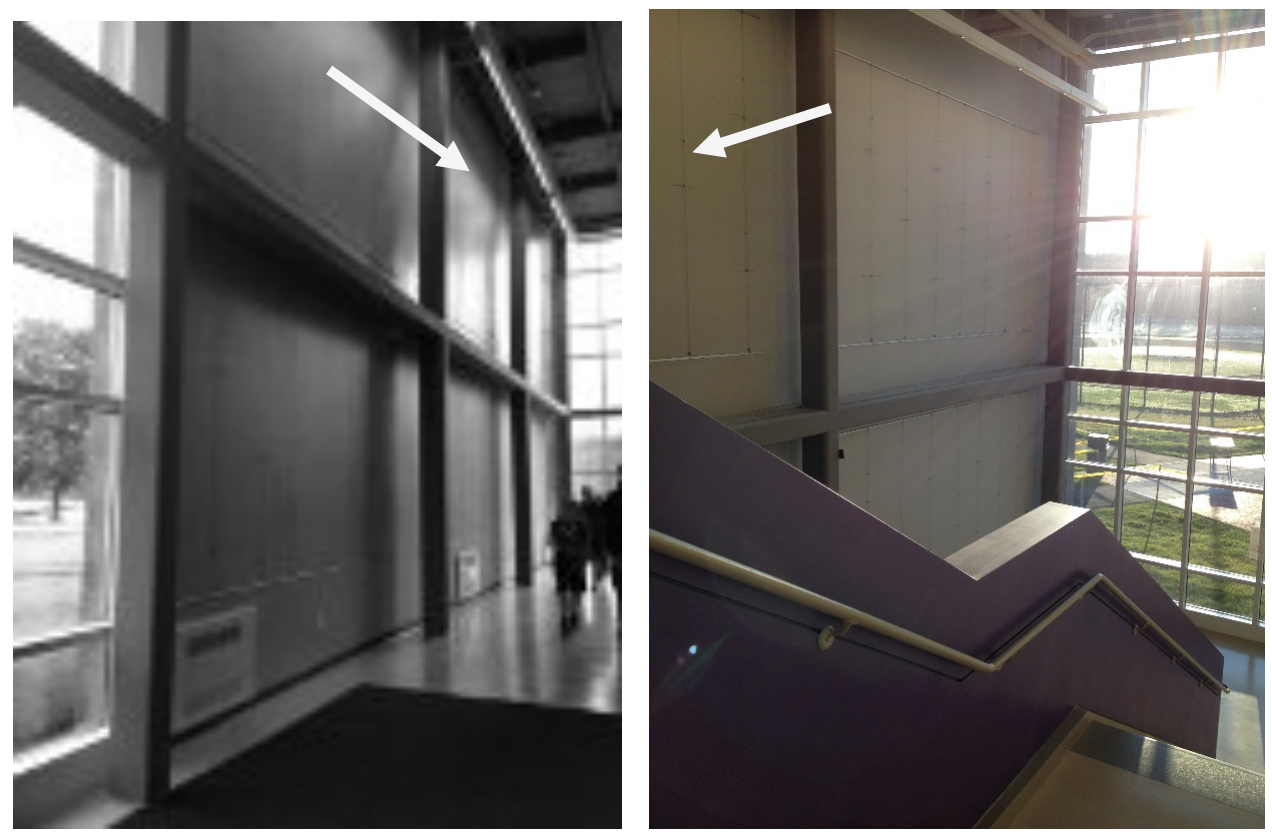
Here are the existing support bars seen in the image below.

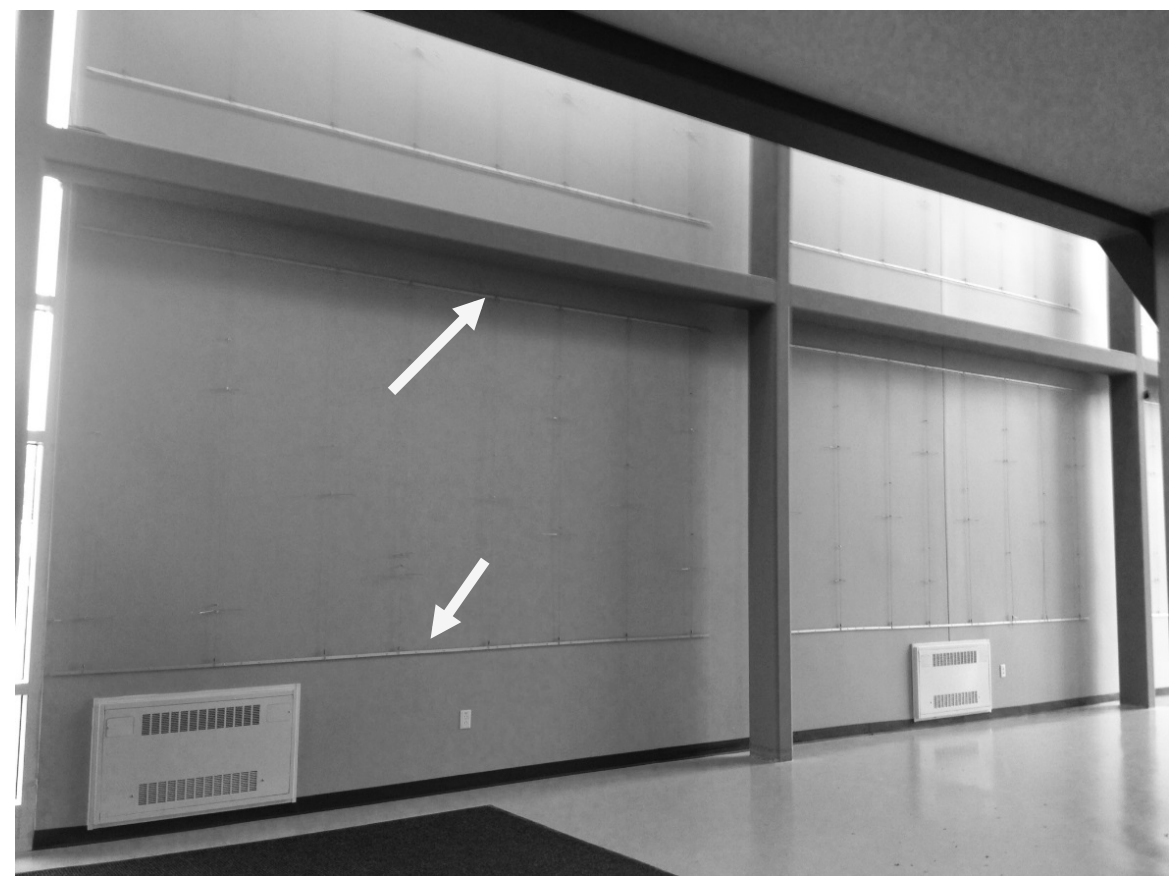

\section{Curriculum Connection}

\section{Essential Questions:}

- What is identity?

- In what ways can a work of art reflect the indiviuality of the artist?

- How can an artist be "Mor-In-Touch"?

- In what ways does an art installation transform spaces?

- How does art create mood/feeling? Do colors help?

- How can artists collaborate to create a message about community?

Learning Objectives/Standards: vary for each class (see below)

How will I- the art teacher- guide them?

Students will be inspired to leave the first collection of visual artwork in our new school construction by discussing the theme of identity, viewing a PowerPoint, which includes 
exemplar installation examples, and having a discussion about what our former school used to look like in terms of creative expression. The goal of the installation is to create unique student pieces that recognize individuality that come together through decisionmaking and physical collaboration in a group setting. The art teacher will promote and facilitate interaction into the class time, as well as, work individually with students. The final art piece will be assembled by the students, with the help of the teacher, for the act of physically attaching and leaving their artwork. This act will mark a tangible connection to the art piece and a sense of community amongst who have participated.

How will I fund this?

Materials from classroom will be used that are on the low end for price. Materials used are part of the art budget, with many, if not all, coming from the discounted READS Art Bid. A large, but slightly worn, commercial grade nylon fishing net was donated by one of my fiancé's friends, who is a lobsterman in Maine. A Plexiglas mirror sheet about the size of $2^{\prime} \times 8^{\prime}$ will have to be funded for about $\$ 75$.

Length of project: Students meet every other day for 90 minutes and is anticipated to take about 3-4 weeks. (The project was definitely pushing four weeks and we could have used a fifth week.)

Installation help: I will need to borrow the scissor lift and get help from the custodians to access the top portion of the art wall. They will need to help me zip tie the project to the metal support bars and potentially use additional materials for support if needed. 
Ceremony: The installation will have an unveiling ceremony that will help to highlight the architectural space of our new school, the artwork made by the students, the students themselves, and the supportive administration.

Assessment: Rubric for each class has a different set of criteria/skills to learn. Common throughout is: creativity, sculptural relief design, monochromatic color scheme, contrast in the designs and group work collaboration/adding their piece to the overall structural support. In the end, each student was asked to write a self-reflection on their artwork. These questions follow below:

- Comment on your opportunity to leave a mark on Norton High School's newly renovated building and being part of the first art installation. How did this make you feel? Why?

- You left your art for others to see such as your peers, teachers, administration, parents, and future students. Describe the relief that you created, which reflects who you are.

- What challenges did you face in the relief installation project?

- What did you do to overcome these challenges?

- What are you most proud of? Why?

The following were a brief breakdown for administration only, before I actually worked out the details at a later date. Actual rubrics that were used can be found in the 'Appendix G' section at the end of the paper.) 
Art 1- Discuss asymmetry-BALANCE and create a cardboard SHAPE that reflects this. Design a 3D relief FORM in asymmetrical balance using the cardboard shape as the base. Discuss low, medium and high relief and plaster over shape and cardboard- possibly leaving wires exposed. Student will need to think about placement of at least 1 mirror within design. Using a specific monochromatic COLOR scheme, students will add color with acrylic paint to their white plastered reliefs to create UNITY. Lastly, students will mix paint/use paint markers/other materials that are predominantly monochromatic to create a personalized asymmetrical balanced design that highlights its features with CONTRAST. Students are encouraged to use symbols, visuals, and words that represent themselves to create a complex design that takes up at least $50 \%$ of the project.

2D DESIGN- Create a shape that fits within their real estate. Design a 3D relief FORM within the shape. Discuss low, medium and high relief and plaster over shape and cardboard- possibly leaving wires exposed. Student will need to think about placement of at least 1 mirror within design. Using a specific monochromatic COLOR scheme, students will repeat it throughout to create UNITY. Students will create 2 CONTRASTING patterns that personally represent them and takes up at least $50 \%$ of the project. The patterns can be created using a variety of materials which are arranged to show MOVEMENT AND RHYTHM. Shellac/Gloss/Matte medium may be applied to seal surface papers. 
3D DESIGN- Discuss Body Casting and FORM/VOLUME. Create a body cast such as a hand, foot or face using plaster strips. The student will attach the form(s) to a cardboard base to create a mid to high relief. Stress the importance of transforming this cast in sculptural ways. They will need to incorporate at least 1 mirror into their relief. Using a specific monochromatic COLOR scheme, students will add color with acrylic paint to create UNITY. Lastly, students will mix paint/use paint markers/other materials that are predominantly monochromatic to create a personalized design that highlights its design feature through CONTRAST. Students are encouraged to use symbols, visuals, and words that represent themselves to create a complex design that takes up at least $50 \%$ of the project.

SCULPTURE- Discuss radial BALANCE- as they are part of the center of the installation (pie wedge shape). Design a 3D relief FORM using the cardboard shape as the base. Discuss low, medium and high relief and plaster over forms and cardboard- possibly leaving wires exposed. Student will need to think about placement of mirror, which takes up $50 \%$ of their real estate space. Show EMPHASIS to mirror closest to center of installation design and dissipating outwards to show MOVEMENT. With the remaining space, the student will use a specific color range (primary or secondary with their 2 respective tertiary colors) to create a blended COLOR scheme. Students will use a variety of materials to design personalize the remaining $50 \%$ of the space that keep with their color range, but shows CONTRAST. 
*All classes are encouraged to hang loose pieces from their relief; drill holes into the Plexiglas mirror or use a metal puncture tool to pierce through the plaster/cardboard materials. This could help to add movement to the environmental space.

* Wire/ misc. fabrics/string is encouraged during the final attachments to the net. (This was the intention, but time was a factor that did not make it possible to do so.)

*Students could write something special on their art piece (time capsule, memory, idea, wish, dream.) It could be on the back/inside their sculpture- to add to the personal factor. (Some students liked this idea and went with it, while others did not. Again, if timing wasn't an issue, then I felt that the concept would have been further embraced.)

\section{1/21/13 Meet with Principal and Asst. Principal}

I showed my sketches, the nylon netting, and some sample projects of cardboard covered in plaster strips with wire hooks. I described the installation idea of individual recognition for each student, but stressed the importance of community and communication for the group. The idea of the art piece creating UNITY was a priority of mine, as well as, the principal. She was concerned that the individual pieces were all going to be thrown up there on the netting and look bad; I then stressed the careful planning and consideration for each part. We also discussed the idea of color. She said that it didn't have to be monochromatic based off the school colors, but didn't want it to be all over the place. She mentioned that the radial design of the installation could possibly lend itself to being a color wheel, but that she wasn't the art teacher and that it 
was up to me; she just wanted it to look good. I agreed that the color wheel was a great option and like the fact that I could incorporate her idea into the art piece. Overall, we were both excited to have the students' artwork showcased in the school and she anticipated a successful outcome. At the end of semester 1 around late January, she would like the installation up and/or ready for the upcoming open house, which is to show off the school's renovation. She asked if there would be a plaque describing the art and its meaning and I said yes. At the end of the meeting, the assistant principal arrived and I quickly debriefed him on the installation.

Planning out the details:

"Go inward... to your center. Reflect on who you are... share this experience with your classmates, peers, teachers and school... let others in." Micaela Morin

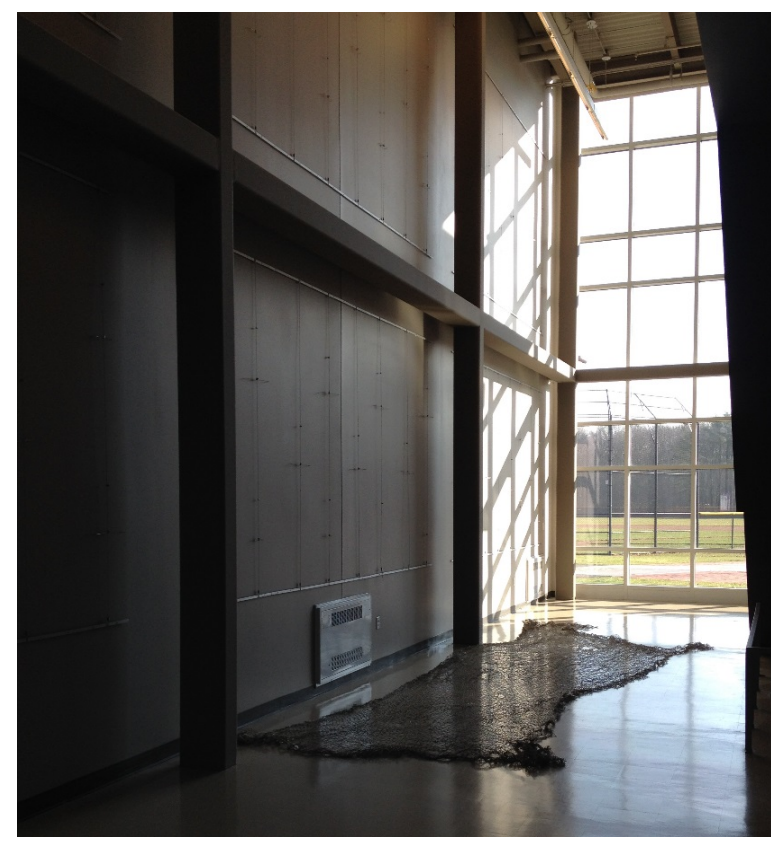

Above: I dragged the net down to ensure the size was correct and it was in good condition. 
*I reworked my sketch from just shapes into an organized plan of basic shapes (still open-ended for students) that reflected in a color wheel scheme. I figured out how many students are in each of my classes so that I could get a sense of how big/small the actual works of art needed to be to fill the space. This count was also important to determine how many of each project from each class needed to be in each part of the color wheel. The breakdown is as follows:

Art 1-35 students (about 6 each section of $R, O, Y, G, B, V$ )

2D- 10 students (1-2 each section OR spanning for tertiaries for blending)

3D- 23 students (about 4 each section of $R, O, Y, G, B, V$ )

Sculpture- 6 students (1 per section -radial aspect of the design $(R, O, Y, G, B, V)$ )

*Created PowerPoint of images: installations, collaborative works of art and mosaics

*Asked a few CAD students help me prepare a "real estate" map/grid to divvy up the installation space and have each correspond with a color and number; goal is for each student from each class to draw out a number, which corresponds to a piece of real estate on the color wheel- that will be their installation spot (I am doing this so that the final art piece doesn't feel so controlled, like it was a few days before. This will allow for more freedom and random occurrences to occur, which I think is exciting for a collaborative project.)

The image below shows the planning of colors within the real estate.

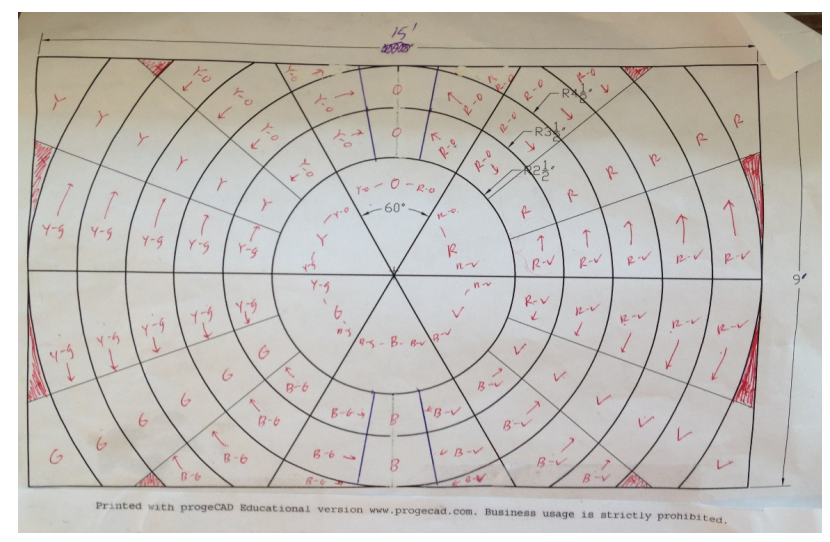

The image below shows randomly numbered real estate, which was filled in by a friend. 


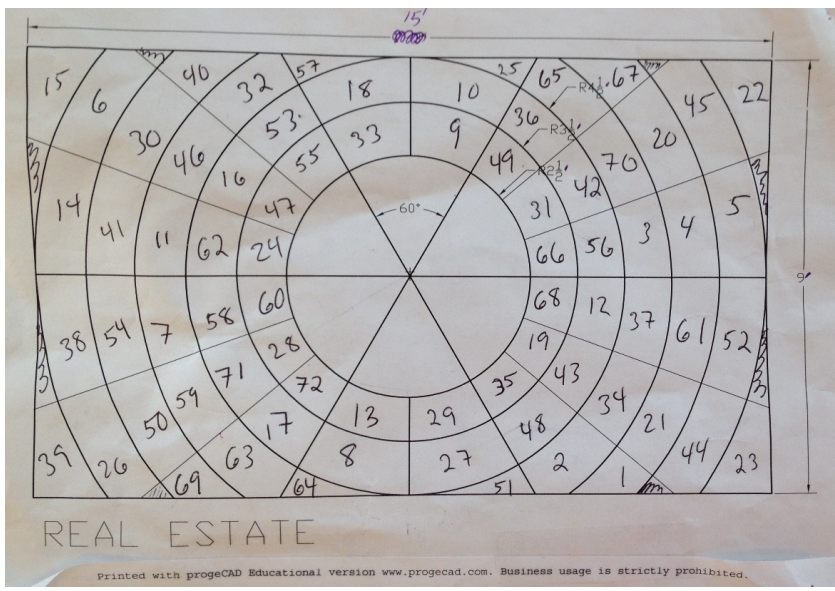

*Used CAD to create the real estate sections (Interested CAD students backed out.)

*Made numbered paper pieces for picking real estate

*Discussed the concept of identity and students' individually brainstormed their ideas using worksheet guide

*I am having thoughts of having a small TV installed near the installed art piece, which will show photographs and short clips of students working individually and together in the process of this collaborative art piece.

\section{Week 1: Introduce "Mor-In-Touch" Installation Project}

*Showed PowerPoint to all classes

*Students pick their real estate (I allowed many who didn't like their color location to pick again in my first class); students signed name on main real estate map. As real estate was chosen, I visually showed and told the students about the connections between people in their class and other classes.

* Overall, there was a lot of positive feedback and excitement from the students! I am thrilled, but exhausted at expending so much of my enthusiasm.

2D: *explained contrasting pattern concept- creating a plaster cast relief (face, hand, object of their choice or own design) and then using paper and shellac to create 2 very different patterns onto their relief

*Collected colored magazine pages that reflect their monochromatic color scheme (encouraged collaboration to help jumpstart relationships); cut their plaster strips 
3D- *showed Power Point on George Segal and we started in on a practice body cast using their finger

Sculpture- *picked color on the center of the color wheel section and handed out homework to start designing their pie wedge shape

Art 1- *many students wanted other colors, so I allowed them to repick and make a decision based on one. I stressed it was a random pick and had to work with it, but the artwork would be personal and about them.

Below shows the real estate, which is colored coded for each class; therefore the class connections are easier to see.

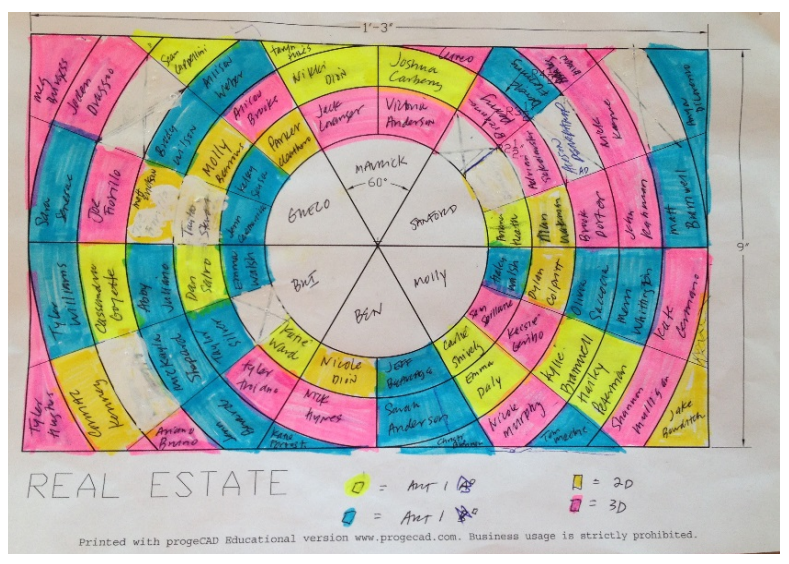

*I did some more dimensioning out of the real estate to give the students a general size frame to work with. If certain real estate neighbors exist within a class, the students can really get funky and creative with their shapes. This will help when coming up with the general paper templates for the project to ensure all of the pieces from each student and all classes will flow and fit before committing to their project shape. 


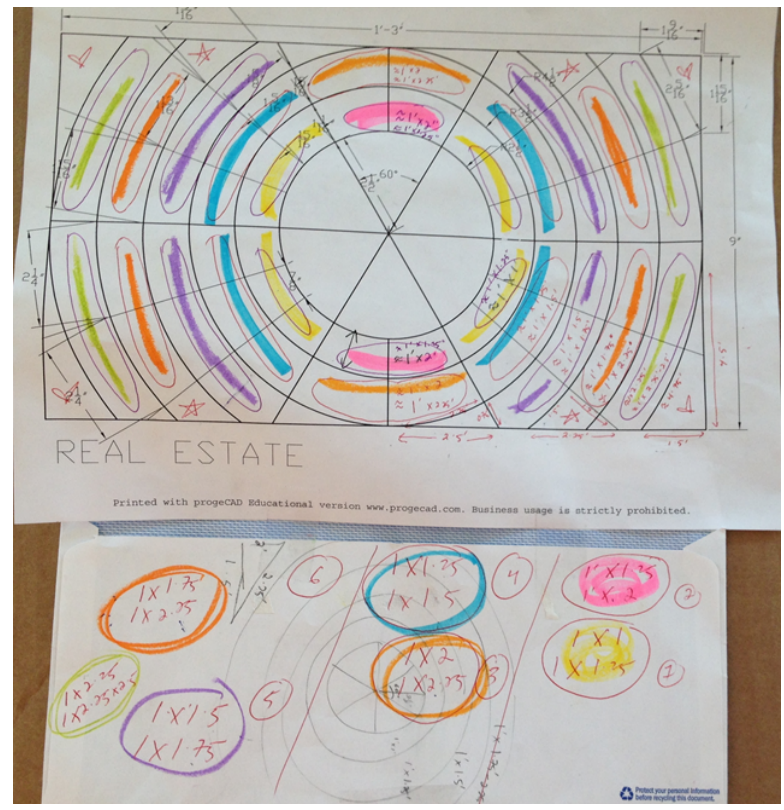

Above shows the real estate sizes using the CAD program, which are then further categorized by the 7 different sizes through a simple color code and general measurement of height and width.

*Laid netting down in back of classroom floor and taped it using Duct tape

*Students cut out their shaped paper templates and lay them down in their correct real estate locations, which include name, class, and color. (This will start the ongoing visual dialogue to come with each class.)

*Students write down their color, basic real estate shape, and size onto their homework sheets; directions for planning are explained, which is to start the shape formation and designing of the 3D relief. (While I told them that I work intuitively, I stressed coming into class with some idea to work with rather than not having an idea. 

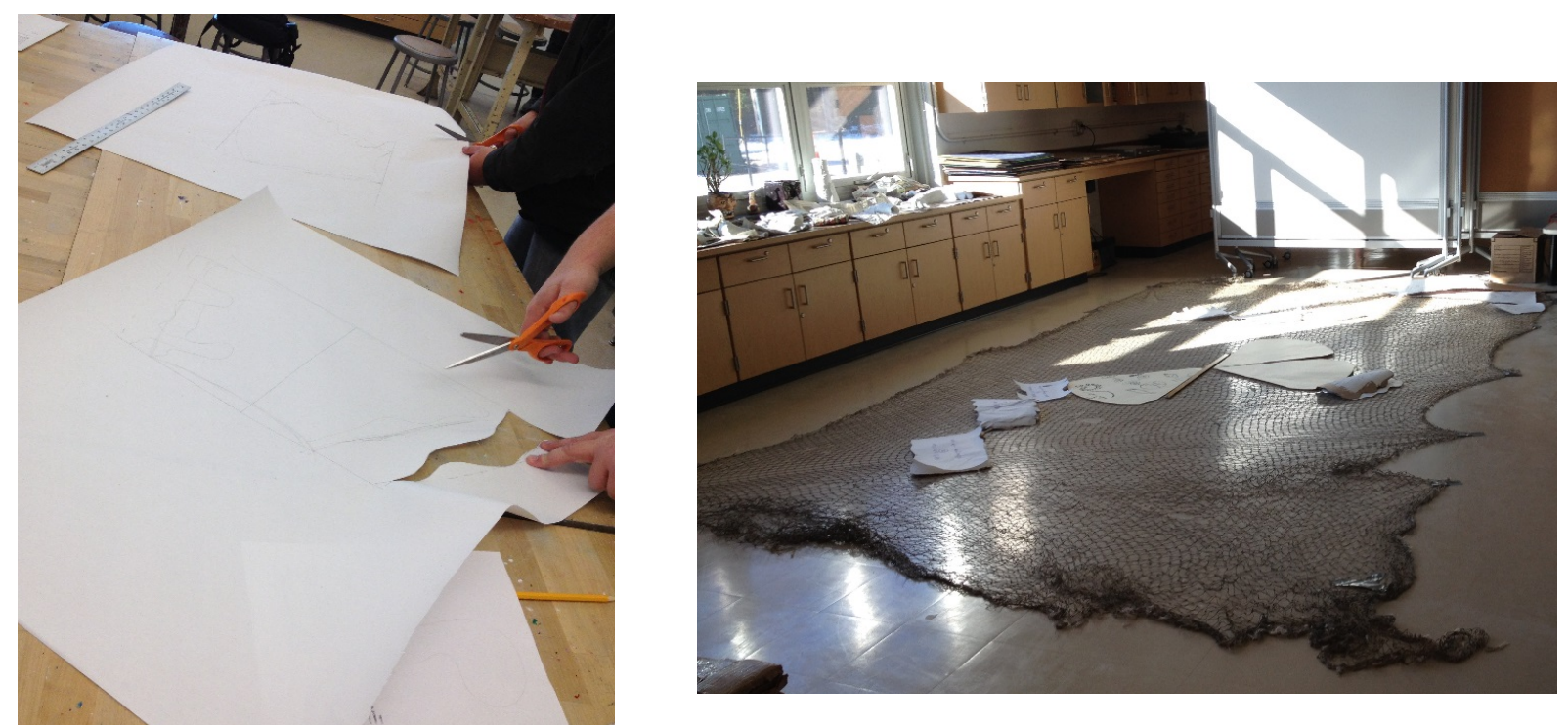

The left image is one of the first real estate shapes created and the right image shows the paper real estate progress on the net.

*5 extra spots left on netting- where I was going to incorporate more mirror, but I think I am going to have the other art teacher ask her class or interested students if they want to participate.

*Clarified homework directions- don't add color as it is hard for anyone to visualize color in its final form, when they haven't completed designing (I have to keep going back to my own process as an artist and internalize my own feelings if I were designing something for this project. As this thesis is a reflection of my process as an artist too.)

*Encourage students to think about making connections when designing their real estate shapes; who are their neighbors specifically for the class? From other classes? What edge(s) of their shape match up with their neighbor(s), so that they could have a conversation with them today about the touching edge(s)? Encourage them to physically visit the netting on the floor and see who is there. The purpose is for them to have a conversation, make a connection with their shapes, and know that their work will be next to others and part of a larger mosaic work of art. (So during my rounds, one student told me that their neighbor in real life was their neighbor within the mosaic. I thought that this was a really cool coincidence.)

* If no surrounding real estate between classmates or prior classes exist, encourage students to make a decision or starting point for others in that section 
With the official start of the project underway, I updated the classroom board. Here is an image of below:

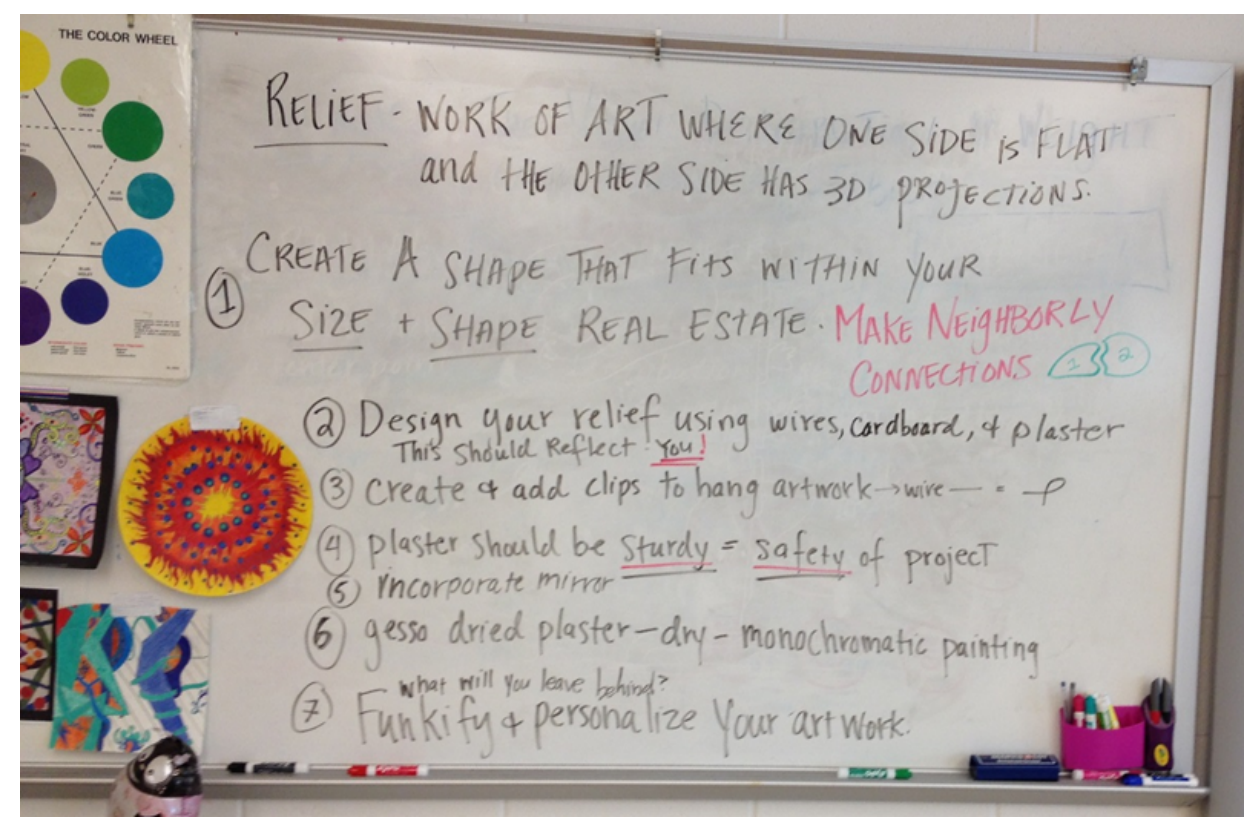

*Tweaking project criteria/rubric/material choices as my ideas clarify; offer more material choices to interest the students

*2D students input changed the criteria from contrasting patterns to a collage (I like how they are taking ownership for their learning and want a different choice!)

Week 2: Planning shapes and fabricating reliefs

*Student connections are happening on their own as students make their shapes; I found two boys cutting away and adding to their shapes with each other.

Here is a picture of the two students and their paper real estate pieces below.

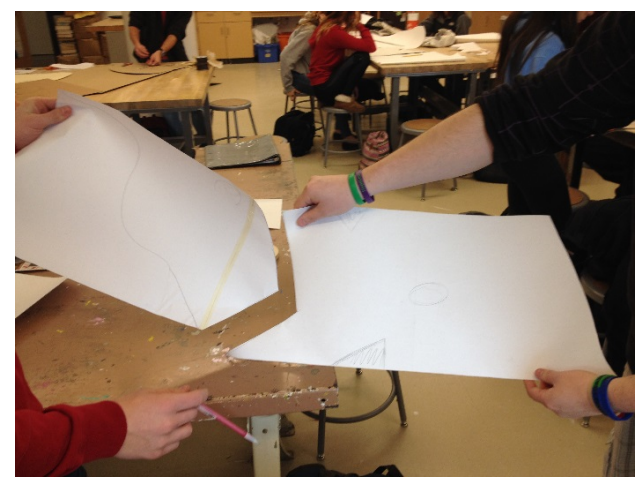


Below are pictures after half of the paper real estate shapes have been made.
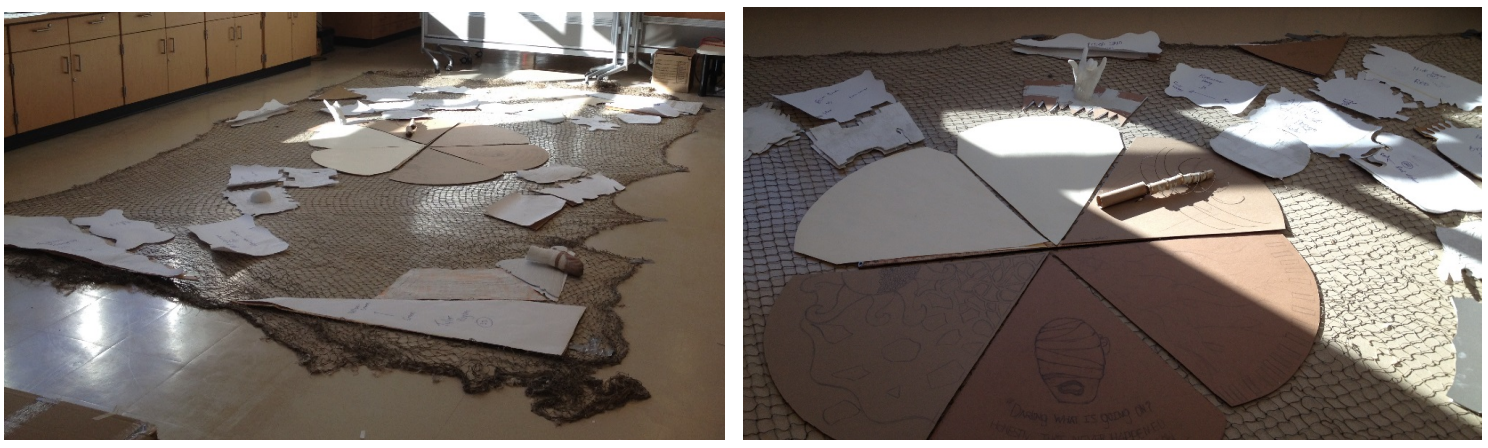

*Students need guidance and direction to figure out their spots/sizes/color orientations, who they are next to, what is already claimed as to the shapes made by prior classes, and their interaction connection with them. This is an exciting part of the process because after the next few classes come through, then all of the paper real estate pieces will be created and laid down, making the total idea real estate map visible! It definitely takes a lot of planning to do this, but I feel that the end will result in an art piece that encompasses the students that made it and their connection with each other, the school, etc.

*After checking over the initial paper real estate shapes, some students need to rework their pieces better (either too small and no connections and one student's piece was too big and overlapping another students). Stress to these students that the shapes need to flow and is a part of the grading criteria. It was helpful to write my notes in a bold color for the students to see and consider- like contour better or too big and overlaps neighbor.

Below is a student rechecking her real estate shape with her surrounding neighbors.

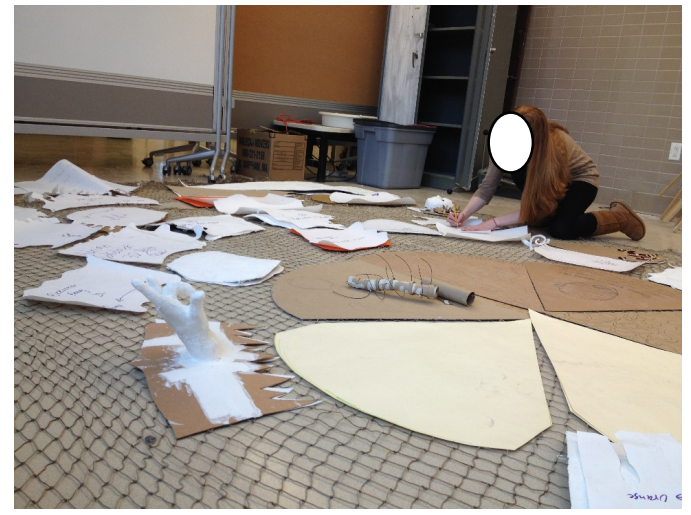


Here are pictures of the students' connecting with the real estate.

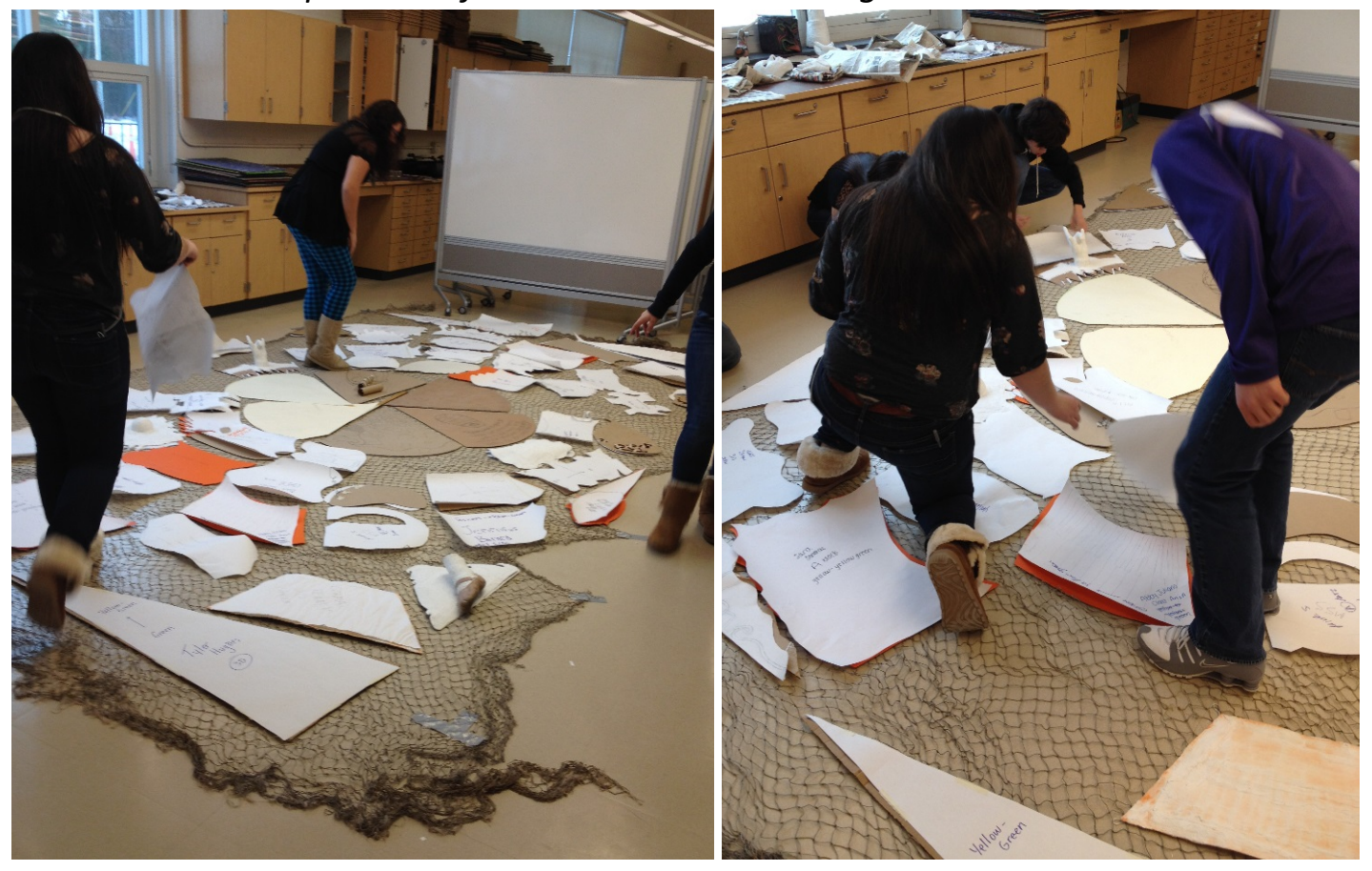

Below they are finagling their shapes alongside the other neighboring shapes.

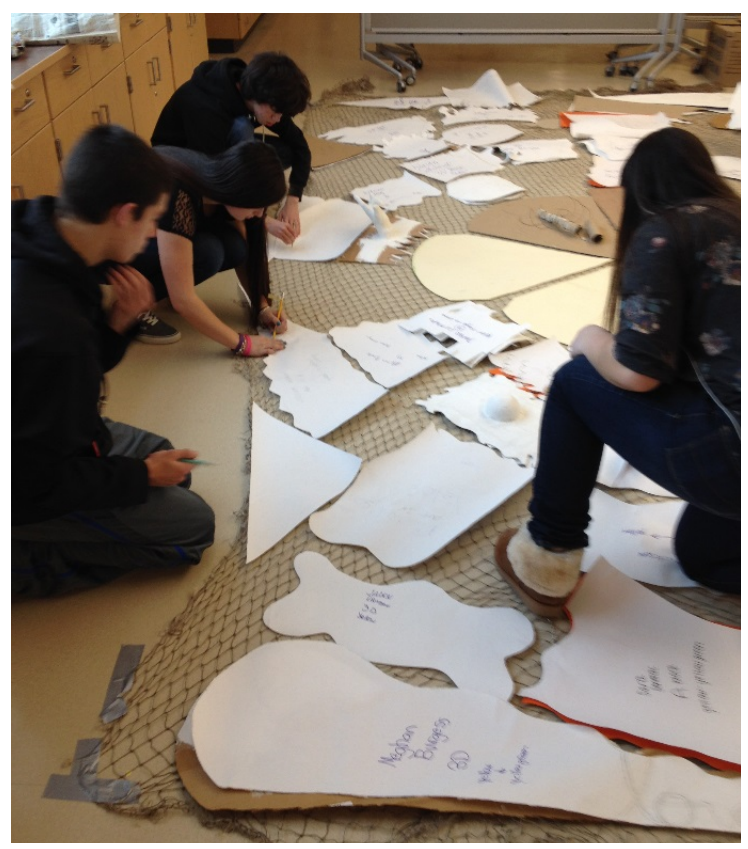


Week 3: Complete sculpting reliefs and start adding color and mirror

*Review grading criteria while students continue to build up the 3-D relief aspects and plastering over them

* Many students are exploring a range of materials: wire, pipe cleaners, cardboard, body casting, Styrofoam- cutting spheres or cubes in half, filing down Styrofoam into organic forms, building up with newspaper and tape, coiling wires and adding cardboard pieces to the tops, wire mesh sheets, paper straws, cardboard tubes, etc. Material choice continues to be very open. I enjoy seeing the personalization from each student's idea expressed in their artwork from material choice to process. Every student is fabricating their ideas and marks for others to see in unique ways. Judith $\mathrm{M}$. Burton writes that a "great deal of learning takes place through this dialectic involving active, hands-on, bodily manipulations of material. "As materials bring responses into focus of mind, they simultaneously act as vehicles of reflection" (Campbell \& Simmons III, 2012, p. 5).

Below, in the next 3 pictures, you can see the students' work in progress using a variety of materials. Their exploration with the materials and its properties to find what works for their design are insightful for me as their teacher, but also for the students who are learning a lot from watching their classmates and sharing their ideas.

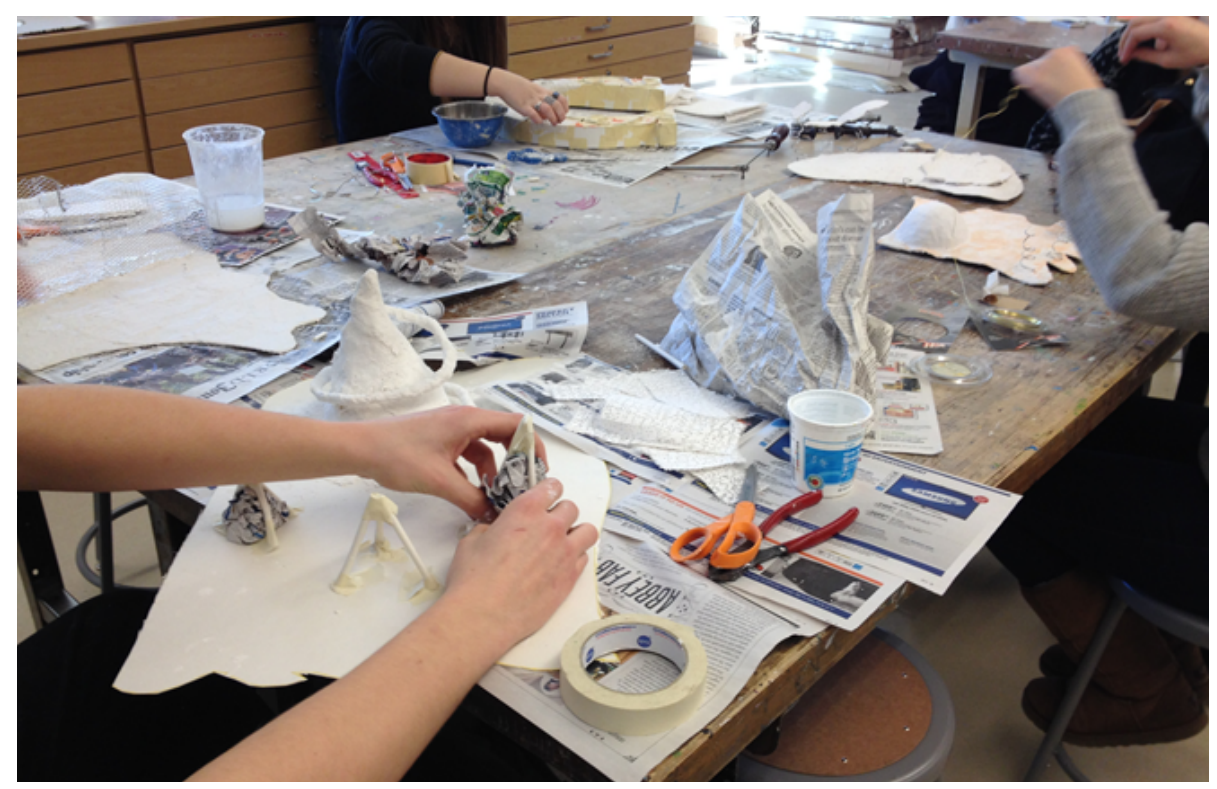



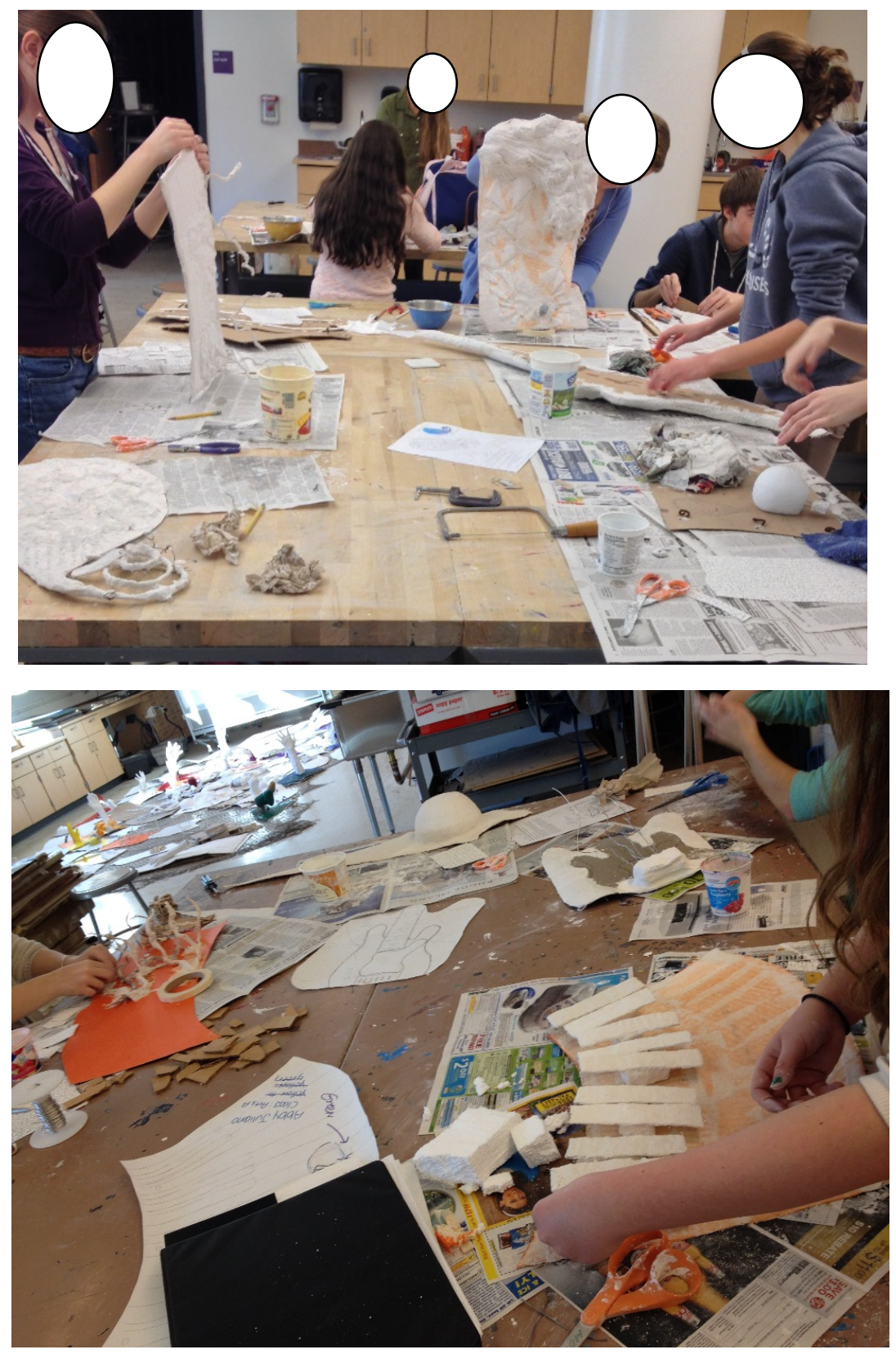

*Some students requested custom mirror shapes and gave me templates. I will either cut them out with a band saw or show those students, whose design is more complicated, how to use a jewelers saw and a clamp to customize mirror shapes. 


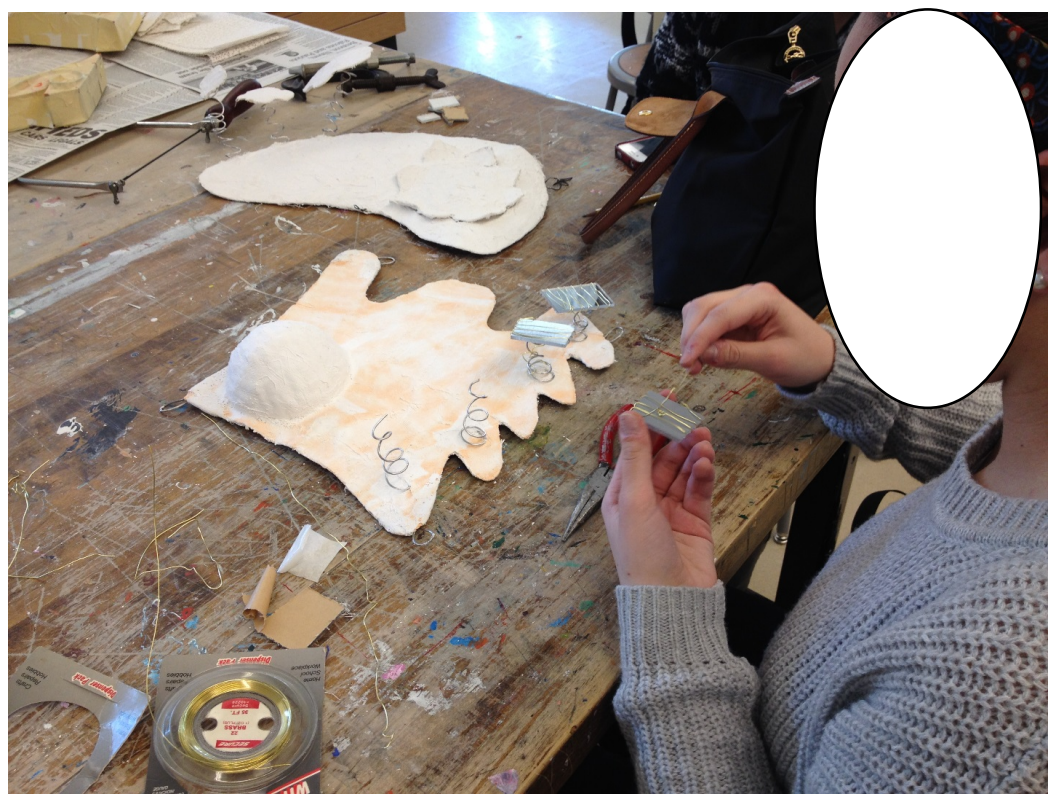

Above is an Art 1 student who is exploring ways to connect mirror to her project. She has decided to wrap the mirror pieces with brass wiring and connect them to aluminum springs plastered to her relief. I advised her to add a touch of super glue for extra stability and safety.

*Students approach color. For future reference, be careful and make sure the students know the correct color they have AND that the direction of their real estate/color are correct.

Below are a few images of 2D students starting the color application.
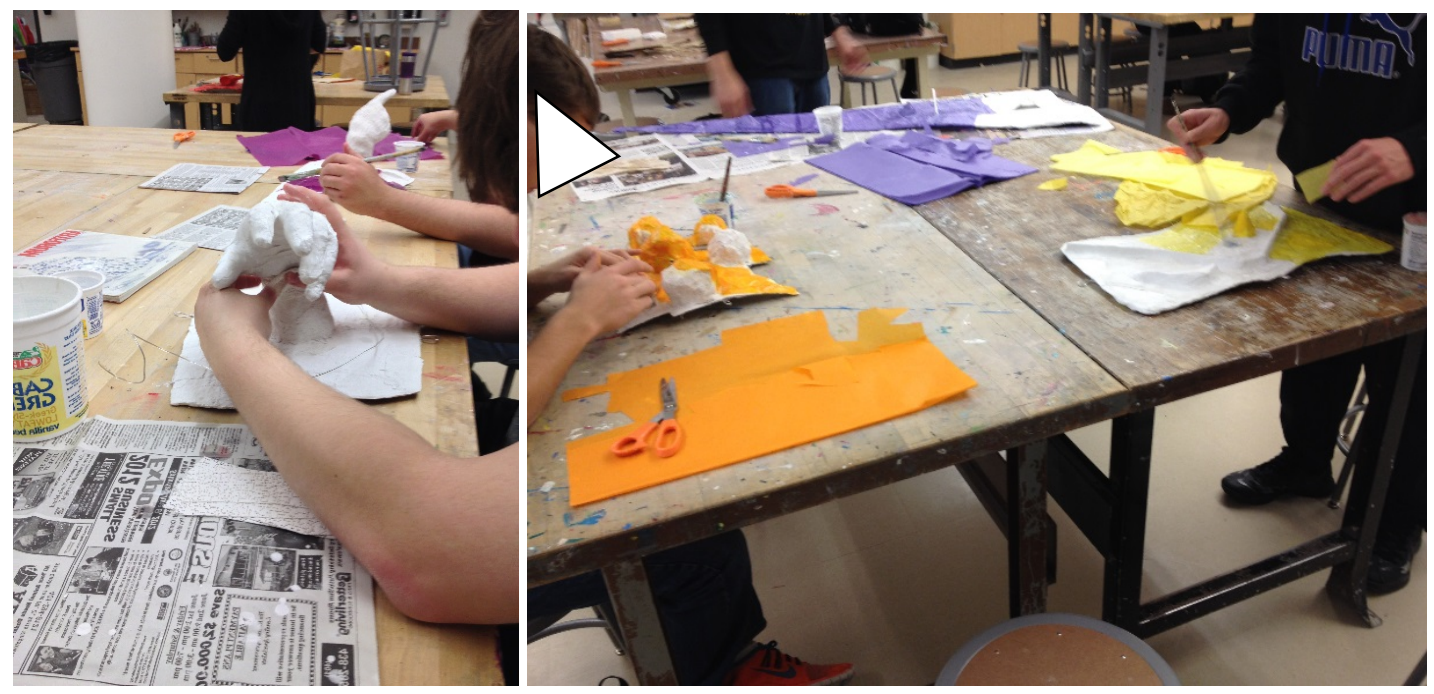
*I am hoping that by moving into color that it will entice some slower moving students as there are only 4 classes left to complete this installation and I definitely feel like we could use an extra week. Nothing kills the mood, when an artist is rushed and doesn't make their best work; I know this from experience. Letting students know that they can come in after school or borrow supplies to work on it outside of class is important for them to know because, unfortunately, artwork that is not finished will not be able to be incorporated into the final installation. We are all counting on one another to make this project complete! (Some students are skipping out on gesso, whether they forgot to or I told them they could due to time constraint. In the future, I would plan more time to allow for this.)

*There is a lot of exciting stuff going on! Upon closer inspection and asking students questions, I am getting to know the students better. In doing so, I am gaining a closer perspective into who they are. I walked around and questioned the students; here are some of their responses and ways to symbolize their interests in life:

$$
\begin{aligned}
& \text { waves = surfer } \\
& \text { dance shoes = ballerina } \\
& \text { music notes, guitars, keyboards = musicians } \\
& \text { Patriots, Bruins logo, soccer net/ball = sports lovers/athletes } \\
& \text { horse shoe = horseback rider/cowgirl } \\
& \text { theatre stage = actor } \\
& \text { phases of the moon, trees, flowers = nature lover } \\
& \text { keyboard/mouse = technology lover } \\
& \text { faces = beauty/makeup } \\
& \text { celestial/ horoscope } \\
& \text { irregular wires/sculpted vines = crazy/chaotic attitudes }
\end{aligned}
$$

* In looking at what has been painted, the majority has been warm colors to this point. I question if those with warm colors experience a sense of urgency with their projects, while those with cool colors are experiencing a more laid back approach and are taking their times? I commented on this out loud around one of my students and she agreed with what I thought; she went on to say that it would be an interesting psychological project! I think it would be too. 
*In retrospect, refrain from using poster board for base pieces as it is too thin and becomes waterlogged too quickly with the plaster. This is especially true for those which would hold any body cast weighing a few ounces or more. Only cardboard should be used for the base as it is lightweight, but durable for the application. The reason I converted to poster board is because I would have used up all of my cardboard needed for the next semester classes and reordering with the office is a big hassle.

*Some 2-D students are using interesting and relatable imagery into their designs, rather than just finding straight color and collaging with it. If I were to go back, I would encourage and model this as an easy way to visually connect their ideas to the project.

*Lots of moving around, guiding, questioning, wondering, being inspired by my students' ideas, teaching on the fly skills/new materials being explored, and wiggling their hanging clips to ensure safety. This collaborative project is really building up each student's sense of ownership and commitment as it is all coming together. It is most definitely a comfortable classroom environment! I will cherish this experience of sharing my "Mor-in-Touch" process and honestly want to do it all over again. Building this artist community with collective experiences has not only been beneficial for me as a teacher and observer, but I really think that the students got a lot out of this. My intention is to have the students reflect on their experience and write up a formal explanation/artist statement when they finish their projects.

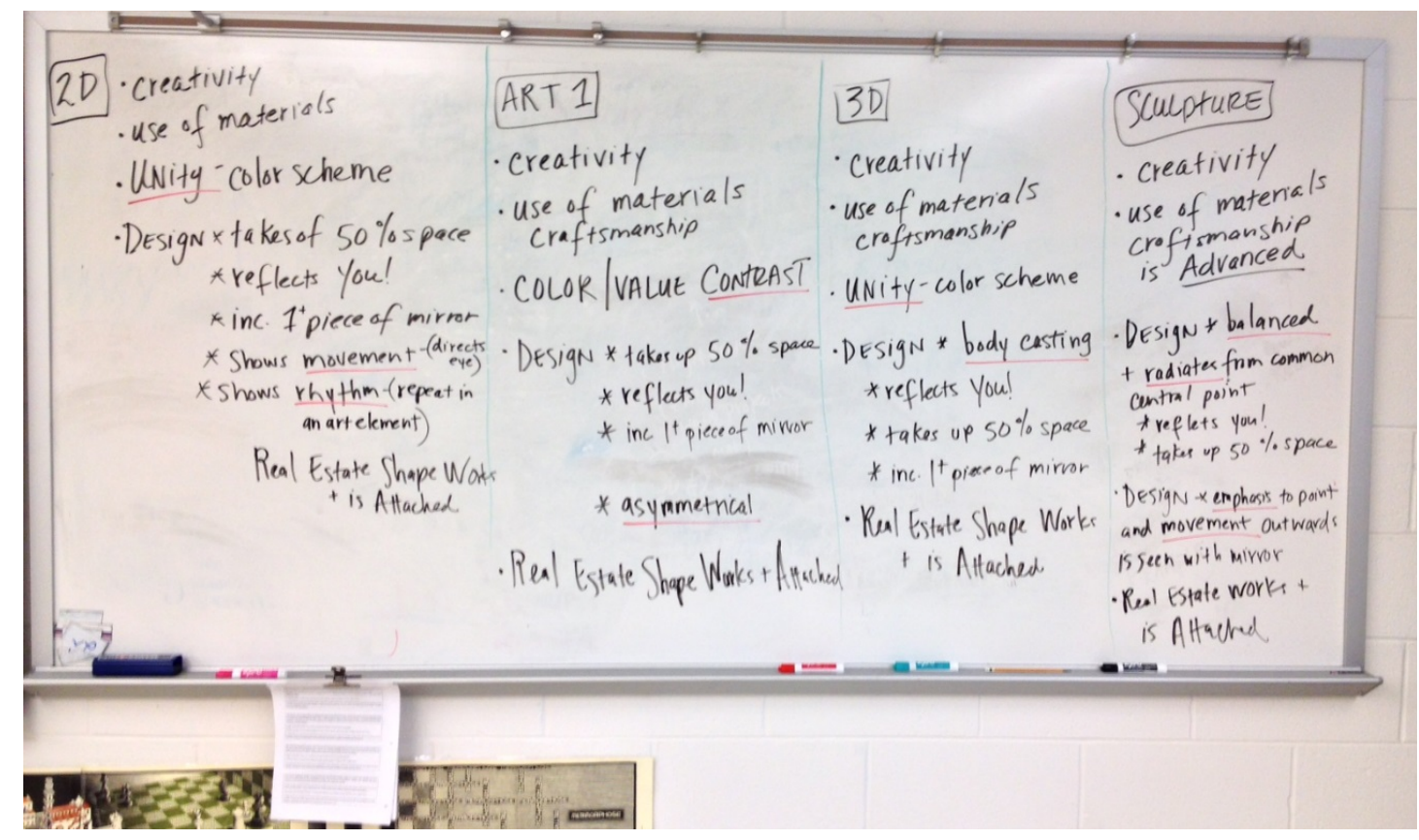

Above is a photo reminding the students about grading as we near completion of the reliefs. Hanging at the bottom of the board are extra rubrics. 

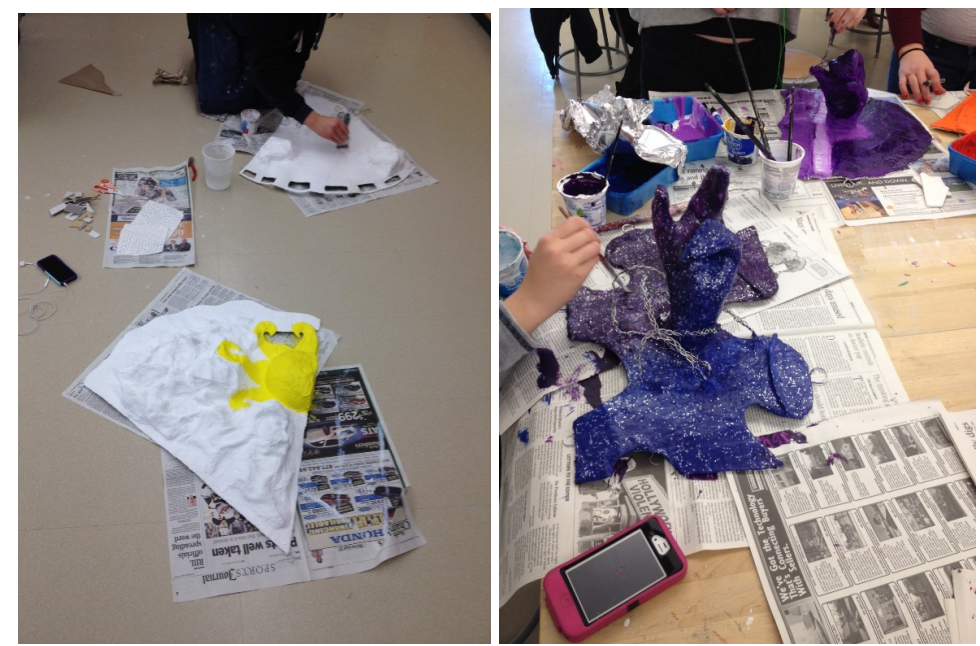

The left picture is sculpture students working on the center pieces for the installation.

The right picture is a 3D student adding glitter and gloss medium over her paint.
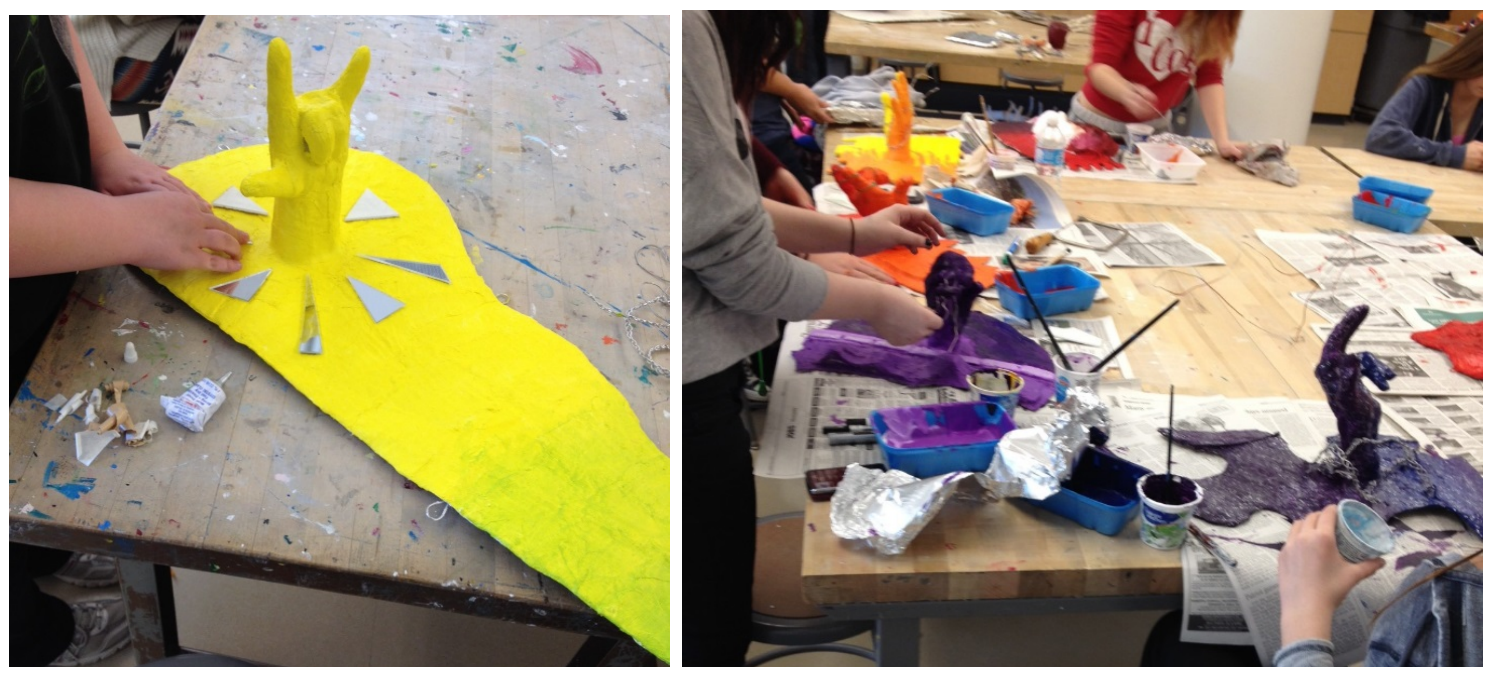

To the left is a 3D student arranging mirror pieces for placement.

To the right are 3D students working on paint application.

*Checking homework assignments-- a colored sketch of their intended finished projects that incorporated at least 1 mirror and contrasting values to highlight their design features. Many did a small sketch on paper with just a drawing of their design and their color. Not many incorporated mirror and not many showed contrasting values. I did not formally type up a homework sheet for this, so it was partially my fault for not spelling out what I was looking for. Although, I do like how I saw one student who did 
not do their homework, took their real estate paper holder and start sketching their idea on it. Because this paper was the real size of their project, they were able to project sizing and placement on a real level. Brilliant! I asked the students if this would have been helpful and many students nodded their heads. In the future, I will have the students do this.

*Then, I commented on a specific student's work because I saw that they didn't have any plan or knew what they were doing. They initially had the intention to work with an idea about cats, but the way the student described it, it sounded more like a joke. When I approached this student at the start of class, I offered my personal insight into their artwork. I said that it appeared as a mountain with a spiral around it, but not conforming to it. The spiral was "out there" a little distance away from the mountain, sort of like the student's personality who has a unique perspective on things, and that the spiral eventually made its way to the top in a sort of wandering fashion. The other 3 mountain-looking forms nearby where in descending height and I saw them as guides or stepping stones to get to where he was going- the top of that big mountain. This student told me they were blown away at what I saw and said and needed a few minutes to gather themself! I immediately related my own artistic process to theirs and said to them that not all artists have an idea when they start a project and that things just happen and intuitive responses kick in. I could tell that I gave this student a lot to think about and that they appreciated our conversation. I said that in years from now, when they look back at life and all of the decisions and outcomes that played out, that it will all make sense for them. Everything we do forms who we are and our paths take clarity later on in life. By making personal connections and gaining profound insight into my own growing process, I am able to share this special experience with my students and give them something to think about. I commended this student for taking a risk, even when they didn't know what they were doing because they were listening to themself in a subconscious way.

*I thought I did a good job at getting students to brainstorm personal connections for the project, but if I were to do this all over again, I would really stress and explain my own artistic process during the brainstorming stage. Coming up with a personal connection seemed difficult for many of my students and I only know this because I read a lot of their self-reflections at the end of the project. Next time, I will explain that as an artist it is O.K. to not have a perfect game plan worked out ahead of time, but instead that flowing with decisions as they arise and following their intuition are ways that they are connecting with themselves and becoming "Mor-in-Touch." Not all students work this way and some do need a game plan; another scenario that could play out is wasted class time with minimal productive time. Overall, this is a powerful reminder to myself 
and other practicing artist-teachers, that the artist side should connect with the teacher side. We need to be "Mor-in-Touch" with who were as artists and what we ask of our students in the art room.
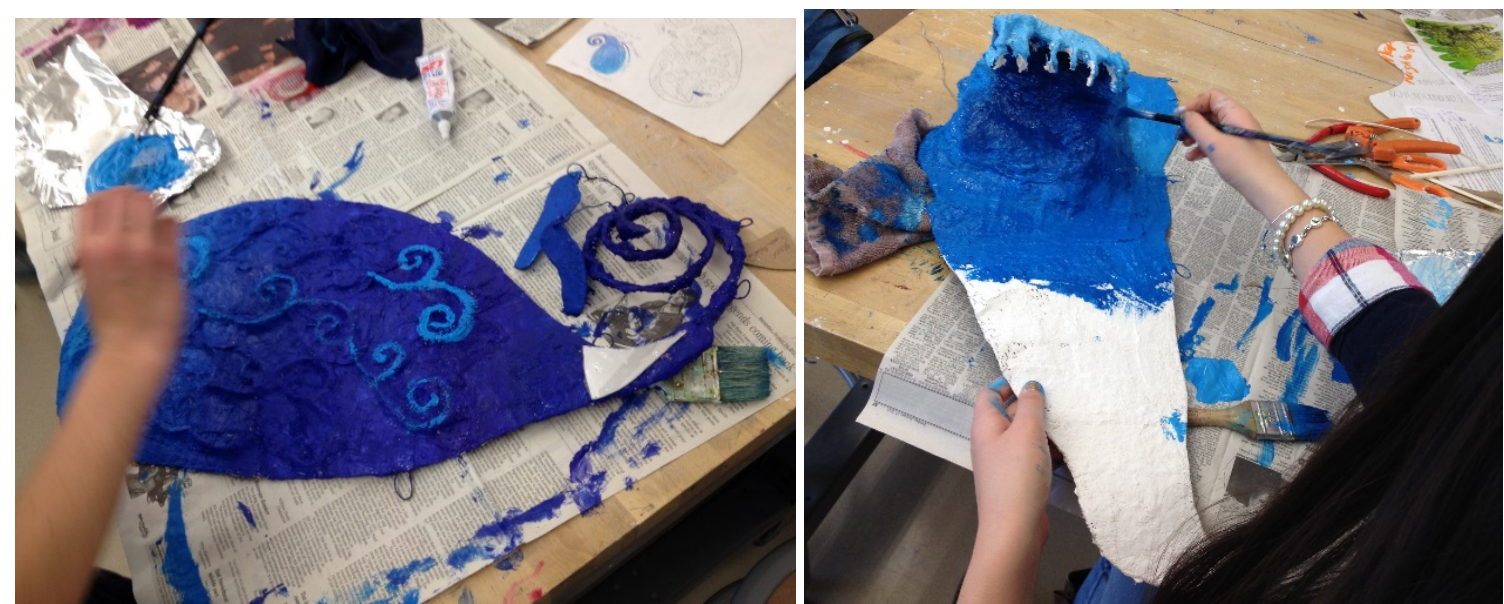

Above are pictures of art 1 students adding paint to their relief designs.

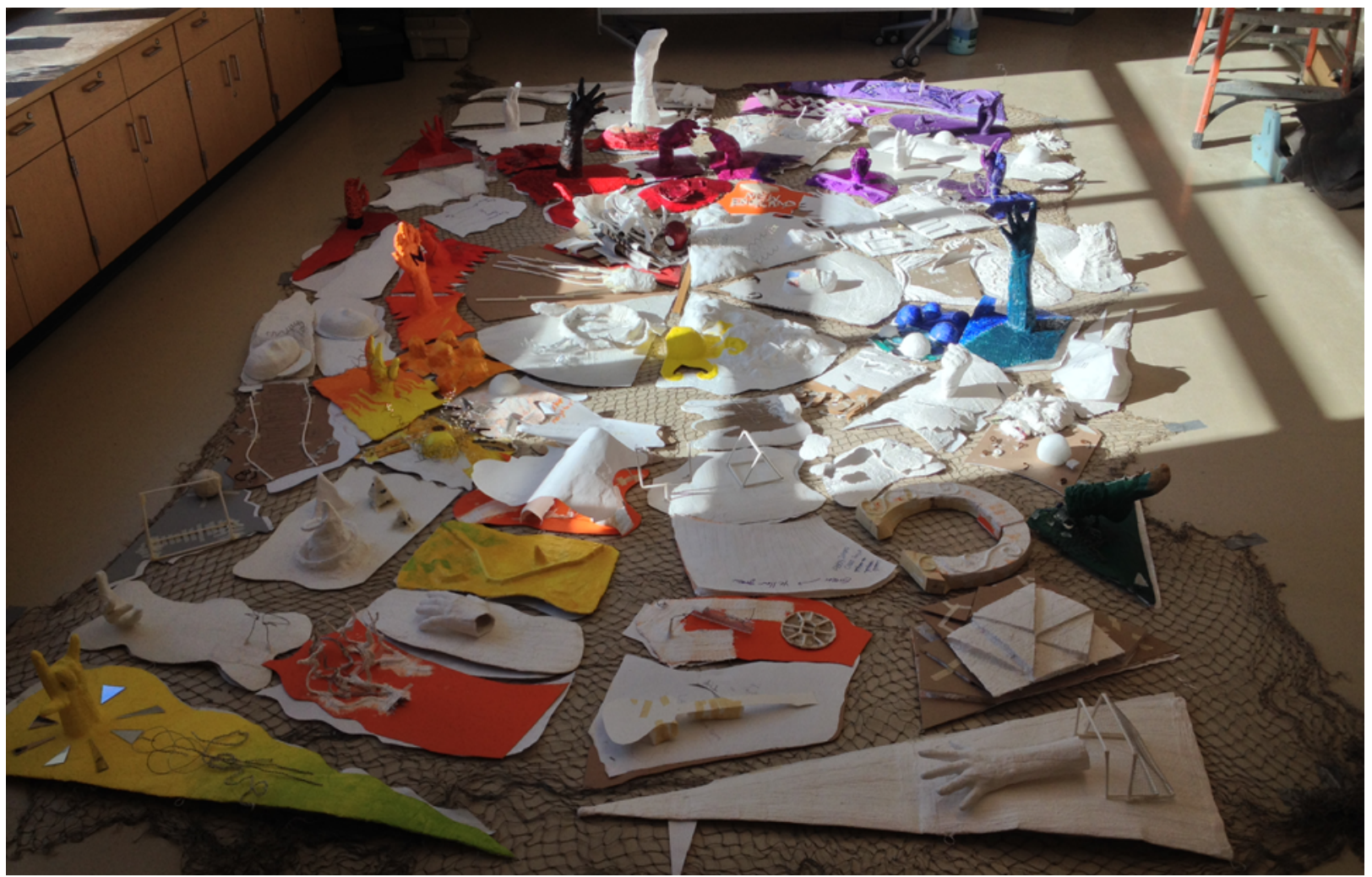

This photo shows where the project is at by the end of the day of Week 3. 
*Prepared to go mad today! Lots of different tools and materials out and the students are working on finishing touches. "Materials invite motor actions, linking discovery to imagination in what will become an inexhaustible interplay guiding artistic growth and development" (Campbell \& Simmons III, 2012, p. 7).

* Offer final feedback for those done: hang/prop their work up and step back the distance it will be seen. Use the rubric to give feedback. Specifically, I was looking for contrast/details/making sure clips are secure. One student was a little upset that her lettering was upside down, but we quickly resolved this since they had time to fix it. In the future, I need to remind students of top vs. bottom of shape and readability of lettering! I am encouraging the students to not only sign their name, but also to write a message on the back; this will create another opportunity to express themselves and leave a personal message/time capsule that isn't readable to others. My question for them went along the lines of "what are your hopes and dreams after Norton High School?"

*All in all, the violet, red, orange, yellow part of the color wheel are all nearly painted, while there is still a significant amount of the cool colors left in their white plaster state. Only 2-3 students have a SERIOUS amount of work to do, as cardboard and plastering are not finished yet.

*I enjoy looking at the evolution of the project through pictures and reading my journal entries about the on-goings happening with each days adventure. I am confident that the installation project will be a success and I plan on designing another for next semester. Acquiring the fish netting was a gift and will be expensive if I need to purchase more, so another material that is light, but tough is chicken wire. I can't help but wonder what the next project will be. Might it be an image to represent our school mascot? Might it extend outwards on both sides of this project with colors from each adjacent edge expanding the color wheel? The other art teacher and I were brainstorming too. We thought of an idea where there was a spiral design where the hands kept connecting in such a way that the students individualize their real estate, but connect to another person in the class through discussion, colors, and physically connecting hand casts. It could be titled "Leaving it in Your Hands." What kind of people are we? Are we a community? Do we help each other out and lend a helping hand? I like the idea of a radial spiral and hands growing off one another.

*All in all, I think I will let the students and administration help guide the next installation for the school environment. I love coming into school with all my classes working on one massive project; it keeps me on the same gear and mindset. It might be a daunting task for some, but I thrive on it! It keeps the community feeling alive for me, 
which I value because of the personal connections and relationships with my students. The other art teacher thinks that it may cut into the art 1 curriculum too much, as we are already pressed for time with having to teach so much in 1 semester; she thought that it was a great idea for the 3-D design classes though.

*In terms of attaching the students' work, I have decided to put the netting back up onto wall in which it will be displayed with gravity and tension all working together. Then I will have the students from sculpture start the 6 center pieces working outward concentrically as best as possible for proper placement. I will help to direct students to hold up nearby real estate to ensure neighbors and their work will fit before attaching.

For grading, now that I have seen the project unfold and have guided my students the best that I can, I have had time to reflect on or clarify the rubrics. These specific approaches/aspects on the rubrics below are what needed to be adjusted, but the final rubrics are listed in the Appendix section

Overall in all classes: *Effort/effective use of time (only a concern for a few students)

Art 1: *Asymmetrical sculpting process takes up at least $50 \%$, not just painted on; *Encourage students to show painting techniques

2D: *Collage shows movement and rhythm in the uses of shapes/textures/lines resulting in a CONTRASTING design through value; *The designed collage shows BALANCE through symmetry, asymmetry or radial

3D: *limit to face/hand (unless written commitment for foot/other body part = more time); *Sculpting process is a cast which is sculpturally manipulated/added onto that takes up at least 50\%, not just a hand and painting around it.

Week 4: Wrap-Up Installation

*Exams start next week- so anyone that isn't done with their project will need to stay after school, come during a study period, borrow materials to take home, or even stay after exams on those early release days. I am stressing to all my students my availability and their options for needing more time for project completion, so that they are able to put out their best work possible. I also stressed that unfinished work, especially unpainted ones, cannot go up because they would detract from the entire flow of the piece. My thesis advisor suggested that I stress the importance of completion and teamwork.

*Touching up plaster, adding forgotten clips, painting the white plaster their main color, or even so much as gluing down mirror and adding final details that contrast. 

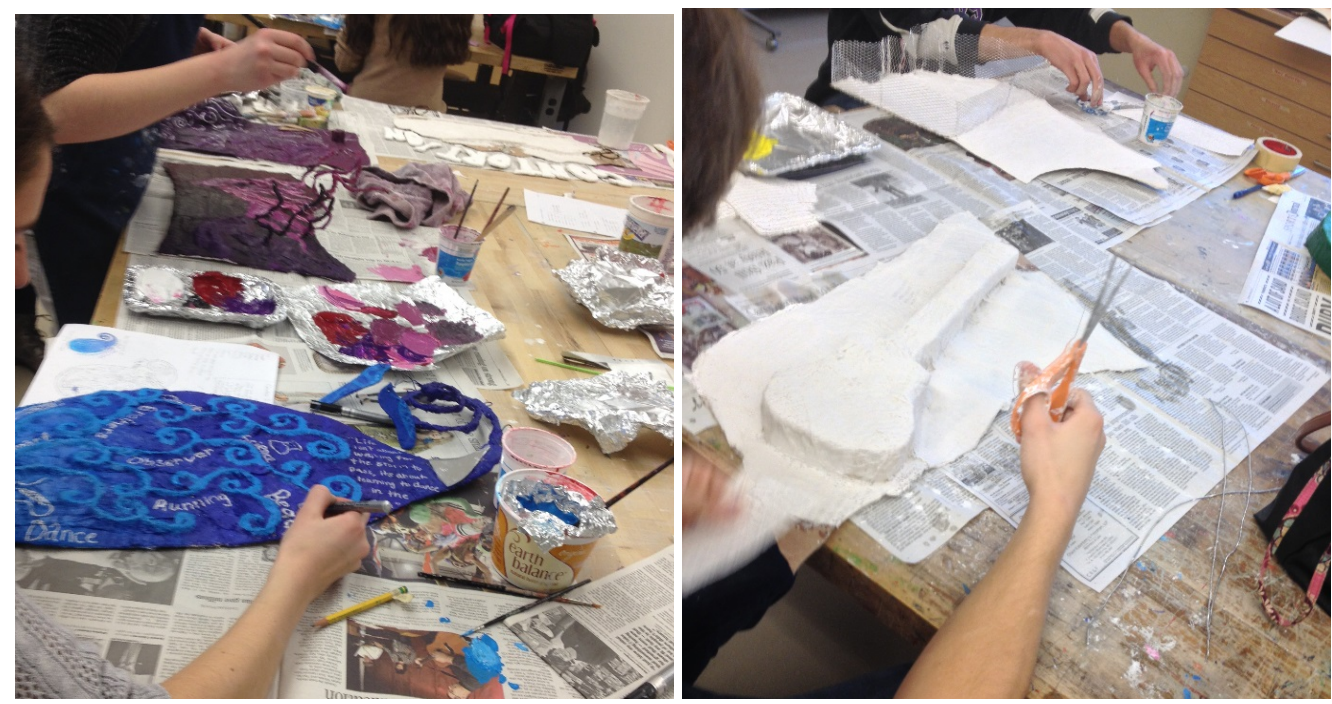

Left: is an Art 1 student writing words; right: is a student is catching up with plaster.

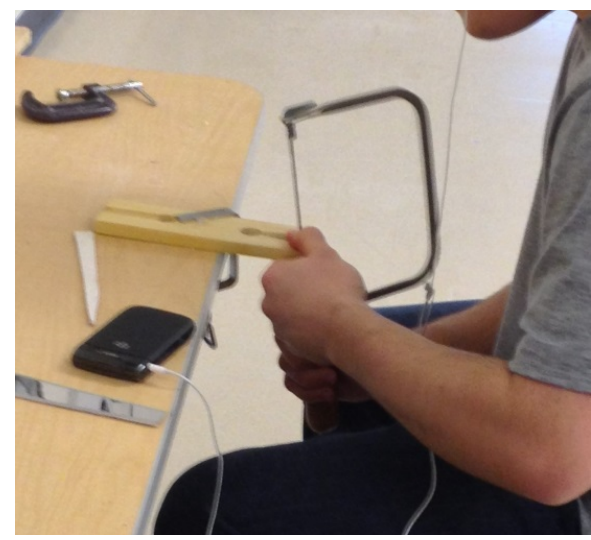

Above is a student cutting Plexiglas mirror with a bench hook and jewelers saw.

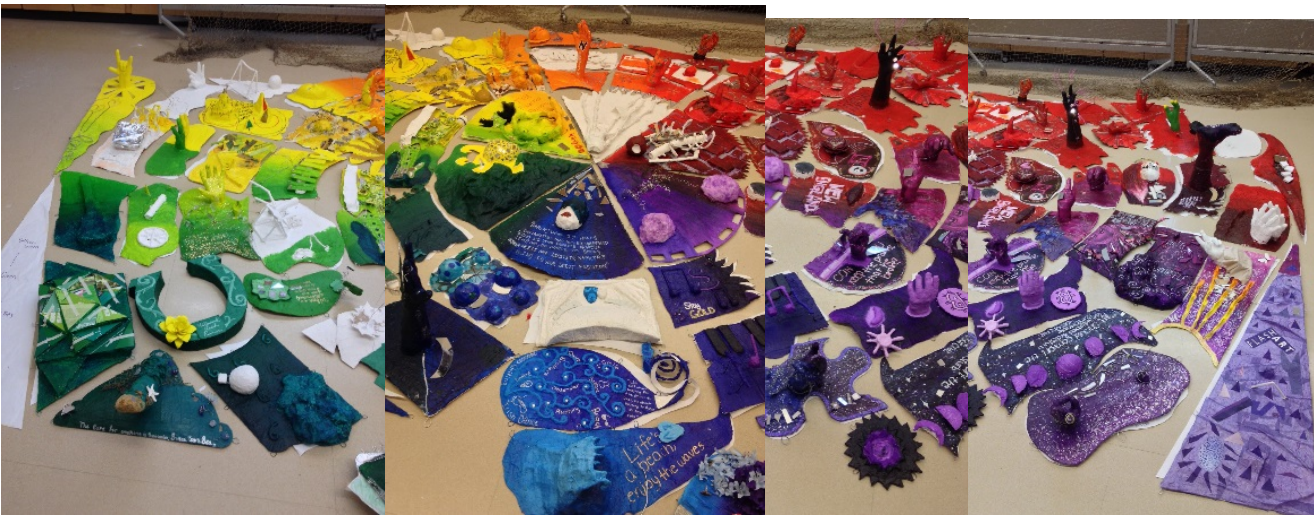

Above is the current stage at the beginning of week 4. I am pleased with the violet section in terms of it feeling completed and the students personalities coming out. 
*Custodian meeting to show in progress installation. We discussed time availability for installing artwork and supporting materials needed.

*Thoroughly check students work for sturdy clips as they near completion.

* Prepare netting for students to attach work to. While I was hesitant to move the netting off the floor because it all fit right, I knew gravity would play a part in the final look. The black bull clips with silver arms were the most secure in hanging the net to moveable bulletin boards. Students helped me measure reference points and use duct tape for a center line and 5 feet down from the top board, which was halfway of the installation height.

*Plan for the work to be hung up either top down or center out. Help and show students to use either the paper template or actual artwork for pace holders to know where their artwork should be hung up. Hang the top half up first, making sure to stay above the horizontal center line.

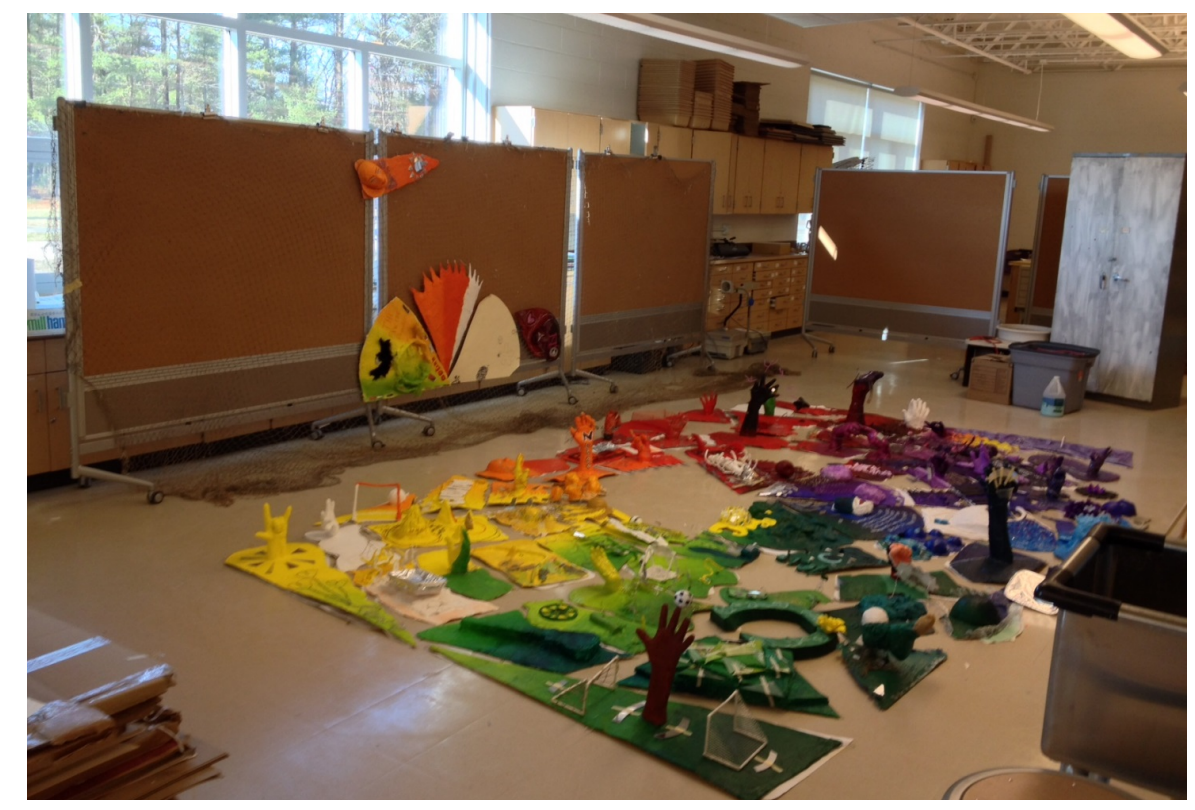

Above is the classroom scene for putting it all together!

*It is impossible to hang the lower half with it attached to the bulletin board because the boards weren't tall enough and the curve to the floor didn't work for 3-D reliefs. Therefore, we carefully returned the netting, with the top half full of student work, back to the floor. Ideally though, the entire 10 foot net would be suspended in the classroom making the opportunity to the hang work easier. Students need to attach their work as it finalizes their participation in the art piece. Plan time with students effectively. 
*Have a bunch of materials for attachments out or precut for students. Include the real estate map to ensure proper locations!

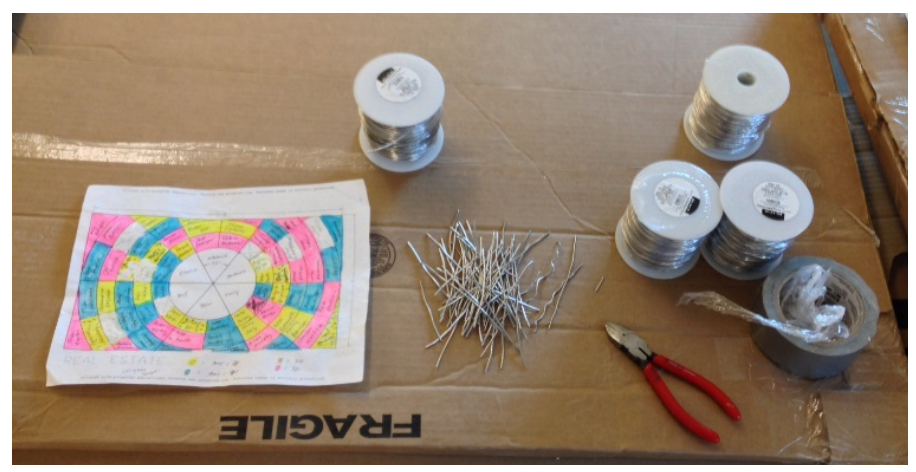

Above is aluminum wires and real estate map.

*Pass out take-home student self-reflections for project. Tell students there are no wrong answers, but want only genuine feedback. It will count as $10 \%$ of their exam grade; by doing this I hope that the students will take it seriously, so that I can gauge their experiences more effectively. My goal is to compile and display their responses into a 3 ring binder with the actual installation. This will only add depth to the project for them by internalizing their experience, but it will also be a way for others to gain insight into the project as a whole and the student's process and artwork.

*Double check with administration about installation timeline and help from custodians. Possibly have them send out an email to fire marshal for final approval. (Today, my principal sent out an email to the fire marshal, so that he could come down to make sure everything was fine before the custodians helped me to install it.)

Week 5: Final Details, Attaching Artwork to Netting, and the Unexpected

*Students are coming in after school hours/exams to complete their work. All are selfmotivated and know what is expected of them.

*At the end of day on Friday, I slipped out of my classroom for a moment. When I returned, the other art teacher approached me and told me that the fire marshal had come through to look at the installation. I did not expect what was said. She told me that the installation would not be able to be hung up. Wait. What? Did I hear that right? She said that the netting was nylon, there was some cardboard exposed between the layers of plaster, some hanging clips looked suspicious, that plaster might not be flame retardant, and that parts of the relief extended too far. He did not think that this would be safe to hang up, especially in the main entrance and exit for the school; in the unlikely event of a fire, there would be problems exiting and entering the building. My 
heart suddenly felt like it was going to thump out of my chest and my blood pressure skyrocketed. I just didn't get it. I thought: "Why had I even typed up a proposal, brought materials, and samples when I met with my administration? I immediately went down to meet with my principal. She told me that she had sought approval from the fire marshal and that she would be in touch to get more details for me. I personally believe that back in late November when we met, when she told me that she needed the O.K. before I could begin. Was there miscommunication or understanding between the fire marshall and her?

The following weeks: Getting Answers

The Superintendent passed through my classroom with some school guests to show off the new art room space. One of the guests, who had passed through weeks before and saw the installation in progress, asked when the project was going up. I had to inform him that it wasn't and the reasons for that. The Superintendent then personally came up to me to inform me on a few things. From what I learned, the fire codes for this main entrance and exitway are much stricter than a regular doorway. When this new addition was designed by the architects, they thought the ceiling height of the entryway would be a great location to display art and was hence called the "art wall." I don't believe that the architects took under consideration the more stringent fire codes.

Both of these men knew that I was crushed because I had spent so much time on it with the students, but what I really wanted them to know was how the students would feel. I told the Superintendent that I had just finished reading the self-reflections written by the participating students. There was so much pride in the project and wonderful experiences, that my heart was both joyful and blessed for this experience, yet broken because the work wasn't able to be hung up, seen, or appreciated. He asked if I could email him some of those responses so that he could take them to a meeting with the architects.

In the meantime, the other art teacher approached me and offered her insight. She said that I should hang the work in my room, even though it only a few will see it-- which defeats the purpose, but at least I will be able to take a picture of it and call in a local newspaper to advertise this special project. While this was an amazing and memorable experience that I got to share with my students, I still can't help but feel upset because I thought I had a solid plan.

In the following weeks, my anger and negativity turned to find ways to make this continue on as a positive experience. I tried to find other ways around this and places to hang it in the school, but I never got anywhere until I met with my thesis advisor, Dr. Virgina Freyermuth. She reminded me that it was a teachable moment and as the 
students' teacher, I was looked upon to model positive behavior. Our meeting revolved around ways to 'Honor the Student.' Here were some shared ideas:

*Find a public place in town, like a bank, library, or gallery, to display the artwork. I didn't think this would work because the artwork was attached to the netting and was already difficult to move around- let alone out of the building.

*Creating a book with pictures of the individual student's work, the overall art piece, and progress pictures. This book could be purchased to buy, as long as there was proper consent to use students' pictures and names. The book could also be created as a keepsake for the school's library and maybe a poster size picture of the artwork could be displayed in the library too.

*Upload pictures of the artwork to the school's website.

*Unveiling ceremony in the school that gives each student a chance to speak about their artwork and recognize their individuality. The ceremony would honor the meaning of the art piece as a whole and signify that while the outcome was a lot different than expected, what was learned and experienced is far more important than what we set out to do. 


\section{Chapter 6: Conclusion}

This entire research and implementation process from start to finish has given me insight into the meaning and value of an artist and a teacher. Foremost, relating the way that I approached and connected with the art-making as an artist and bringing that into the classroom where I could model and teach it was enlightening and special for me. By modeling the "Mor-in-Touch" approach, I created an opportunity to foster a deeper dialogue with my students through the art-making process to discover who they genuinely are. This would not have been possible if I did not keep the process of my self-reflective work or my passion for student and learner-centered teaching, because the main goal was designing instruction for each student to connect in personally meaningful ways.

I learned that when high school students have never been asked to use artmaking as a way to reflect and show who they personally are, many struggled with how to begin and what they wanted to do. From this project, I realized that most of my students never really had this sort of experience before now to connect with their art on a deeper and more meaningful level. I think too that not telling my students what to make and what materials to use was a real eye-opener; they had to decide and figure out what worked for them. This created a lot of initial uncertainty in the classroom because there was only minimal classroom instruction and guidelines. Further, when you invite students to open up and share who they are with the world, the environment 
that this takes place in has to feel safe enough for them to express their individual differences and take risks.

To see my students struggle with ways to bring forth, comprehend, and create their ideas into a visual format, gave me affirmation that the "Mor-in-Touch" process was working. What I was asking them to do was connect to the moment, their ideas, materials, the creative process, choices and decisions, and each other; they were digging inside themselves and searching for meaning. My students were making personal connections and choosing certain artistic processes with a mindful attitude towards those around them. This sort of dialogue promotes "self-reflection, recognition, and tolerance for diversity, as well as an ability to listen to and learn from the ideas and thoughts of others" (Campbell \& Simmons III, 2012, p. 14). This collaboration's success was dependent upon each student's commitment to their work of art because they all had to work together in unity from the size and shape of their real estate to the coloring. My intention for this "Mor-in-Touch" process was to bring awareness to and teach that the art-making process can be meaningful.

Of importance is that this thesis project directly connected to the revised 'First Glimpse' for the National Visual Arts Standards. The project aligned perfectly with the NVAS artistic process- "Connecting: Relating artistic ideas and work with personal meaning and external context" and specifically with the "Anchor Standard- Synthesize and relate knowledge and personal experiences to art" (NVAS poster, 2014). In moving 
forward, this means that the revised standards will require art educators to find ways in which art making can engage students to connect more meaningfully.

As every teacher knows, there is always the challenge of finding ways to connect with their students' lives. I recognized a real-world problem that would affect my students' lives and looked for solutions to solve it or make it better. The initial planning phase of this art installation was a challenge and took a lot of careful thought to ensure its success. Proper approval was also another key component when working on this level of commitment with the students and executing it was even more energy.

One of the most important things, that I learned in this thesis project is when things don't go as you intend, you must find ways to make a positive out of a negative. By modeling leadership qualities and persistence in an otherwise undesirable situation, participants and onlookers learn ways to overcome setbacks. Aside from the unforeseeable hurdle that the installation project faced, students gained a powerful sense of purpose when they came together to collaborate as a community to make a work of art; it is a meaningful way for any art teacher to become more in touch with their students' lives and enrich it. When you have motivation, enthusiasm, and passion to do what you love, then sharing these ideas are worthwhile endeavors for both the teacher and student; we can connect on more genuine levels. I love making art, teaching art, and relating with my students through their art. Further, through utilizing my "Mor-in-Touch" process in this collaborative art installation, I have grown to see 
what is important to me as an artist and a teacher-connecting and finding meaning in all that we do.

On that note, as this thesis evolved, I realized that the "Mor-in-Touch" phrase gradually morphed into my own art-teaching philosophy. This project solidified my belief that being or becoming more in touch ("Mor-in-Touch") will bring deeper satisfaction to the artistic process. This attitude supported my own art-making, how I wanted to teach, and what I wanted my students to learn. Qualities that encompass this art-teaching philosophy are:

- Art-making: nonlinear/open-ended/unknown; intuitive; personally meaningful; introspective/reflective; quiet work time; collaborative work time; choice-based opportunities- ideas, materials and/or processes; skills that go with materials/processes; care for materials/tools/classroom

- Teaching and learning approaches: connective/interactive; supportive/encouraging/accepting; community orientated; collaborativeclassroom teacher is learning from student(s): classroom student(s) are teachers; classroom teacher- shares personal art experience/tips; enthusiastic; safe environment; open communication

- What the community gains: exposure to classmates/people/ideas/skills, recognition/tolerance/respect of differences; sense of belonging; collaborative projects $=$ commitment of each member 
In conclusion, it has been several months since the installation art piece has been completed. In this time period, I have been more reflective and more in tune with my own natural processes as an artist and with my teaching than I have ever been in these last six years as an artist-teacher. When I see my students struggling, I am more aware of what they are experiencing and better able to relate to them. I am able to bring my own personal artistic advice to the situation and not just the teacher side that I was bringing before; it feels more genuine now and this is forming stronger bonds and trust amongst my relationships with the students. I am not telling the students how to make art like me, but rather I am offering my insight and experience to help them. We are able to go beyond teacher and student and connect as artists for a moment.

The installation piece finally received recognition in the annual art show on April $9^{\text {th }}$, after months of trying to figure out where to hang it. The assistant principal came up with the idea of using portable volleyball posts and with the help of several custodians, a few gym dumbbells, and zip ties, we were able to attach and hold the netting up. This installation had the intention from the beginning of being publicly presented and displayed so that the involvement of each artist could be shared with others. Even though the art piece was only on display for a few hours, the feedback was well received and made a positive impact in the school setting. This would not have happened had it stayed in the art room. The superintendent, principal, assistant principal, many teachers and students, and friends/family/guests during the night were intrigued with the artwork. It was helpful to have a plaque nearby describing the 
intention of the art piece for guests to read.

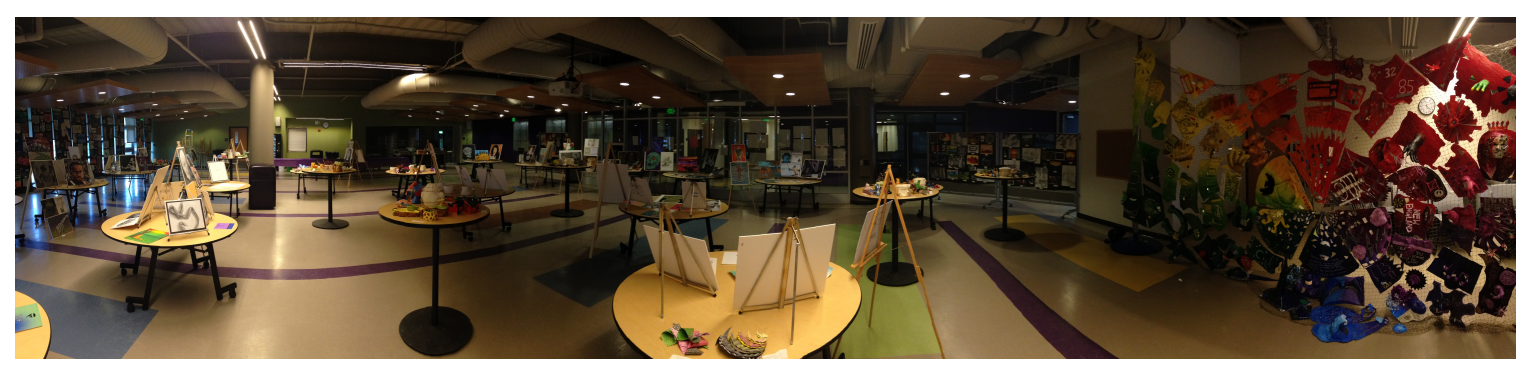

Here is a panoramic view of the 2014 Norton High School art show with the installation to the far right.

The day before April vacation, I was able to call down the students to the main foyer, which was the intended initial location for the art piece to be displayed. It thought it was nice to have everyone together again, and one student so much as verbalized these same feelings out loud. In that space, in that time, with those artists, we had a brief ceremony which honored their efforts. While it was difficult to tell them that the art piece would not be able to be displayed in the entrance foyer, where we were standing, due to fire code violations, I told them that it was displayed during the recent art show where we got some great responses and photographs. I thanked them for taking risks, finding personal meaning in a very open-ended project, and for expressing their individuality for others to see. I pointed out that the success of the art piece was the fact that every person got involved and committed themselves until the very end. Although short-lived and in no way what we all envisioned would happen, I wanted them to walk away with two things: that we are capable of transforming spaces with art to create positive and inspiring messages of hope, especially when we work with one another and to try and stay more in touch with their ideas and processes and 
recognize the relationships and connections to others and their environments.

Personally, I revealed to them that this project taught me how to better connect the artist in me with my role as a teacher and that I learned how to bring the artist to school with me more genuinely.

In conclusion, it is important to share these successes with others. The principal has already asked me for pictures from the art show to upload for the school's website and I sent in pictures to the local newspaper for publicity. A few other ways to use technology to recognize this or any large, public work of art could be to: videotape or compile images of the process and create a slide show, create a web page or blog that would feature the progress of the work, create a digital on-demand book of the process of the mural, or even create a projected slide show, perhaps for local cable access TV.

On a positive end note, here are a few noteworthy quotes from student projects:

- Remember who you are.

- Smile
- Free

- Don't lose yourself.

- There's no cosmetic for beauty like happiness.

- Keep on dreaming, don't stop breathing, fight those demons.

- When it is all finished, you will discover it was never random.

- You can't live a positive life with a negative mind.

- Others have seen what is and asked why; I have seen what could be and asked why not. 
- Improve, adapt, and overcome. Hard work will beat talent- when talent refuses to work hard.

- Life isn't about waiting for the storm to pass it's about learning to dance in the rain.

- If patience is worth anything, it must endure to the end of time. And a living faith will last in the midst of the blackest storm.

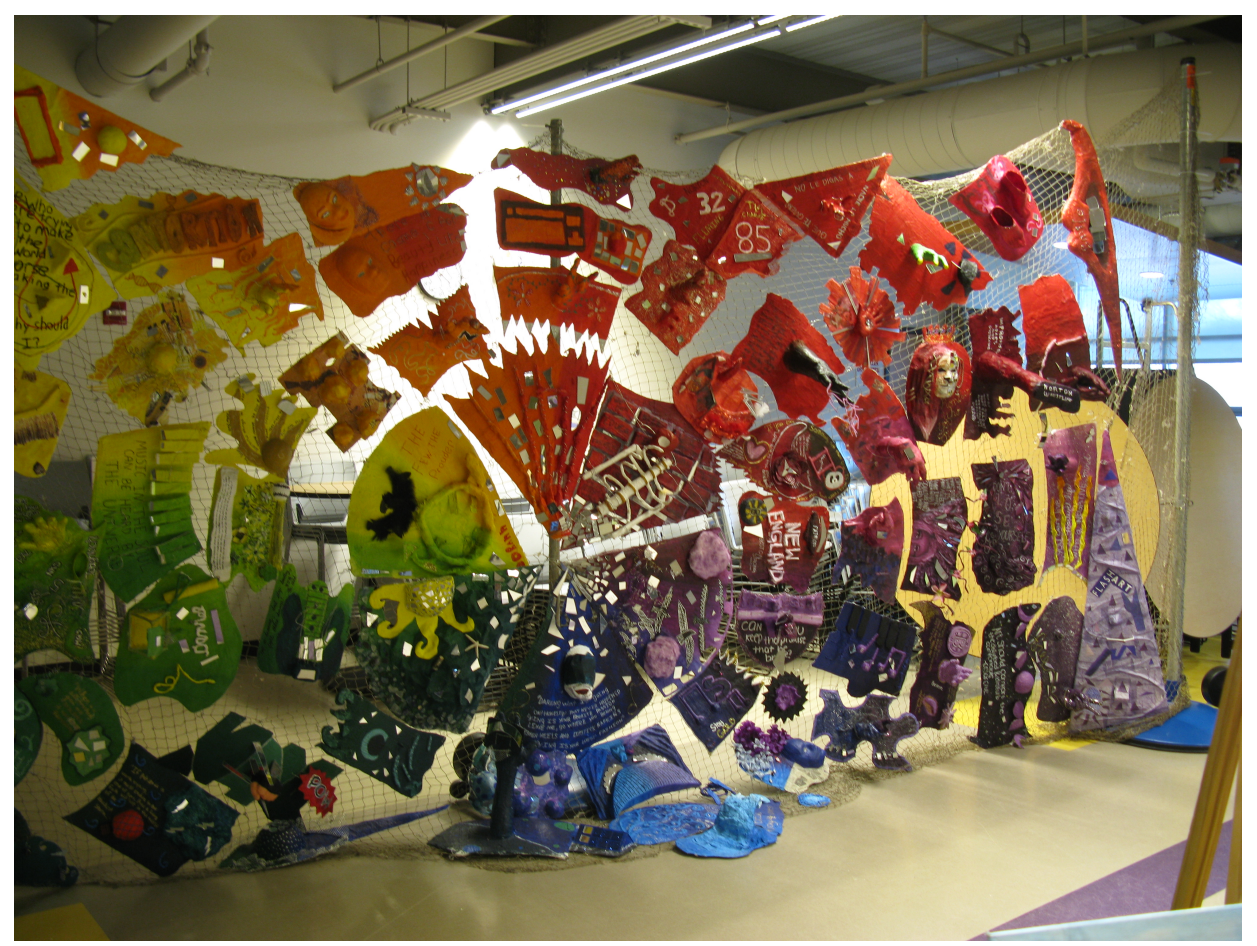

These students got it right and I am very proud of their "Mor-in-Touch" connections. 


\section{REFERENCES}

Ayers, W. (1993). To teach: the journey of a teacher. New York, NY: Teachers College Press.

Even though this author gears his examples more towards elementary and middle age students, his points about teaching are valid. Teaching is challenging and Ayers speaks to these challenges in many ways within his differing chapters. The chapters that resonated most with me are: "seeing the student", "creating an environment for learning" and "liberating the curriculum." These were all helpful for me to self-reflect on my teaching to make it better.

Barone, T., \& Eisner, E. (2012). Arts based research. Los Angeles, CA: Sage Publications. I plan on using the information taken from this book in my 'Research Methodologies' section. . I only read a small section to get a better idea on this type of research.

Bogdan, R. \& Biklen, S. (1998). Qualitative research for education: an introduction to theory and methods. Boston, MA: Allyn \& Bacon.

This book was helpful for my 'Research Methodologies' section. It gave me a better understanding between qualitative vs. quantitative research and what the characteristics of each are. This book provided a table of descriptive terms, key concepts, goals, data, methods, relationships with subjects, and data analysis, that gave me a better idea for how to wrap my head around the processes I took.

Buffington, M. \& McKay, S. (Eds.). (2013). Practice theory. Reston, VA: National Art Education Association.

This book had many relevant articles written by art educators, who utilized research to further their own teaching and methodologies. Their findings are compiled in this book to contribute to the area of teacher researchers. Specifically, I was interested in an article on self-exploration of the artist and teacher.

Campbell, L., \& Simmons III, S. (Eds.). (2012). The heart of art education: holistic approaches to creativity, integration, and transformation. Reston, VA: National Art Education Association.

This book offers more than 20 articles that are based upon holistic learning. Some are focused on high school perspectives, which I valued, and others on approaches to gaining stronger connections to get the whole student involved in their learning. The book was most valuable for the holistic/student-centered section in my research.

Collins, D. (2008). Identity. Retrieved from http://www.asu.edu/cfa/wwwcourses/art/SOACore/themeidentity.htm

This online article offers a solid introduction to the concept of identity. It list four questions that provide the opportunity to reflect on identity of self, of cultures, and how 
this can be seen through and in a visual work of art. I used this article to transition into the "Mor-in-Touch" unit.

Collins, D. (2008). Signature style. 2D unit II: Marks and Lines. Retrieved from http://www.asu.edu/cfa/wwwcourses/art/SOACore/marks_IIA.htm

This online article offers a lesson plan to help a student develop their own personal style using lines and marks by way of approach and varying medium use. This was helpful when brainstorming possible project relief ideas for my 2D design class.

Coutts, G., \& Jokela, T. (Eds.). (2008). Art, community and environment: educational perspectives. Chicago, IL: Intellect Books.

While this book is geared toward the environment and its connection to art and community, it did share some important information about the learning environment in an educational setting.

Deal, T., \& Redman, P. (2009). Reviving the soul of teaching: balancing metrics and magic. Thousand Oaks, CA: Corwin Press.

This book was more for a teacher who has lost touch with the reason they began teaching in the first place. While the book offered validity, it wasn't entirely for mesince I haven't even come close to losing the spirit that drives my teaching work. There was an important quote within it that was helpful to summarize my true joy in why I teach.

Dery-Wells, L. (2005, Fall). Healing as a work of patience, humility \& compassion. Cape Healing Arts, 17-18.

This article is about an artist self-reflecting on her experiences as a psychotherapist and artist in regards to the healing process. That we (teachers) need to carry hope for others (our students.) We need to provide experiences for others to be healed....this is seen by expanding our awareness of ourselves and lives we are living.

Eisner, E. \& Day, M. (2004). Handbook of research and policy in art education. Mahwah, NJ: Lawrence Erlbaum Associates.

I plan on using the information taken from this book in my 'Research Methodologies' section. It has lots of great chapters such as: 'Spirit, Mind, and Body: Arts Education the Redeemer", "Sculpture: Representational Development in a Three-Dimensional Medium", "Teacher Education as a Field study in Art Education: A Comprehensive Overview of Methodology and Methods Used in Research About Art Teacher Education", and "Studio Art as Research Practice." 
Hatton, S. (2005). Teaching by heart: the foxfire interviews. New York, NY: Teachers College Press.

This book offers the opportunity to read interviews from several well-known educators in regards to 'becoming a teacher', 'teaching and the power of story', 'teacher as moral and philosophical guide', 'teaching place, fostering consequential learning', 'teaching and educational change' and 'reflections on powerful conversations.' I connected with Nel Noddings and Parker Palmer the most. Overall, these interviews made me experience a reflection within myself on what I value with my students and what I struggle with. It was meaningful to connect with powerful voices in the education community.

Intrator, S. (2002). Stories of the courage to teach: honoring the teacher's heart. San Francisco, CA: Jossey-Bass.

I plan on using the information taken from this book in my 'Self-Reflection as Artist and Educator: How they Unite' section.

Intrator, S. (2003). Tuned in and fired up: how teaching can inspire real learning in the classroom. New Haven, CT: Yale University Press.

This book delivers insight into teachable moments that really stuck out for one high school teacher and his students. His classroom environment and culture made getting to know his students on a deeper level possible. This book offers several case studies with the most valuable being: "The Kids Were on Fire- On the Nature of Inspired Learning and Potent Teaching, "Forging Community- an Episode of Deep Connection", "Grasping Insight- an Episode of Coming to Know Yourself" and "Tangling with the Unspeakable- an Episode of Facing Conflict in Conversation.

Kessler, R. (2000). The soul of education. Alexandria, VA: Association for Supervision and Curriculum Development.

This book has been so valuable in its contribution to the idea of reflective teaching. It has given me the main ideas behind teaching and honoring the "soul" in education. Its very nature is based on holistic and student-centered learning.

Lantieri, L. (Ed.). (2001). Schools with spirit: nurturing the Inner lives of children and teachers. Boston, MA: Beacon Press.

This book was an amazing research companion, which included several articles by different authors. I really resonated with the articles titled: 'The Circle of Courage: Children as Sacred Beings', 'Lessons of the Wild', and importantly 'The Gift of the Arts.' The book promotes building healthy relationships with students and inviting them to explore meaning in their lives through their schooling. Awakening our inner lives... 
Lichtman, M. (2006). Qualitative research in education: a user's guide. Thousand Oaks, CA: Sage Publications.

I book was helpful in my 'Research Methodologies' section pertaining to qualitative research as holistic, feminist research, learning through observation like an anthropologist and self-reflexivity and subjectivity.

London, P. (1989). No more secondhand art: awakening the artist within. Boston, MA: Shambhala Publications.

I plan on using the information taken from this book in my 'Holistic/Learner-Centered Art Education" and "Inquiry-Based Education" sections.

London, P. (2011). Joining heaven and earth: art education and ecology. Retrieved from http:/transformativeteacherproject.com/TRANSFORMATIVE_TEACHER_PROJECT/Article

This online article is written to make the reader aware of connecting their actions on earth to their future/awareness/spirit of life. He makes us acute to the relationship that exists between our behavior and actions in relation to our school surroundings where we are as a species and where we need to go to stop the destruction. Conscientious decision making needs to come forth and the art field is a major contribution to this awareness in our lives. This article gives an example of a school and how every part of its being is infused with life, passion, beauty and care. It is an ideal future that striving towards makes an exciting journey.

London, P. \& Freyermuth, V. (2011). A sanctuary of becoming. Retrieved from http:/transformativeteacherproject.com/TRANSFORMATIVE_TEACHER_PROJECT/Article

This online article offers insight into what is needed in the classroom environment for a student's emerging self to feel welcome and be able to grow. This is impacted specifically with the teacher, or Transformative Teacher that creates it.

London, P. \& Freyermuth, V. (2011). Excellent and transformative teachers. Retrieved from http:/transformativeteacherproject.com/TRANSFORMATIVE_TEACHER_PROJECT/Article

This online article offers an introduction to what an Excellent and Transformative Teacher are specifically what qualities they should possess to have students succeed in their classroom.

London, P. \& Freyermuth, V. (2011). Invitation. Retrieved from http://transformativeteacherproject.com/TRANSFORMATIVE TEACHER PROJECT/Invit tion

This online article offers an introduction to what is a Transformative Teacher and what is meant by the word "becoming." 
Louv, R. (2008). Last Child in the woods: saving our children from nature-deficit disorder. New York, NY: Workman Publishing.

This book gave a very interesting perspective on children who are deprived and out of touch with nature and who turn to indoor play and electronics for stimulation.

McNiff, S. (1998). Art-based research. London, UK: Jessica Kingsley Publishers.

I plan on using the information taken from this book in my 'Research Methodologies' section. I only read a small section to get a better idea on this type of research.

Neuman, W. L. (2000). Social research methods qualitative and quantitative approaches ( $4^{\text {th }}$ ed.). Boston, MA: Allyn and Bacon.

This was my first research book, which helped to define the different types of research there were. It helped to break down the 7 steps needed to undergo a body of research. It was helpful to clarify feminist research and postmodern research.

Northestern Illinois University. (2012). Arts integration. Retrieved from http://www.neiu.edu/ middle/Modules/science\%20mods/amazon\%20components/A azonComponents3

This website was useful for the basic understanding of inquiry-based learning.

Northestern Illinois University. (2012). The benefits of inquiry-based instruction. Retrieved from http://www.neiu.edu/ middle/Modules/science\%20mods/amazon\%20components/A azonComponents2

This website was useful for the basic understanding of inquiry-based learning.

Palmer, P. (2004). A hidden wholeness. San Francisco, CA: Jossey-Bass.

I plan on using the information taken from this book in my 'Research Methodologies', 'Holistic/Learner-Centered Art Education' and 'Inquiry-Based Education' sections.

Ruiz, D. (1997) The four agreements: a practical guide to personal freedom. San Rafael, CA: Amber Allen Publishing.

This book is a new age book designed to help guide one's life on a more positive path. I have used the basic four agreements and posted them in my art classroom since day 1 of teaching back in 2008.

Sultan, A. (2013, April 14). Author's tips for happier, less chaotic family life. Providence Journal, p. $\mathrm{H} 5$.

This newspaper article discusses from the point of view of families, but is very applicable for a teacher's relationship with their students. The article specifically addresses the community dynamic by engaging each member to feel part of a team, equality in 
conversation and incorporating input on behalf of others to make their investment successful.

Thibodeau, J. (2005, Fall). Nature \& culture. Cape Healing Arts, 15-16.

This article spoke about how the world and its cultures all go back to nature and how humans find ways of returning to nature from our hectic cultures. It is not separate from us, but our core and essence.

Walters, J. D. (1997). Art as a hidden message: a guide to self-realization. Nevada City, CA: Crystal Clarity Publishers.

This book offers insight into the future of art such as literature, music, and visual. It expands the idea self-realization of one's place in the world and where art fits into it. This book was a guiding help to decide on unit topics to explore with my students that will give their life and time a sense of purpose worth pursuing. It will help them to extend inward to their own lives and spirits. We all have stories to tell!

Whitehead, J. \& McNiff, J. (2006) Action research: living theory. Thousand Oaks, CA: Sage Publications.

This book was helpful for my 'Research Methodologies' section pertaining to action research. It discusses how a practitioner can investigate and explain why they do what they do.

Wink, J., \& Wink, D. (2004). Teaching passionately: what's love got to do with it? Boston, MA: Pearson Education.

This book breaks down what 'transformative' means. It also weaves together the importance for teachers to have both personal and professional passion. Nel Noddings is quoted about care in the classroom as well.

Worcester Art Museum. (2009). Rona Pondick: the metamorphosis of an object [Pamphlet]. Worcester, MA: N.P.

This pamphlet was helpful in seeing firsthand an artist putting together her thoughts and selected sculptures for an exhibit. Her personal quotes were useful in the selected artists I chose to explore. 
Appendix A: Unit Handout

\section{Becoming “Mor-in-Touch" Relief Mosaic Installation}

OBJECTIVE for INSTALLATION: Each student will create a relief that reflects who they are through symbols, imagery, and words and use this work of art to create a relationship amongst the other art students to be displayed in our new school's environment. The art installation is intended to become a positive, inspiring, and energizing visual representation, that stands for students coming together to express their individuality and sense of community.

\section{ESSENTIAL QUESTIONS:}

- What is identity?

- In what ways can a work of art reflect the indiviuality of the artist?

- How can an artist be "Mor-In-Touch"?

- In what ways does an art installation transform spaces?

- How does art create mood/feeling? Do colors help?

- How can artists collaborate to create a message about community?

MA Curriculum Frameworks: 1.9, 1.12, 3.9, 3.10, 4.9, 4.10, 5.10

\section{Vocabulary:}

"MOR-IN-TOUCH"- one's self being more in touch with their process, approach, materials, choices, subject matter, space, environment, others, etc.

RELIEF- a work of art where one side is flat and has 3D parts projecting off of it

MOSAIC- is the art of creating images with an assemblage of small pieces of colored glass, stone, or other materials

INSTALLATION- is a work of art created for a specific location, that can interior or exterior

COLLABORATION- working with more than one person to create something together COMMUNITY- a group of people of any size that shares common values

IDENTITY- who we are as people that can be identified socially, culturally, economically, visually, etc. 
MOVEMENT- (art principle) how your eye is directed through a work of art from object to object by way of its placement and position.

EMPHASIS- draws immediate attention in a work of art

BALANCE- (art principle) the visual distribution of weight: Symmetrical (= weight both sides), asymmetrical (unequal weight, but = eye attraction), radial (comes out from common central point) Seen through the placement of parts in relation to one another.

GESSO- paint primer, which helps paint stick to the material better and prevents chipping and flaking

TINT- add white to a color, makes it lighter

SHADE- add black to a color, makes it darker

MONOCHROMATIC- using only 1 color plus its tints and shades

CONTRAST- extreme differences

UNITY- (art principle) when all parts of your art work well with the other parts and no part sticks out (repeat in art elements)

\section{Learning Activities:}

- Discuss Identity and brainstorm personal connections through symbols, imagery and/or langauge

- PowerPoint on installations, collaboration, and mosaics

- Discussing the master plan of the real estate. Have students pick real estate location/color randomly.

- Desiging a shape for project with real estate location, classmates and other established real estate shapes in mind

- Designing your relief to incorporate students personal connections through symbols, imagery and/or langauge

- Learning how to use materials to sculpt forms (cardboard, plaster strips process, wire clips, etc.)

- How to use value to make design features pop out to show contrast

Timeline: 4 weeks; meet every other day for 90 minute classes. 


\section{Ways to transform material from flat to sculptural:}

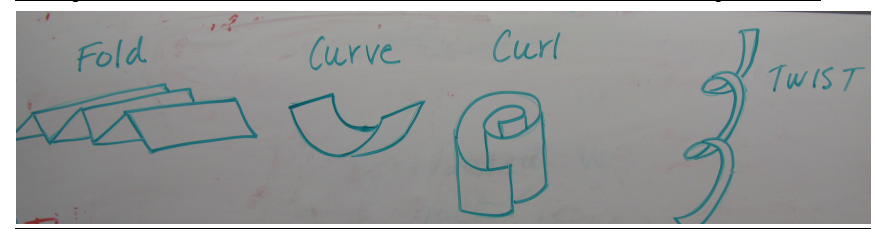

\section{Project Steps:}

1. Using kraft paper, measure out the general size of your real estate area with a ruler and pencil. Use the CAD drawing map for sizing. Create a custom shape that maximizes your real estate space. Pay attention to neighbors next door and already established real estate from other previous classes. Write your name and color scheme on the paper (paying attention to orientation) and claim your real estate spot. This will lock in your area and let others know what's going on visually.

2. Use an 1/8" piece of cardboard (not posterboard) to trace and cut out real estate shape. This will be the base for your project. Begin to use the materials of cardboard, wire, wire mesh, plaster, art straws, masking tape, etc., to begin to form your 3D relief pieces.

3. Follow demo for preparing to plaster! Wear a smock, pull hair back if needed and take off all jewelry, watches, etc.

Gather: warm-hot cup of water, newspaper to cover table, plaster scissors, \& cut plaster strips.

4. Plaster over all parts of your relief, making sure to go over the edges to the backside. Add in at least 4 clips sturdily to hang your relief up on the support/netting. Follow demo to do this/ensure stability for finished work.

5. Once plaster has dried, gesso the dried plaster to prep it for painting. If collaging, than this is not needed.

6. Gather your color materials (acrylic paint or collage materials) and begin to apply to dried surface. Think contrast to pop the design aspects of your relief. Light values near dark values; dark values near light values. Your color scheme will unify your project. You can add in small amounts of other color; just be sure that the dominant color fits in with your real estate on the color wheel.

7. Further personalizations? Will you scour my art closet? Bring in personal items? Remember this cannot be flammable- so no fabric or exposed paper. 
APPENDIX B: Identity Brainstorm Sheet

Name

We all need opportunities for expressing who we are as human beings!

Who am I? Where did I come from? What do I believe in? Where am I going in my life? Such highly personal questions are part of being human. They go to the core of establishing a unique, personal identity-and understanding how one fits into the fabric of society. Individuals may pose these questions differently or at different points in their lives. Thoughtful people in every culture, in every historical epoch, have asked just such questions of themselves. We all know people who have constructed clear personal identities, established cultural roots, engaged a system of beliefs, or charted a course for a productive life. Such individuals can be useful models for understanding-and challenging-how we view ourselves. By comparing our own "picture of ourselves" with others, we can gain a greater understanding of ourselves.

In many cultures, artists express who they are, where they come from, and where they are going through their artworks. The act of creating a painting, sculpture, video tape, or other work can be helpful in determining and shaping who we are as individuals or as a member of society.

Inquiry Questions/Food for Thought:

1. How do you identify yourself? How does society at large identify you?

2. How do other societies or cultures or groups identify their members?

3. What graphic elements/marks can artists use to express their identity in a work of art?

4. How can you use, replicate, combine, or transform these elements in your own artwork?

(Cited from www.asu.edu/cfa/wwwcourses/art/SOACore/theme-identity.htm)

Use the space below to brainstorm symbols, imagery and language that define your identity: 
APPENDIX C: Homework Sketch Handouts

Name

DUE

\section{Homework Art 1 Design Drawing for Installation}

Relief- a work of art where one side is flat and has 3D parts projecting off of it

Part 1:* Based on your real estate boundaries, create an asymmetrical shape below. Now create a 3D Relief Design within the shape that pops up from the surface (wire, cardboard, plaster materials). The design reflects your identity through a variety of visual symbols/words and takes up 50\% of your shape. Incorporate at least one mirror into the design. DRAW A TOP VIEW AND SIDE VIEW (with 3D aspects)

Part 2: *Add color to finish this off based on your real estate. Is it a straight color like blue or on the cusp of another color and fade from blue into blue-violet? You will be graded on your project showing a monochromatic color scheme that connects all parts of the artwork togetherthus creating UNITY. Your design needs to also show contrast- Monochromatic design is clearly seen from a distance based on color choices of value. Light near dark; dark near light. 
Name

DUE

\section{Homework 2D Design Drawing for Installation}

Relief- a work of art where one side is flat and has 3D parts projecting off of it

Part 1:*Based on the cast you created and shape of your real estate- come up with a drawing that reflects this below. Now, come up with a design that creates movement (how your eye travels) and rhythm (repeat in an art element in a predictable way) through the art elements (color, shape, line, value, texture, space) onto your cast and shape. What image or theme will reflect you? Your design needs to take up at least $50 \%$ of your space. ((Words/phrases/thoughts (typed or written) can be weaved throughout the design for added personalization.)) Incorporate at least one piece of mirror into the design. () DRAW A TOP AND SIDE VIEW (with 3D aspects)

Part 2: *Add color to finish this off based on your real estate. Is it a straight color like blue or on the cusp of another color and fade from blue into blue-violet? You will be graded on your project showing a monochromatic color scheme collage that connects all parts of the artwork together- thus creating unity. 
Name

DUE

\section{Homework 3D Design Drawing for Installation}

Relief- a work of art where one side is flat and has 3D parts projecting off of it

Part 1:* Based on the cast you created and shape of your real estate boundry- come up with a drawing that reflects this below. Now, add to your cast 3D components that come up and off your surface creating a relief. The 3D Relief Design- reflects your identity through a variety of visual symbols/words and takes up 50\% of your sculpture's space. Incorporates at least one piece of mirror into the design. These components can be made out of wire and cardboard and covered with the same plaster materials. DRAW A TOP AND SIDE VIEW (with 3D aspects)

Part 2:*Add color to finish this off based on your real estate. Is it a straight color like blue or on the cusp of another color and fade from blue into blue-violet? You will be graded on your project showing a monochromatic color scheme connects all parts of the artwork together- thus creating UNITY. Remember to show contrast light values near dark values; dark values near light values. 
Name DUE

\section{Homework Sculpture Design Drawing for Installation}

Relief- a work of art where one side is flat and has 3D parts projecting off of it

Part 1:*Create a design of what you might like to do for the installation project. Start with a pie wedge shape with a degree of $60 \ldots .$. Draw it big to fill a 9" $\times 12$ " space. The design needs to start at the point of the triangle (most amount of mirror = EMPHASIS) and dissipate as it moves outward- showing MOVEMENT in its arrangement. Aside from the mirror taking up $50 \%$ of your space, your design should reflect your identity in some way. Think body cast, symbols, words, etc. Material choices are wire, cardboard, plaster, mirror (nothing flammable like paper or fabric). ADVANCE your techniques as your artwork is the CENTER OF ATTENTION!!! DRAW A TOP VIEW AND SIDE VIEW (with 3D aspects)

Part 2:*The surrounding color/space beyond the mirror needs to reflect the color range you are working in... (Ex. If orange is your color- then you are working yellow-orange to orange to redorange) Have your sketch reflect the colors too. What else will you add to make your work personal and stand out? 
APPENDIX D: Self-Reflection Handout

Name:

"Mor-in-Touch" Artist Self-Reflection

Comment on your opportunity to leave a mark on Norton High School's newly renovated building and being part of the first art installation. How did this make you feel? Why?

You left your art for others to see such as your peers, teachers, administration, parents, and future students. Describe the relief that you created, which reflects who you are.

What challenges did you face in the relief installation project?

What did you do to overcome these challenges?

What are you most proud of? Why? 
APPENDIX E: Examples of Completed “Mor-In-Touch" Artist Self-Reflections

\section{Exceeding Standards/Connections}

Ms. Morin

Art 1

Name:

Comment on your opportunity to leave a mark on Norton High School's newly renovated building and being part of the first art installation. How did this make you feel? Why? (2 pts)

it feels good to leave something behind in

the new school. To me the school seems to baren, we have nothing but white walls in this school. Personally I was surprised when I first walked into the school this year at how boring it was. last year we had wall art and personal celing tiles; thats why Im gladweare doing this You left your art for others to see such as your peers, teachers, administration, parents, and future Project.
students. Describe the relief that you created, which reflects who you are. $(2 \mathrm{pts})$

I love cute quote, Panda's, anything about the moon and astroligy, and the color purpie. All of what I have put on my rellef is a reflection of myself and What is apart of my life.

What challenges did you face in the relief installation project? $(2 \mathrm{pts})$

The main challenge was creating a unique shape that worked with everyone around me. The last thing I wanted was for my relief to look like eveyone araund me.

What did you do to overcome these challenges? ( 2 pts)

I created the shape that I invisioned then shaped a few pieces of the edge to Conect with thoes around me.

What are you most proud of? Why? (2 pts)

I'm most proud of the flower in the center of the peice. It is 3D like I wanted, the the miror in the center to reclec h creative. I put
wighter near the polonstemsof the flewer. The silver paint flowers are 


\section{Exceeding Standards/Connections}

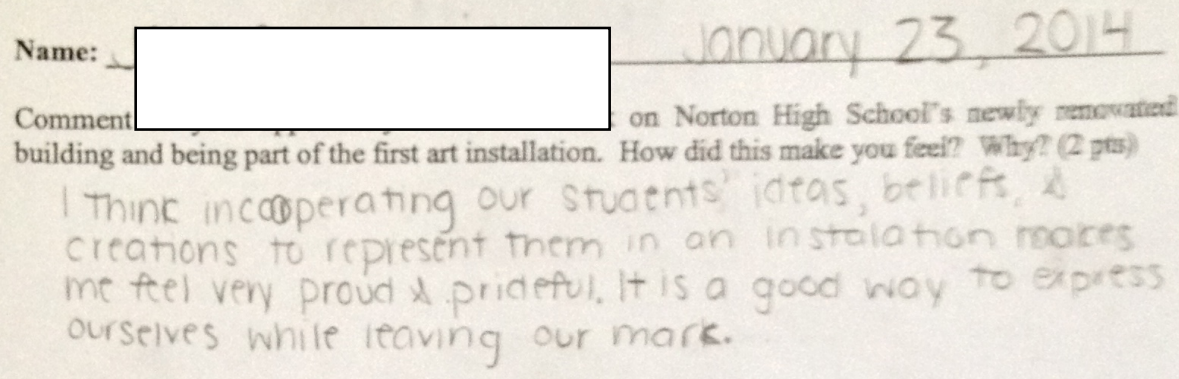

You left your art for others to see such as your peers, teachers, administration, parents, and finure students. Describe the relief that you created, which reflects who you are. (2 pts)

The relief I created fur the instalation reflects one of my

favorite things; baseball. I Dainted on a small field of

fowers with a baseball $\infty$ bat: filong with this is the

Iyrics to "Tessie", a.famous song about the Bosten Rec sox.

What challenges did you face in the relief installation project? (2 pts)

1 faced challenges such as creatrng contrast $x$ finding newsways to incooperate 30 pieces. F couldnit find a noy

to make certain parts stick out with color. The bacieground made it hard to create good contrast. I had difficulty

finding ways to mace the nowers pop out, roo.

What did you do to overcome these challenges? (2 pts)

1 created controst by using blact \& white with iess aneen

A yellow to make Grastic color change. I used mites

in various wayste mace them stickput. le ceated

stems used it as petals. I used tope to moke

fiowers pop.

What are you most proud of? Why? (2 pts)

I'm soost proud of how I refiected baseball in my

relief. The colors I used macte it easier to create

more of an earthy, springtime feel. I liced the hoy

I could use a quote to back up my work. 


\section{Exceeding Standards/Connections}

Ms. Morit

Art 1

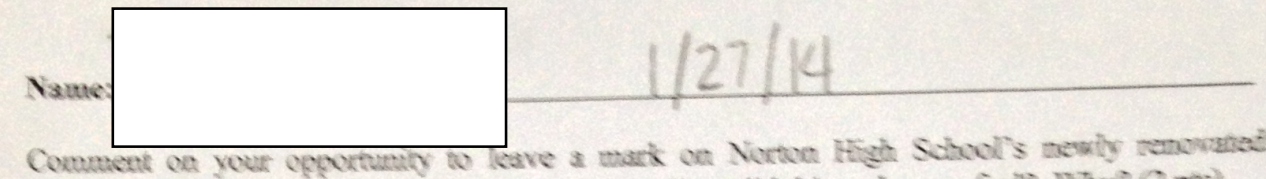

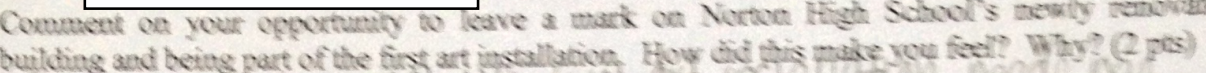

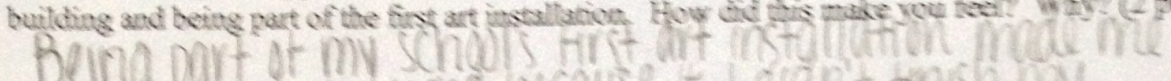

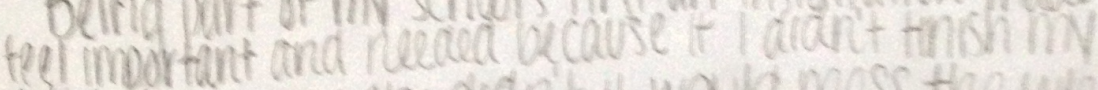

estate yr someve else didnt, it would mess the whole

installation up.

You left your art for others to see such as your peers, teachers actmimiseration, parentas, and furture

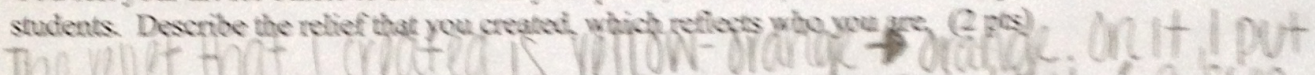

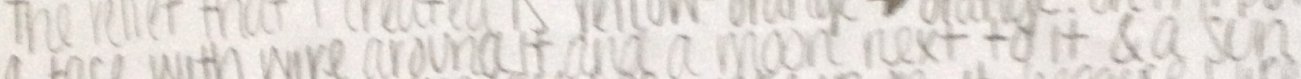

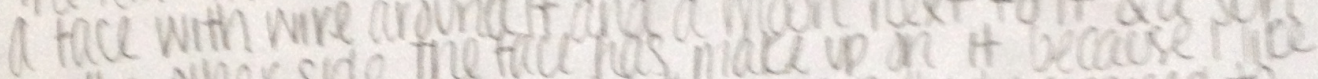

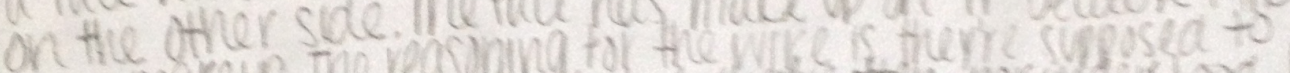

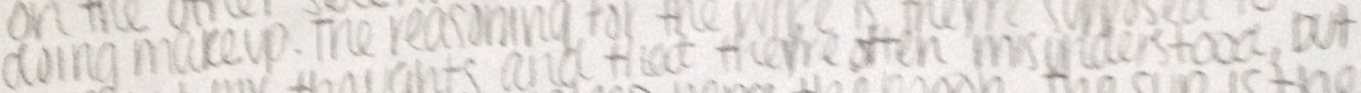
redesent my thougry imasleep llena the moon. the sun is the

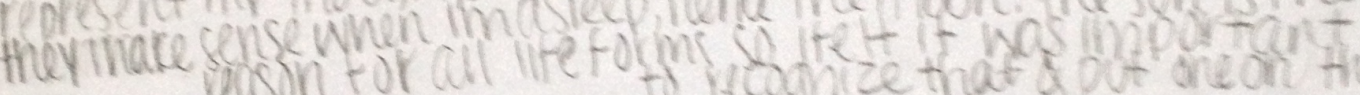

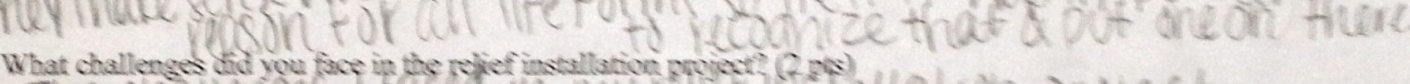

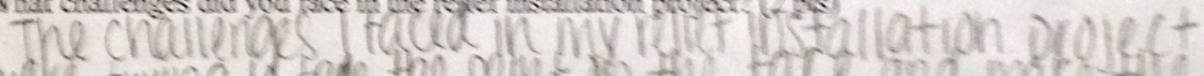

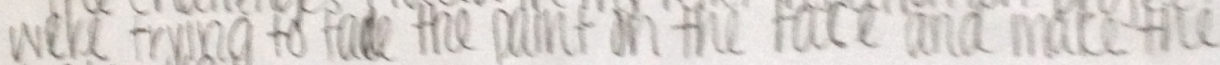

Dlaster that.

What did you do to overcome these challenges? (2 pes)

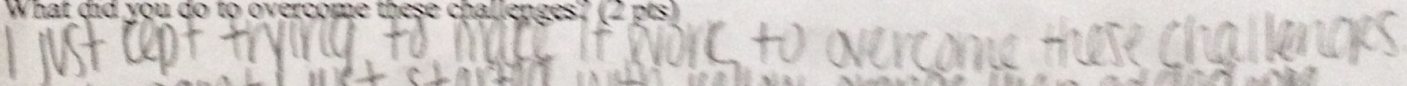

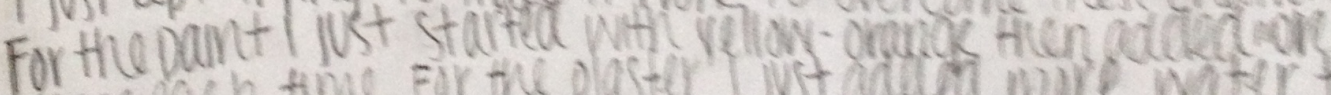
ranae cach time. For the olaster l just adeded more water to mace it platter.

What are you most proud of? Why? ( $\mathrm{ps}$ )

I minimnst nroud of fiow mench I have oroaressed

thes vear because of fius glass, not just des an antst

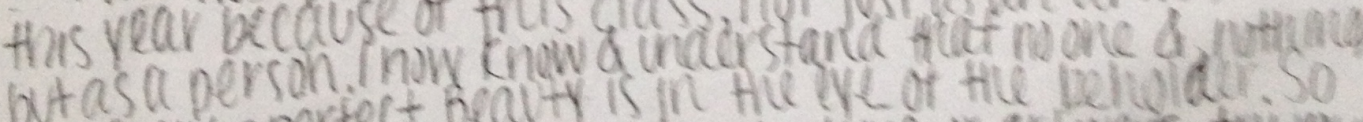
can ever be pertect. beanty is in the ye of tile beluda.s. 0

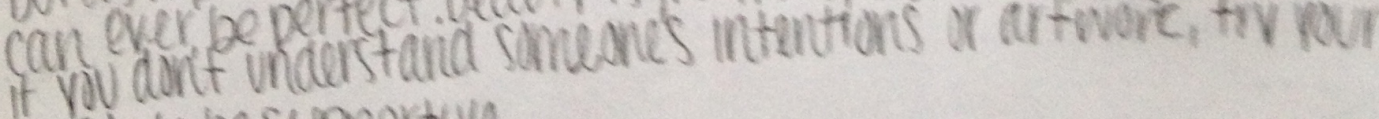
oest to be suportive. 


\section{Exceeding Standards/Connections}

Ms. Morin

Art 1

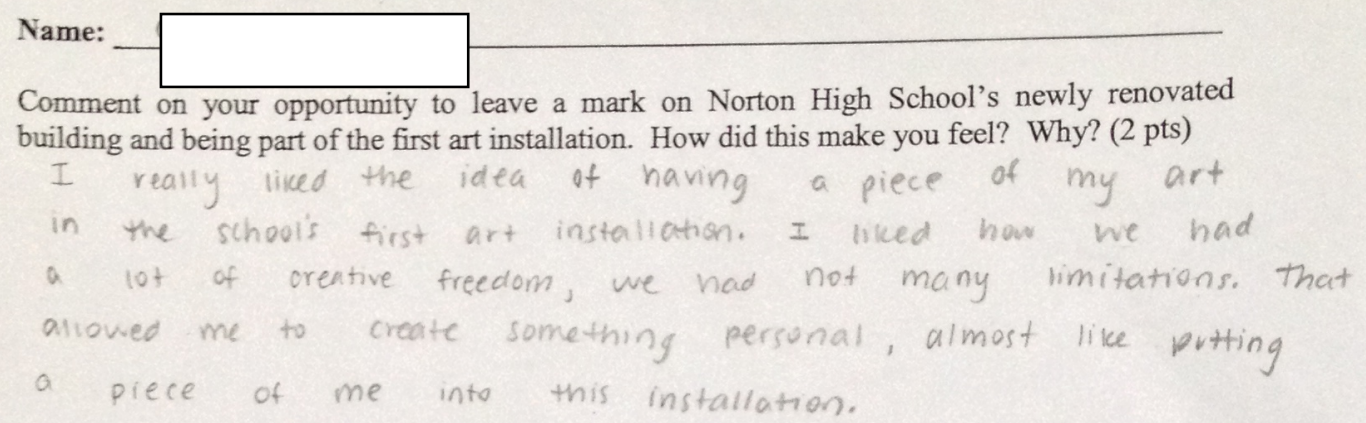

You left your art for others to see such as your peers, teachers, administration, parents, and future students. Describe the relief that you created, which reflects who you are. (2 pts)

My relief is a picture of a girl, the face cut off right under

the eyes, with tree branches growing behind her. I have a

quote about creativity next to the picture part, and my relief

is painted red-violet to videt. This represents me because its really

deseribing my thoughts evrrentiy. I really have no idea what I want to do in the future. My thoughts are kind of jumbled.

What challenges did you face in the relief installation project? (2 pts)

$$
\begin{aligned}
& \text { I had some trouble getting the tree branches to } 100 x \text { like } \\
& \text { actial tree branches. I also had a hard time finding the } \\
& \text { nght colors for her face. I had a hard time with paint in } \\
& \text { general because I'm not that } m \text {. }
\end{aligned}
$$

What did you do to overcome these challenges? ( 2 pts)

$$
\begin{aligned}
& \text { I went home and looked up rome videos on youtube on now } \\
& \text { to paint trees and how to paint faces. I experimented in } \\
& \text { class inhat looked the best too. }
\end{aligned}
$$

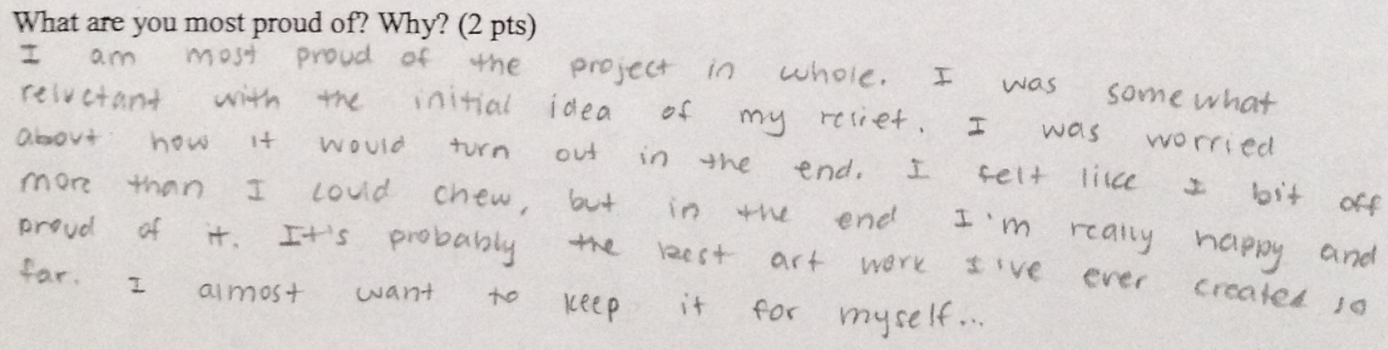




\section{Exceeding Standards/Connections}

Ms. Morin

Art 1

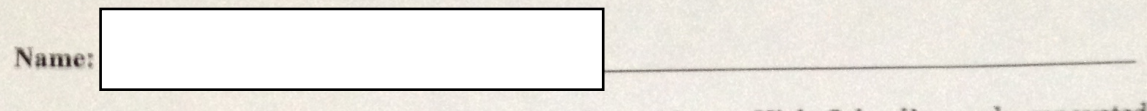

Comment on your opportunity to leave a mark on Norton High School's newly renovated building and being part of the first art installation. How did this make you feel? Why? ( 2 pts)

As a freshmen, I think it is really cool that I get to be part of the first group of people to add to the new high school. It's really neat to know
that futer students will see my ant bing after I've left

the high school.

You left your art for others to see such as your peers, teachers, administration, parents, and future students. Describe the relief that you created, which reflects who you are. (2 pts)

The relief I created is made cut of a cadboard base, plaster,

wire, and pipecleaners. When I came up with my design, I wanted to make a piece that was simple and flowy. So, I made it be a raised design of flowy curls, and it is in the buc to blue-violet section. It reflects me because I used paint warker to write words that describe me. Also. I wrote one of my favorite quotes on it and put plaster shoes for running and dance What challenges did you face in the relief installation project? (2 pts) my two sperts.

When working on this project, one of the

Challenges I fabed was getting the heavy wire and plaster swirl at the top of $m y$ project to be supported. It was super heavy and was drooping, I was worried it would snap.

What did you do to overcome these challenges? (2 pts)

To overcome this challenge, I plastered the part where the wire and the cardboard meet a bt. Now, it is sturdy and stays in place. Also, I added clips to tie it to the net all arownd the swirl so it it's supported in that w

What are you most proud of? Why? (2 pts)

The pait of my projict that I like the most are the little crystals that I added to the center of some of the swirls. They are like little mini mirrors. Atso, for me. I like the because they were extras from an old dance costume so it ties in that copect of me to my project. 


\section{Exceeding Standards/Connections}

Ms. Morin

Art 1

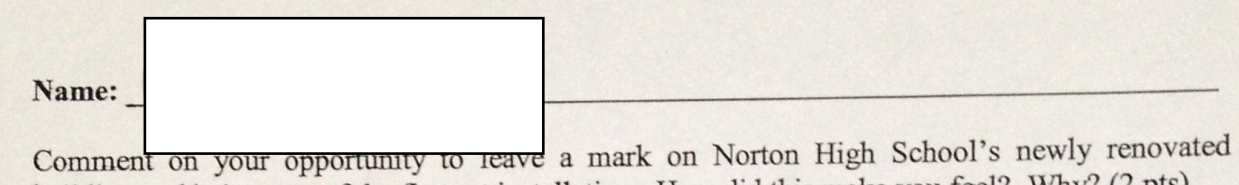

building and being part of the first art installation. How did this make you feel? Why? (2 pts)

I think this opportunity to leave a mark on Norron High schoul is grcat! Being new to the

schuol and being able to leave something that means a lot to $m e$ is very cool. I ful that with this project, everyone is abte to come together as one in a inewailiation School with new peopre.Being part of the to future. This mad 1) the first kelckgtefoncthing bluper and an important You left your art for others to see such as your peers, teachers, administration, parents, and future $\mathrm{School}^{\mathrm{l}}$. students. Describe the relief that you created, which reflects who you are. (2 pts)

The releif I arcatid had a peachy encime to it. It is blue fading into bive-vioiet and it refielts who I am. I created a wave because I love the beach and I am always there in the summer. I also included flip flops because I alwuly have them on and to me they symbolize nappincss and wamth in the summer. The quote "Lifes a beach; What challenges did you face in the relief installation project? (2 pts) waves" or problenc you tow some challenges 1 faced good will come from them. installation project were when 7 was crating the waves getling the plaster to stay up and not say andidroop down was a smugyie. Also, getiling the flip flops to siek to the reilif

What did you do to overcome these challenges? ( 2 pts)

I overcame those challenges by putting newspaper. in betweon the wires to keep the plaster Up. To get the fllp flups to sick, I held down on the flipflops and the relief to malce sure they didn't slide off.

What are you most proud of? Why? (2 pts)

I am most proud of the wave and how it came out with the lighter colurs on top and darker colurs under. I. think it symbolizes me very well and what I enjoy about life and the beach and surfiny, 


\section{Exceeding Standards/Connections}

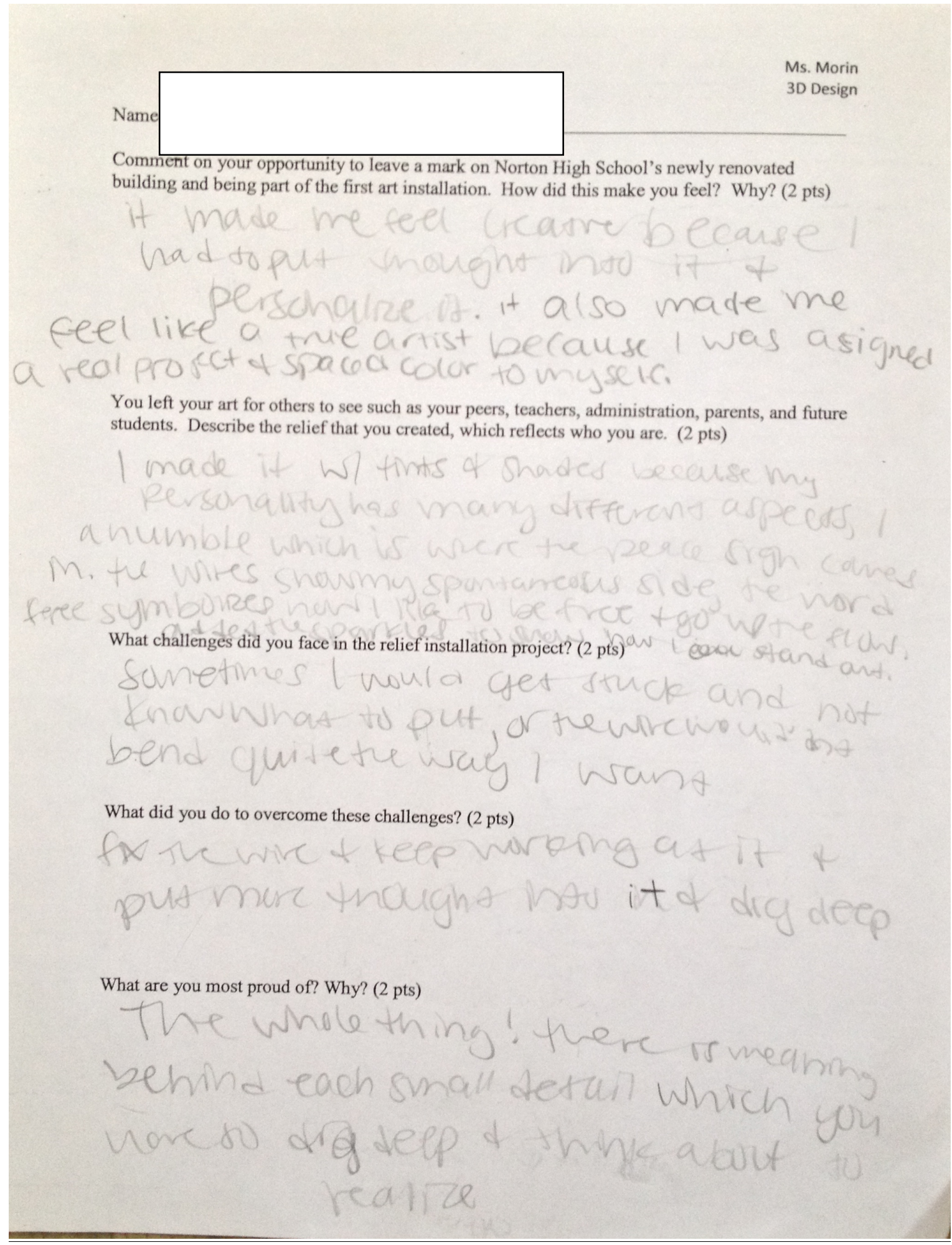


Meeting Standards/Connections

Ms. Morin

Name:

3D Design

Comment on your opportunity to leave a mark on Norton High School's newly renovated building and being part of the first art installation. How did this make you feel? Why? (2 pts)

Being able to be apart of Norton Hian's

first art installation hecause it mares the feel special because no other students that araduated before me. Its like peopic will definately have a remamberence of me when i graduale how.

You left your art for others to see such as your peers, teachers, administration, parents, and future students. Describe the relief that you created, which reflects who you are. (2 pts)

1 am a very sensitive person and

also very passionate so the quotes

on my artwork are about loving someone.

Also, i adted a heart to mine.

What challenges did you face in the relief installation project? ( $2 \mathrm{pts})$

I had a hard time deciding what

1 should put on my relies installation project.

What did you do to overcome these challenges? (2 pts)

I thought about what would make it $100 \mathrm{k}$ more personal for me and I chose spanish

quates man a song I love.

What are you most proud of? Why? (2 pts)

im pratd myartwaic

came out pretty good

because inever thougnt I

could make somlething

so cool and original. 


\section{Struggling to Meet Standards/Connections}

\section{Ms. Morin}

Art 1

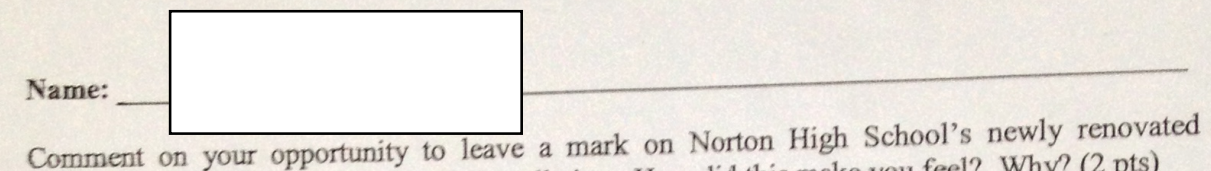

Comment on your opportunity to leave a mark on Norton High school's neel? Why? (2 pts) building and being part of the first art installation. How did this make you

$$
\begin{aligned}
& \text { It makes me foel Ok To be a part } \\
& \text { of it jIt doemit Realq Impact he. }
\end{aligned}
$$

You left your art for others to see such as your peers, teachers, administration, parents, and future students. Describe the relief that you created, which reflects who you are. (2 pts)

$$
\begin{aligned}
& \text { My pelief } K, \text { a few. Random peices }
\end{aligned}
$$

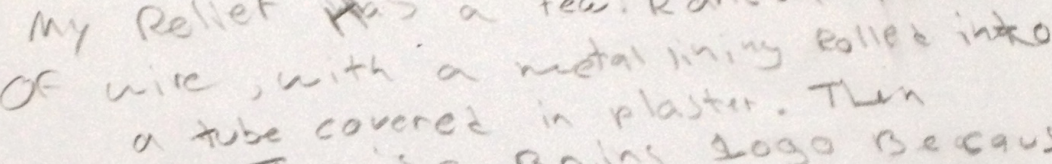

$$
\begin{aligned}
& \text { There is a Bring logo Becaude } \\
& \text { I like the osston Bruns and } \\
& \text { Hockey }
\end{aligned}
$$

What challenges did you face in the relief installation project? (2 pts)

$$
\begin{aligned}
& \text { Th Challenges I Saceb was creating/conn } \\
& \text { up with the desigh = would put on rmy } \\
& \text { section. }
\end{aligned}
$$

What did you do to overcome these challenges? ( 2 pts)

$$
\begin{aligned}
& \text { I ploced Random wire and other things } \\
& \text { and crentes a by somthis that } \\
& \text { represents hockey } \\
& \text { And Tine. }
\end{aligned}
$$

What are you most proud of? Why? (2 pts)

$$
\begin{aligned}
& \text { I am mast ploud of the sruins logo } \\
& \text { I made becaus It to a long pine } \\
& \text { Tomare, tere and I wess a pain to } \\
& \text { Plaster but it tormes out good. }
\end{aligned}
$$


Struggling to Meet Standards/Connections

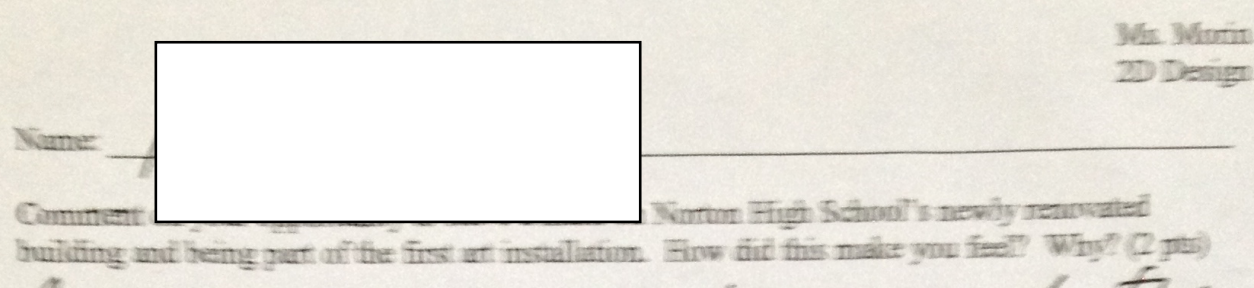
A lot of oy artark went ye orend the subwl. It was cod peeng any wark With the collag I fal I left $y$

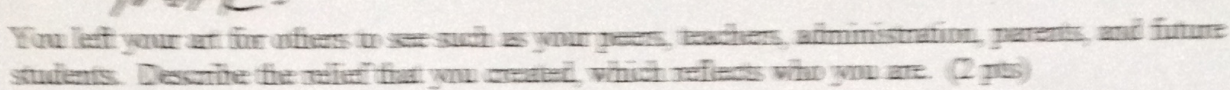

Is haved cedrane who I way Thingh my artwork

Getting The colors dow was the bigkest probten. (Yctioxto y-G)

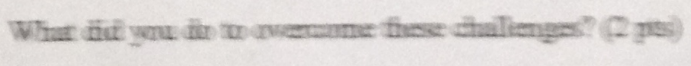

I worled throug them

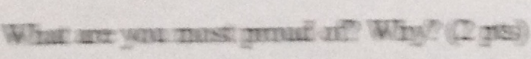

My Fist prece becuse I fal it was thy bert widk. 


\section{APPENDIX F: More Noteworthy "Mor-In-Touch" Self-Reflections}

\section{...with school}

Comment on your opportunity to leave a mark on Norton High School's newly renovated building and being part of the first art installation. How did this make you feel? Why? (2 pts) Being cable to be one of the first to leave my

mark on the new highscharl is a great feeling.

knowing that my artwork nill be on display

for everone to sea. It will be cool to be one of

the firsts to stant making the walls of

NHS come to life again.

Comment on your opportunity to leave a mark on Norton High School's newly renovated building and being part of the first art installation. How did this make you feel? Why? ( 2 pts

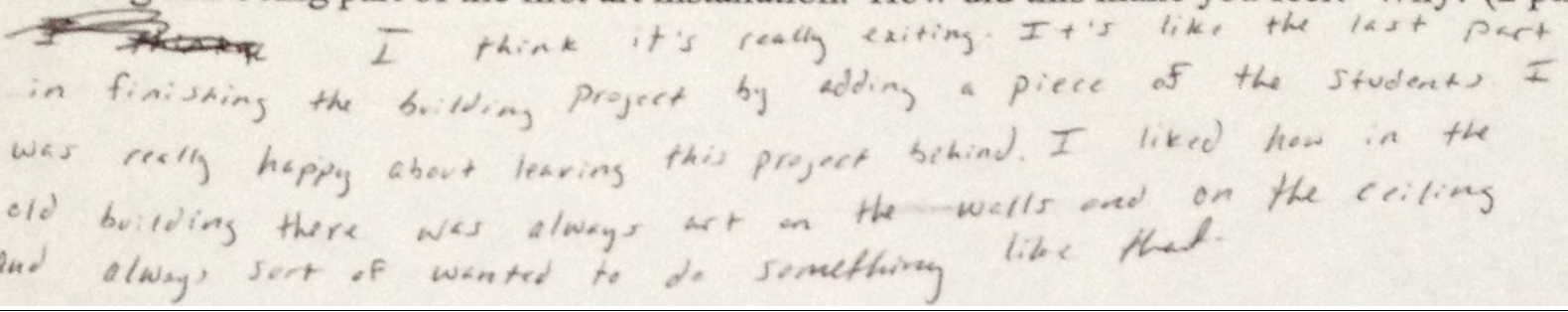

Comment on your opportunity to leave a mark on Norton High School's newly renovated building and being part of the first art installation. How did this make you feel? Why? ( 2 pts)

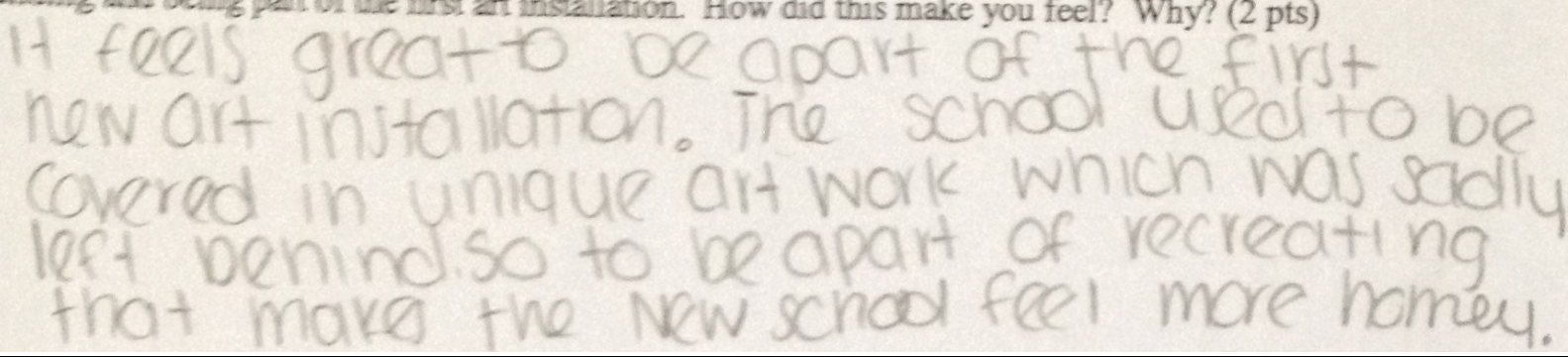


Comment on your opportunity to leave a mark on Norton High School's newly renovated building and being part of the first art installation. How did this make you feel? Why? ( 2 pts)

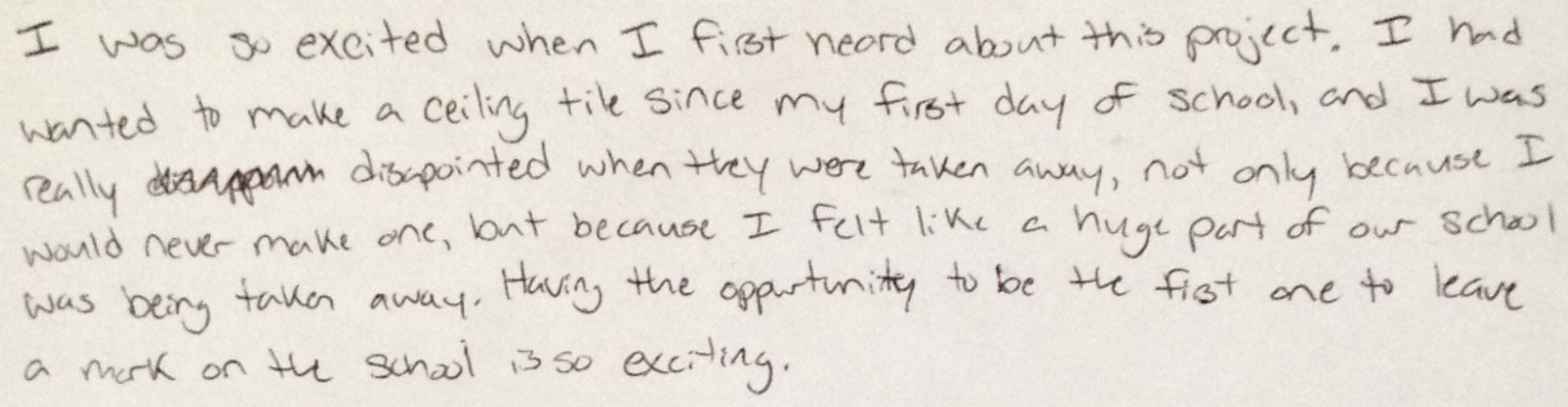

Comment on your opportunity to leave a mark on Norton High School's newly renovated building and being part of the first art installation. How did this make you feel? Why? ( 2 pts)

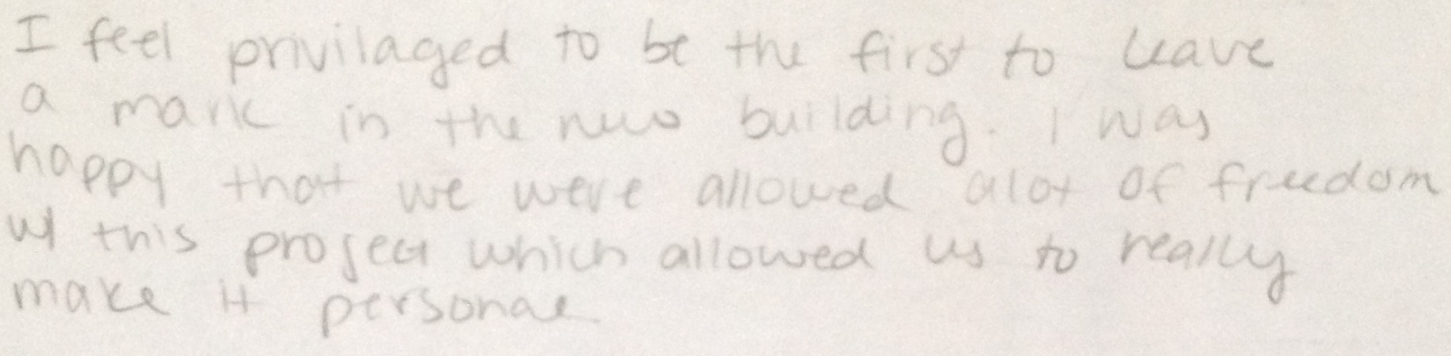

What are you most proud of? Why? (2 pts)

I am poud of being able he be a part
of the installation. When it goes up, many
people will loch in awe and it will be
hice in know I was a part of that

\section{...with personal ideas}

You left your art for others to see such as your peers, teachers, administration, parents, and $\mathrm{fi}$ students. Describe the relief that you created, which reflects who you are. (2 pts)

$$
\begin{aligned}
& \text { The project I created is an eye and that } \\
& \text { is representive of me because this year is } \\
& \text { a year of self reflection for me. }
\end{aligned}
$$


You left your art for others to see such as your peers, teachers, administration, parents, and future students. Describe the relief that you created, which reflects who you are. (2 pts)

In my relief I did my face, and madehalf a lion, because that been my favorite animal for a long time and I'm a leo. I did the hair as kind of a value scale because that's what my actual hair looks like. The shattered glass shows that though experiences in hive schmo nav break US, those challenges that you over come reflect who you

You left your art for others to see such as your peers, teachers, administration, parents, and future students. Describe the relief that you created, which reflects who you are. (2 pts)

I had the colors yellow end gelled orange. The roles reminded me of a picture I took of a sunset up in New Hempormile over the lake my family stags at

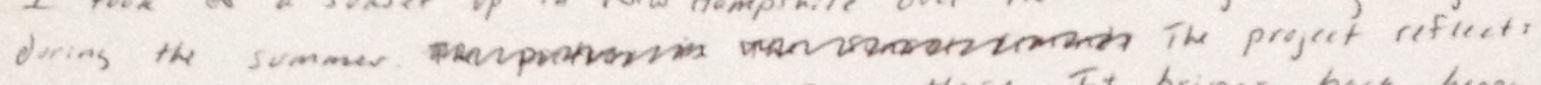
the calmest and happiness if feel when Jim these. It brings back happy memories with my family.

You left your art for others to see such as your peers, teachers, administration, parents, and future

students. Describe the relief that you created, which reflects who you are. (2 pts) foot with a real ballet shoe ontap. I chose to leave a real piece of mu life berceuse ill always De nee in some way and because of all the good memones it has lavs went with a beach theme because i be the beach and nat ire

You left your art for others to see such as your peers, teachers, administration, parents, and future students. Describe the relief that you created, which reflects who you are. (2 pts)

My project has a positive feel to it. There are many bright collars and symbols of peace. I hope people see it and think of me as a positive person. 
You left your art for others to see such as your peers, teachers, administration, parents, and future students. Describe the relief that you created, which reflects who you are. (2 pts)

The relief I crested represents overcoming the constraint stresses

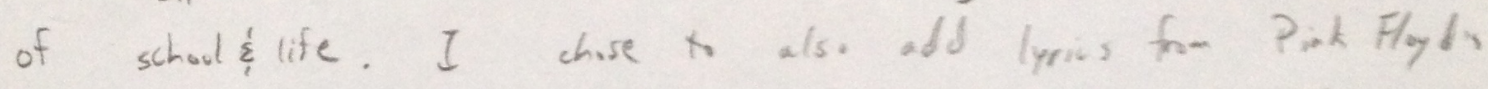
"The will", one of "n, favorite albums which I hast helped the The and show what I the through music

You left your art for others to see such as your peers, teachers, administration, parents, and future students. Describe the relief that you created, which reflects who you are. (2 pts)

My relif fades from red-videt to vide. It Portrays a night SKY with the words "DONT LOSE YOURSELF'. The piece sevres as a reminder to me to do just that, while the night represents the darkness of the unknown the clods represent the masked tn th of our world, the star symbolizes

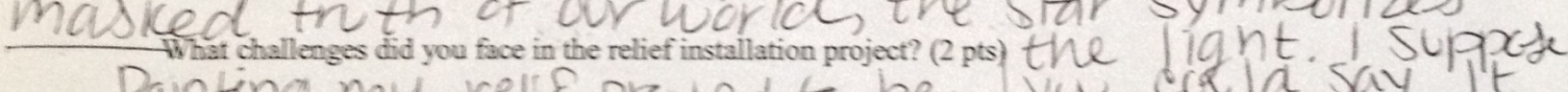
Painting my relief proved to be yo col la say it the biggest issue -the paint tended means to stay

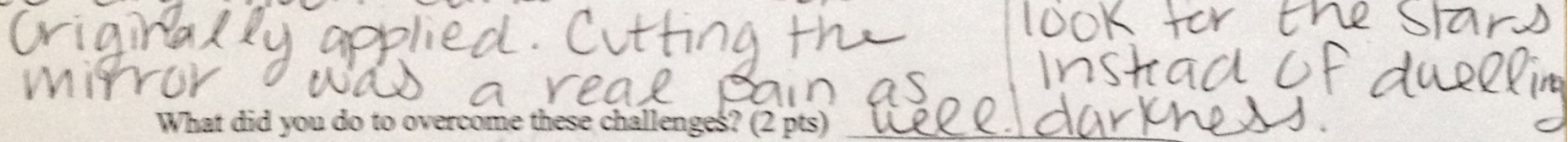

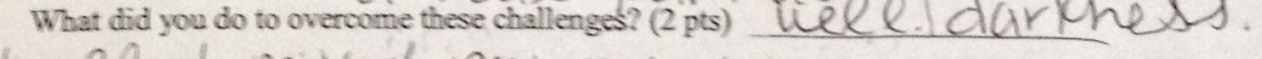

well, I mixed my paint with magenta instead of red. It gale me a mien more Livid color. I had some help cutting the minor, too. 
You left your art for others to see such as your peers, teachers, administration, parents, and future students. Describe the rebel that you created, which reflects who you are. (2 pts)

My relief is of a hot air balloon heading towards a dark thunderstorm. I think this reflex me because no matter how bad things get I want to always be able to see that
hopelight even in the 'darkest storm?

What challenges did you face in the relief installation project? ( 2 pts)

- blending the colors

- Cutting the miner

- Deciding what I wanted it to look like What did you do wo overcome these challenges? (2 pts)

- I kept trying and learned

different and bettor ways to blend and cut the materials

Also it was trial and error it some cases

-I Picked the one that insured the the most.

...with faced challenges

What challenges did you face in the relief installation project? ( $2 \mathrm{pts})$

The challenges I faced in the relief installation project was figuring out how to make an the objects Inured on my relief.

What did you do to overcome these challenges? (2 pts)

What I did to overcome these challenges wastry out a lot of the material that we had, and I put together something that I liked. 
What challenges did you face in the relief installation project? (2 pts)

My biggest challenge was that I had tw mapy ideas. Becuuse I had such a lage space to wark with. I fond it difficult to decide what to fill it with. I went through five or six different ideas befure I finally decided on the final product.

What did you do to overcome these challenges? (2 pts)

I overcame these challenges by moving forwerd with each idea, and using trial and error to see if each one wanld work. The fur ther I got in the prigect, the easier it got for me to decide which iden to go with.

What challenges did you face in the relief installation project? ( $2 \mathrm{pts})$

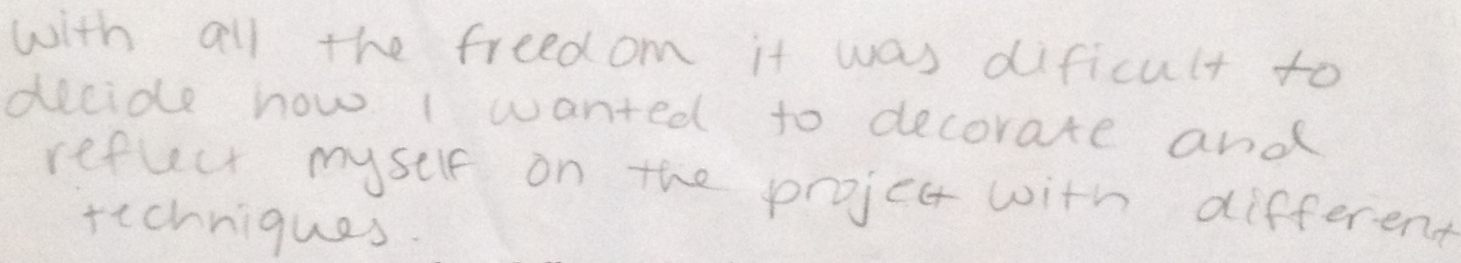

What did you do to overcome these challenges? ( 2 pts)

Asked advice suagestions of teacher friendy ang peers and make it personal.

What challenges did you face in the relief installation project? $(2 \mathrm{pts})$

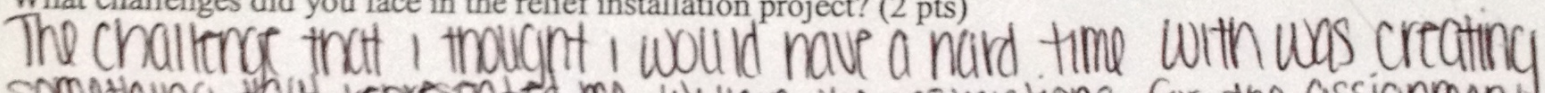
somothing thit requesnted me, within the insthuctions for the assignment

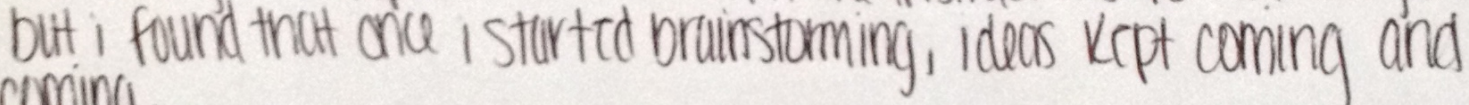
coning.

What did you do to overcome these challenges? ( $2 \mathrm{pts})$

To overrome thess challifnats, i cleared my mind and thargit of the cirative thrins' thit compose me. 
APPENDIX G: Rubric Handouts

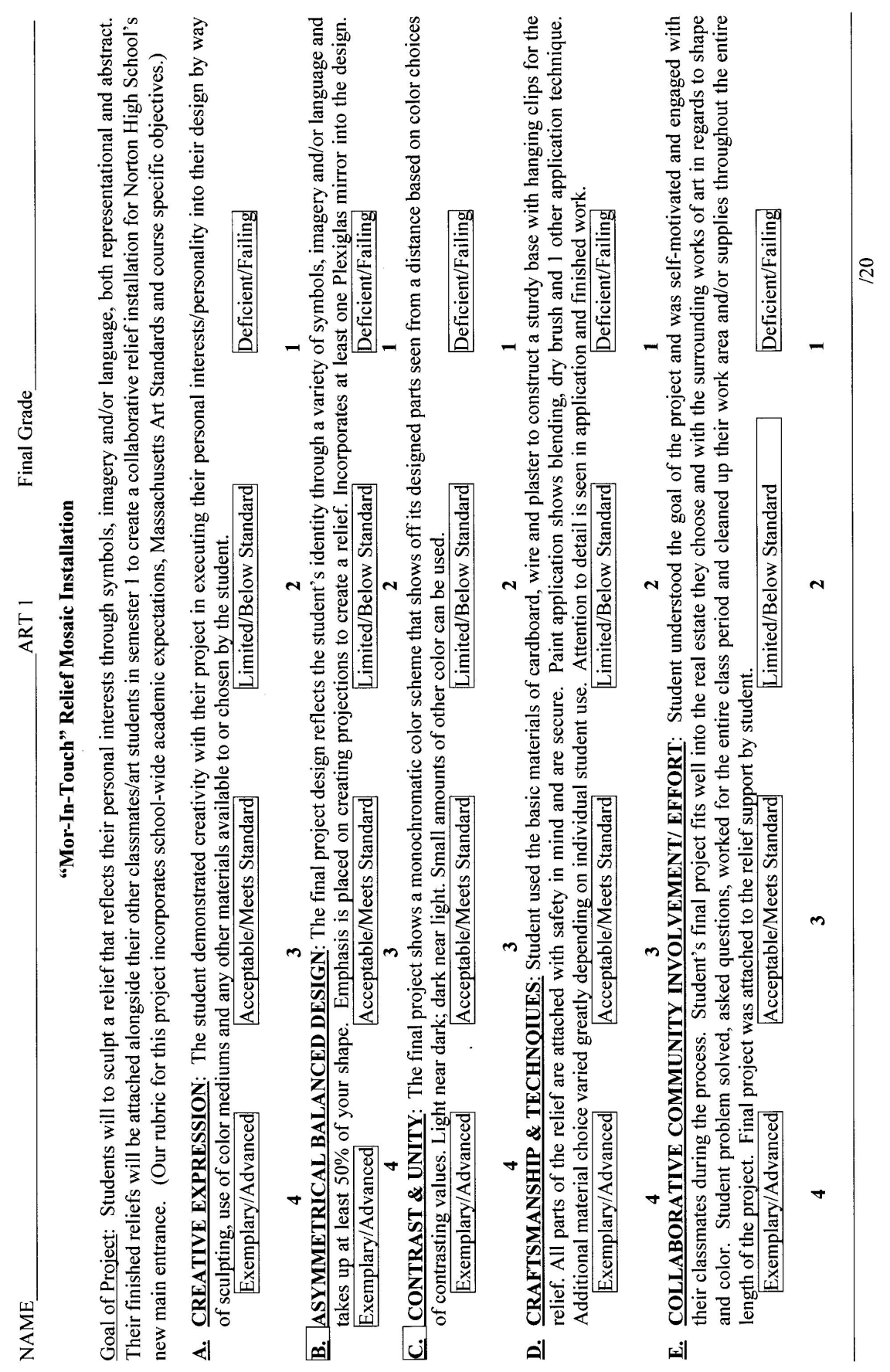




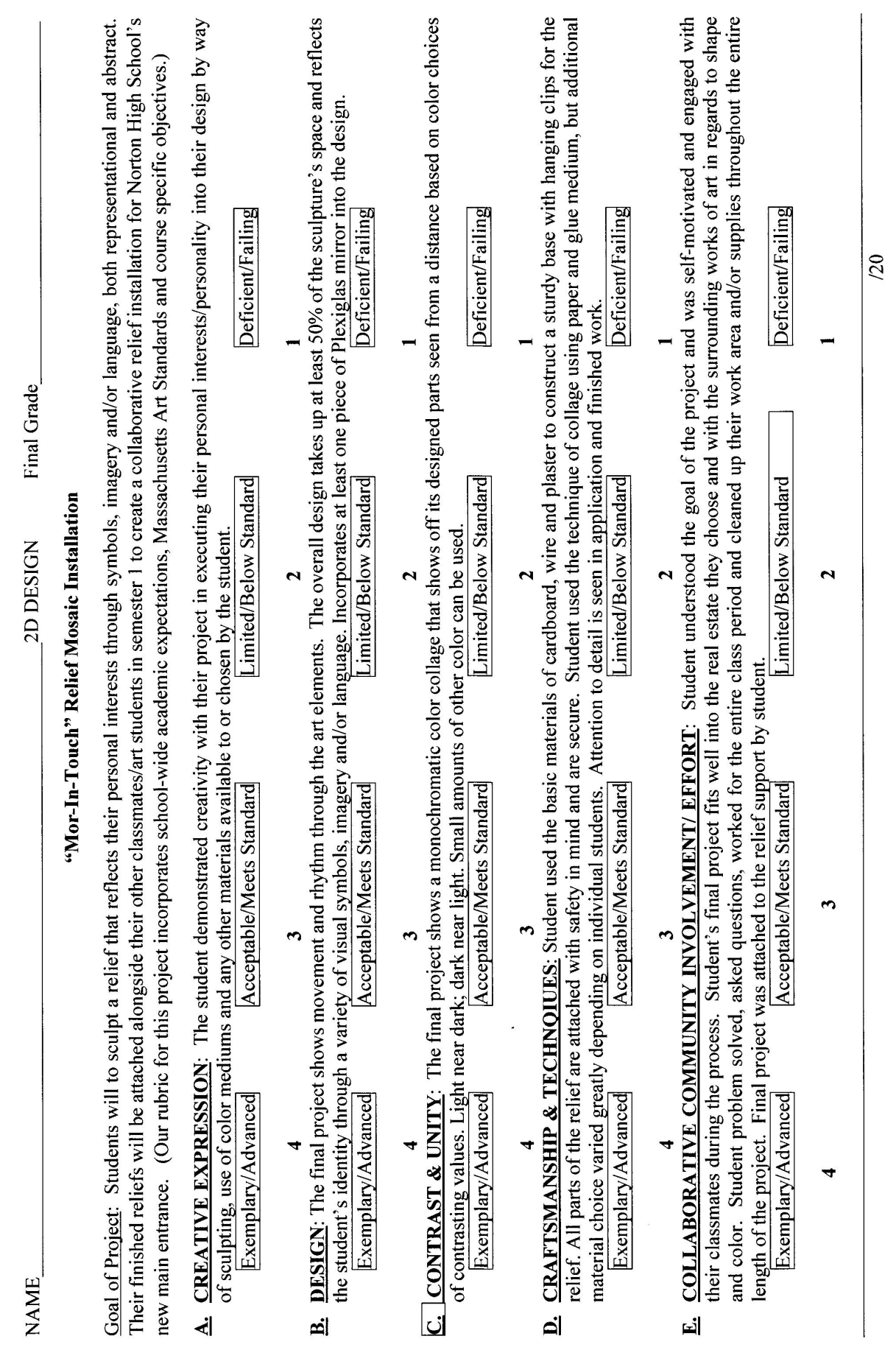




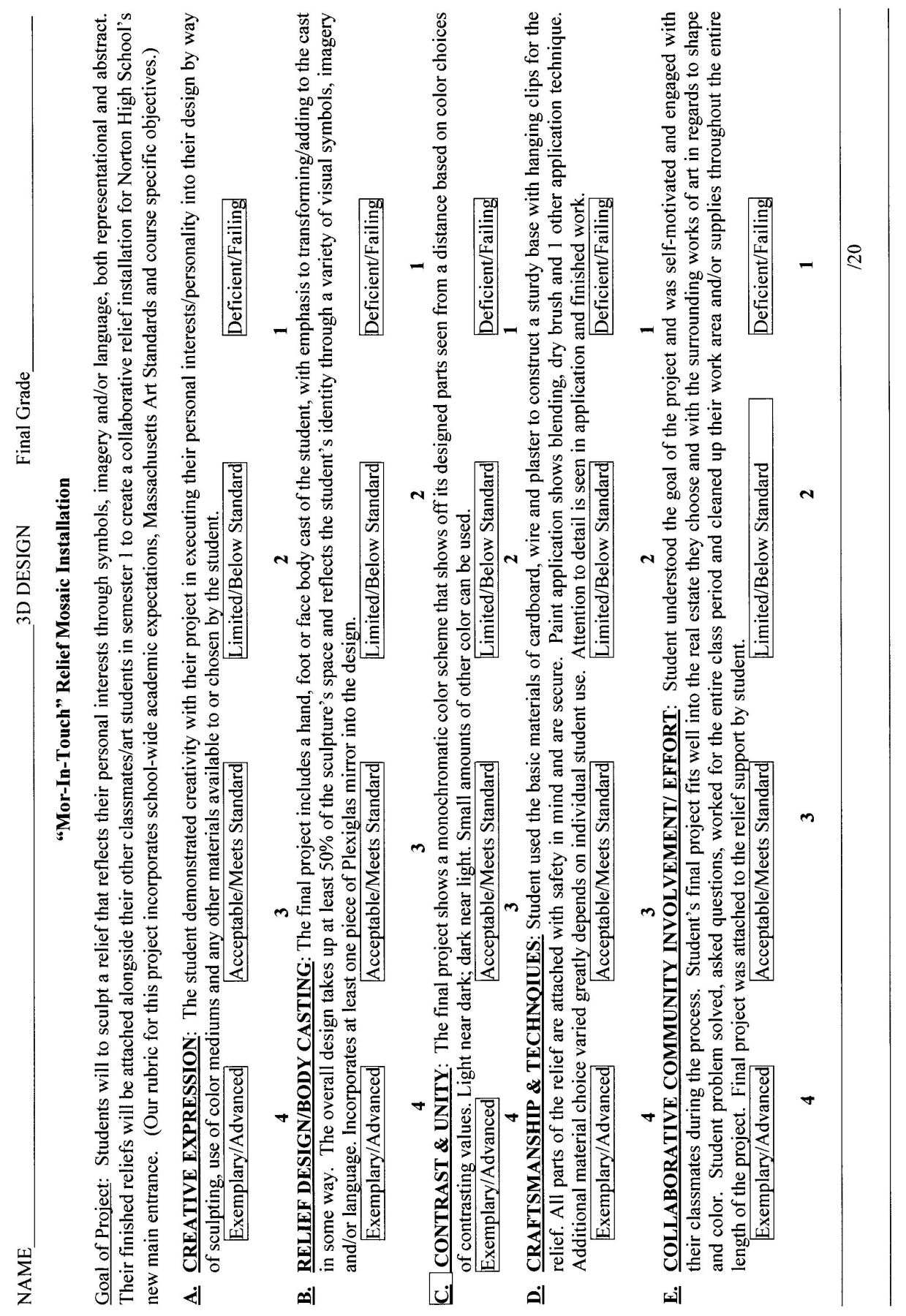




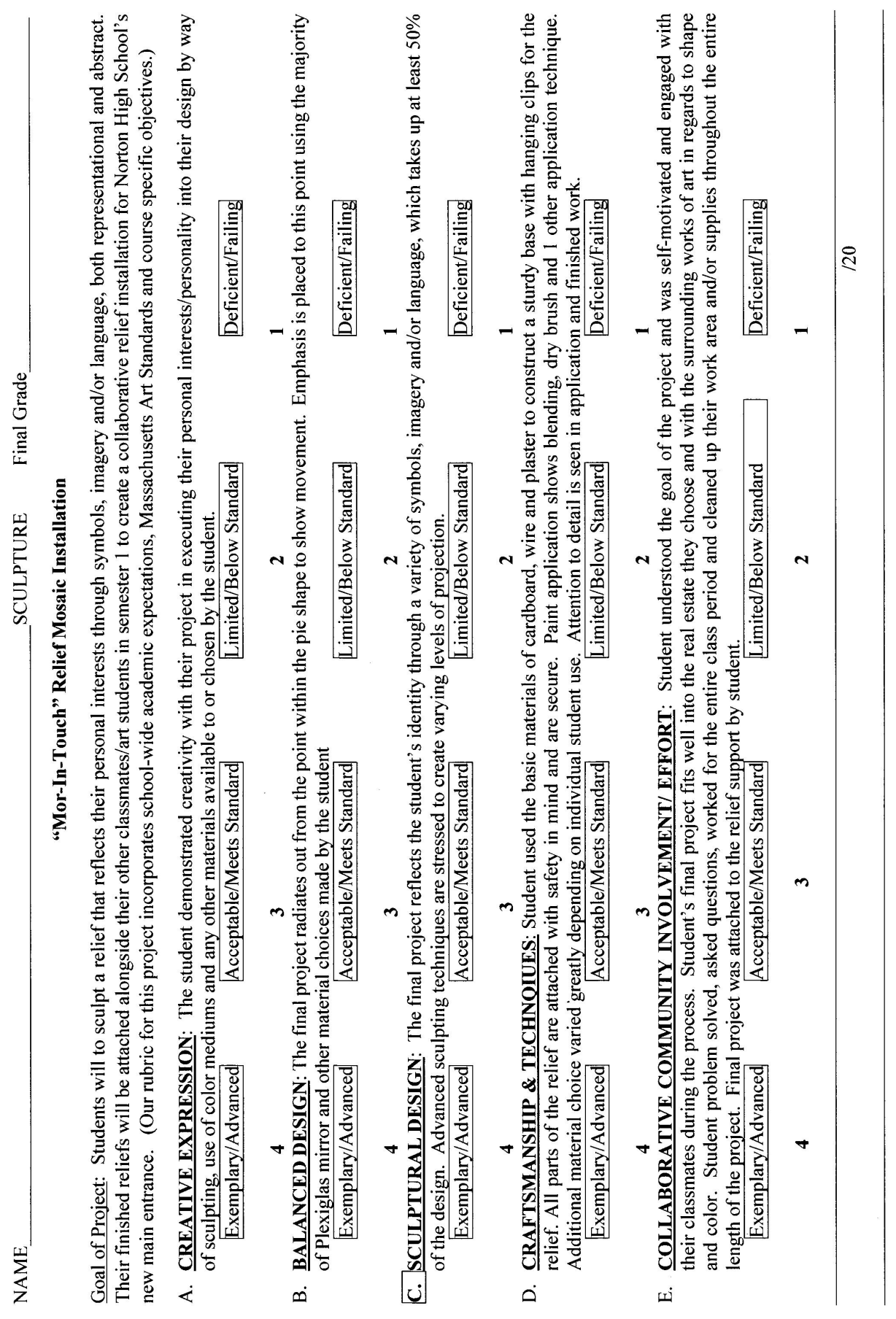




\section{APPENDIX H: PowerPoint Slides}
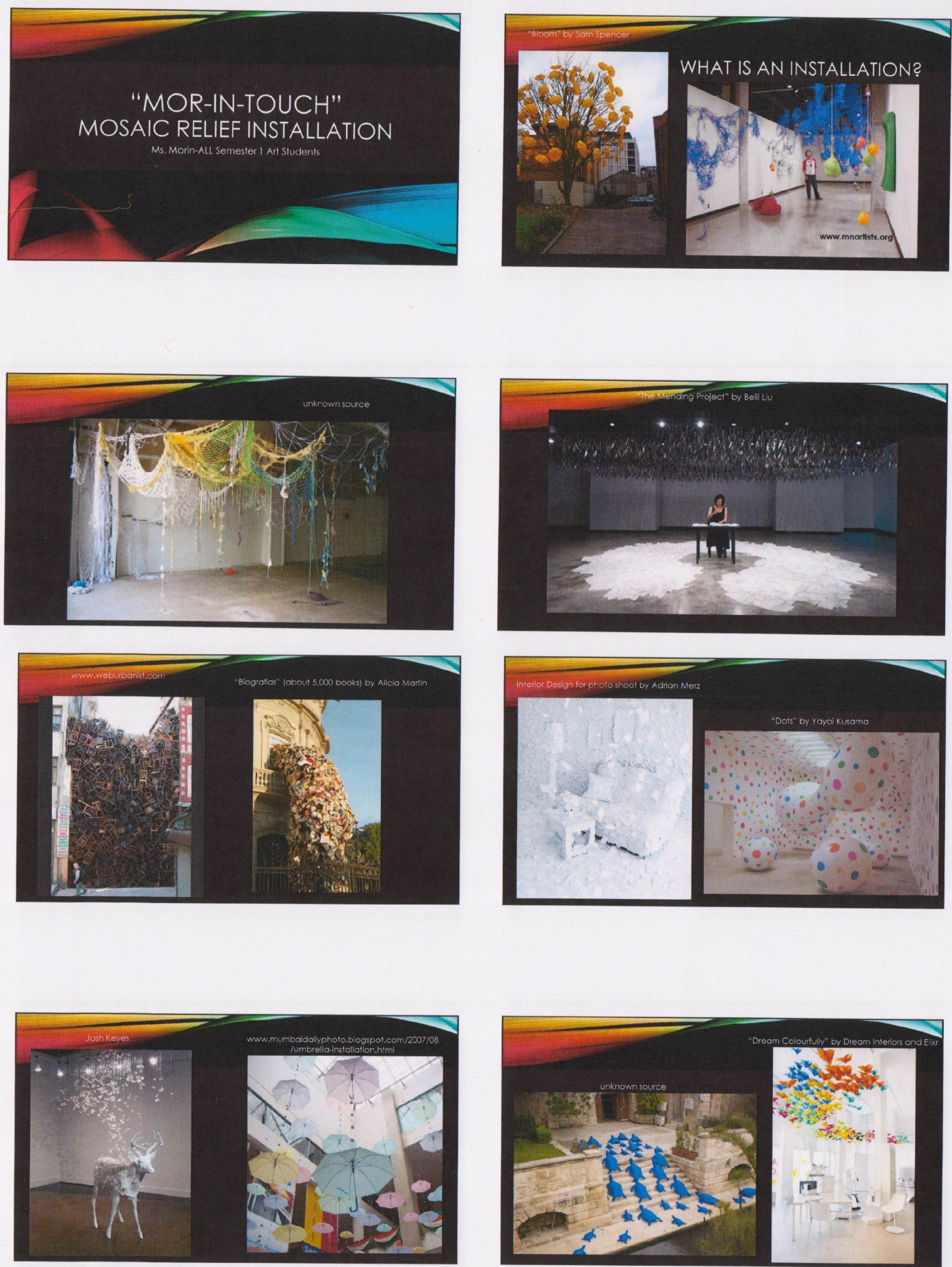

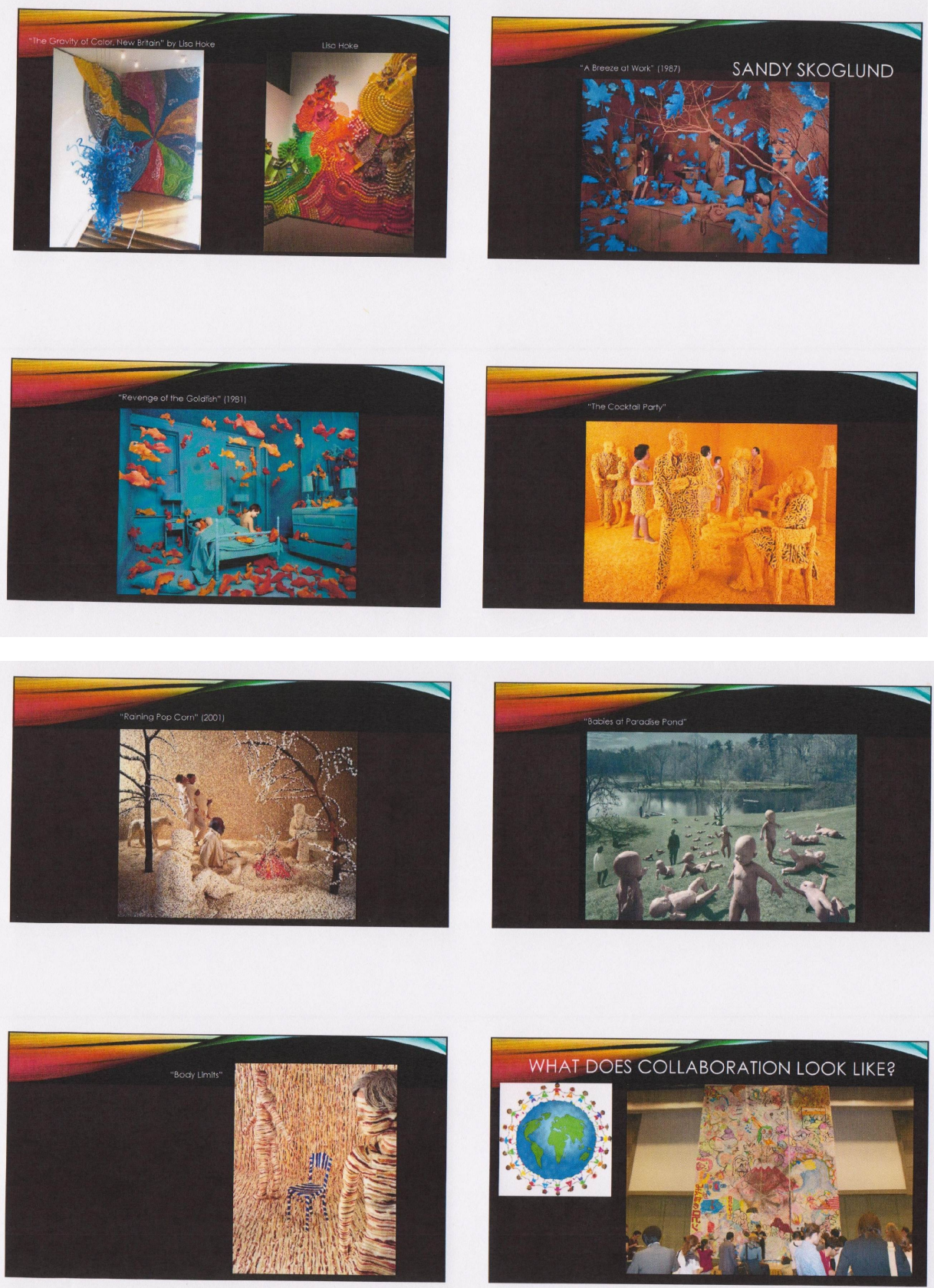

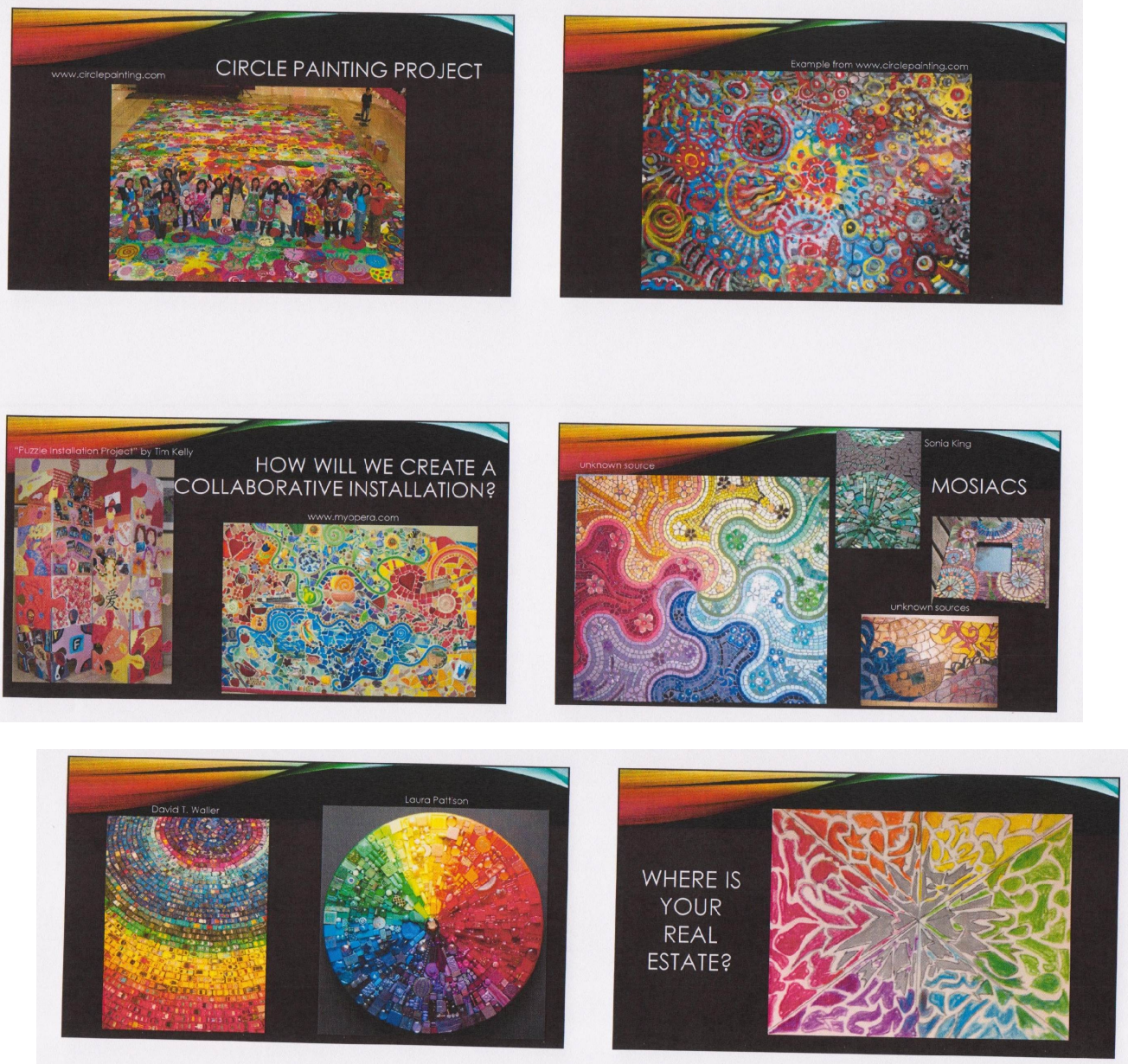
APPENDIX I: Ceremonial Picture Honoring the Installation Artists 